University of Rhode Island

DigitalCommons@URI

Open Access Dissertations

1982

\title{
Age Related Changes in the Induction of Hepatic Mixed-Function \\ Monooxygenase System in Miniature Pigs: Effects of \\ Pentachloroanisole, Pentachlorophenol and Phenobarbital
}

Alan Paul Agins

University of Rhode Island

Follow this and additional works at: https://digitalcommons.uri.edu/oa_diss

\section{Recommended Citation}

Agins, Alan Paul, "Age Related Changes in the Induction of Hepatic Mixed-Function Monooxygenase System in Miniature Pigs: Effects of Pentachloroanisole, Pentachlorophenol and Phenobarbital" (1982). Open Access Dissertations. Paper 505.

https://digitalcommons.uri.edu/oa_diss/505

This Dissertation is brought to you for free and open access by DigitalCommons@URI. It has been accepted for inclusion in Open Access Dissertations by an authorized administrator of DigitalCommons@URI. For more information, please contact digitalcommons-group@uri.edu. 
AGE RELATED CHANGES IN THE INDUCTION OF HEPATIC MIXED-FUNCTION MONOOXYGENASE SYSTEM IN MINIATURE PIGS: EFFECTS OF PENTACHLOROANISOLE, PENTACHLOROPHENOL AND PHENOBARBITAL

BY

ALAN PAUL AGINS

A DISSERTATION SUBMITTED IN PARTIAL FULFILlMENT OF THE REQUIREMENTS FOR THE DEGREE OF DOCTOR OF PHILOSOPHY

IN

PHARMACEUTICAL SCIENCES

UNIVERSITY OF RHODE ISLAND 
DOCTOR OF PHILOSOPHY DISSERTATION

OF

ALAN PAUL AGINS

Approved:

Dissertation Committee

Major Professor

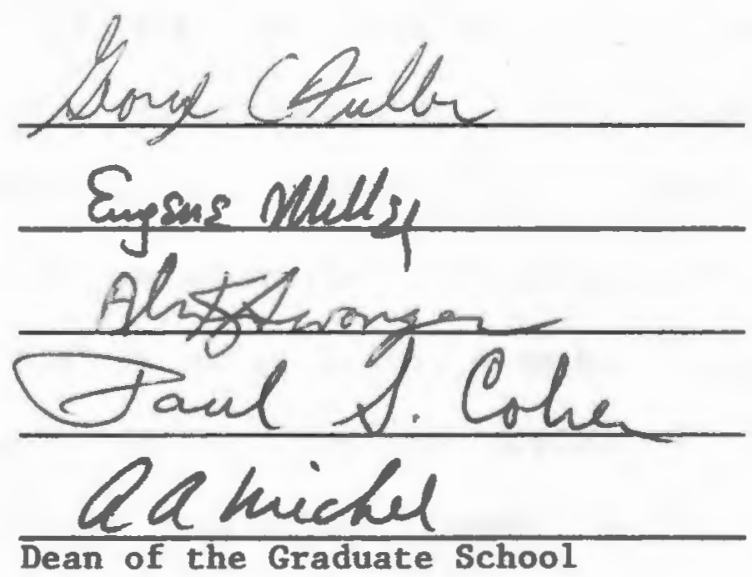

UNIVERSITY OF RHODE ISLAND

1982 
Agins, Alan P., Ph.D., University of Rhode Island, 1982. Age Related Changes in the Induction of the Hepatic Mixed-Function Monooxygenase System in Miniature Pigs: Effects of Pentachloroanisole, Pentachlorophenol and Phenobarbital. Major Professor: Dr. George C. Fuller.

Pentachloroanisole (PCA), an environmental degradation product of the biocide pentachlorophenol (PCP), has been detected in the food chain. The metabolic fate of PCA was examined in miniature pig hepatic microsomes, in vitro. The compound was shown to be a substrate for a cytochrome 4 450-dependent demethylation reaction, which results in the regeneration of the parent compound, PCP. A disproportionately large increase in PCA demethylase activity (PCADM) following pretreatment with phenobarbital suggests that the compound is preferentially metabolized by specific-inducible form(s) of cytochrome $\mathrm{P} 450$.

A comparison of the effects of PCA and purified PCP on the hepatic MFO system of miniature pigs was conducted at various stages of postnatal development. Phenobarbital was utilized as a positive control for induction. PCA, PCP and phenobarbital (10 mg/kg/day X 4 days, P.o.) were administered to piglets at 1, 4, and 8 weeks of age and the levels of cytochromes $\mathrm{P} 450$ and $\mathrm{b}_{5}$, and the activities of NADPH-Cytochrome $c$ reductase, aniline hydroxylase (ANOH), p-nitroanisole demethylase (NADM), and PCA demethylase were determined. In one week old piglets, PCA produced significant increases in all parameters measured, with the greatest effect ( $300 \%$ of control) on its own in vitro metabolism. The pleiotropic response evoked by PCA 
was similar to that of phenobarbital, but of lesser magnitude. PCP produced small increases in only $\mathrm{P} 450$ and nitroanisole demethylase. The qualitative differences in the induction patterns produced by PCA and PCP suggests that the two compounds exert different effect on MFO. By eight weeks of age, the magnitude of induction by PCA was diminished. Furthermore, although specific activities for ANOH, NADM, and PCADM in phenobarbital treated pigs were similar at 1 and 8 weeks of age, examination of catalytic activity profiles suggested an age dependent decrease in the induction of specific forms of cytochrome P450. On further investigation, Eadie-Hofstee plots from kinetic experiments with ANOH and PCADM exhibited biphasic patterns suggestive of multiple forms of 4450 catalyzing the same reaction. By integrating the effects of age and treatment on the various kinetic species for each substrate, a minimum of four forms of cytochrome $\mathrm{P} 450$ are suggested to exist in miniature pig hepatic microsomes. Of the four forms, two are inducible by phenobarbital and one of these forms appears to display age-dependency in the magnitude of induction. These data indicate that MFO induction by exogenous chemicals varies qualitatively as well as quantitatively with age. 


\section{ACKNOWLEDGEMENTS}

The author wishes to express his sincere appreciation to his major professor, Dr. George C. Fuller, for his guidance and understanding over the years. Special thanks are equally extended to Dr. Eugene Miller for providing me the opportunity to conduct this investigation as a member of the Beltsville Research Facility of the Food and Drug Administration. Dr. Miller's continued support and encouragement throughout my incumbency are acknowledged with gratitude. The entire staff of the Beltsville Research Facility are to be thanked for their intellectual, moral, and technical support during this investigation. James 0 . Peggins is gratefully thanked for his invaluable assistance in the laboratory and for sharing his expertise in statistical analysis. The contribution by $\mathrm{Dr}$. Werner Seibel, in electron microscopy, and Mr. Ronald Thomas, in analytical chemistry, are also gratefully acknowledged.

Most importantly, however, I would like to express my deepest gratitude and heartfelt thanks to my wife, Paula, for her love and understanding, encouragement and sacrifice over the years. 


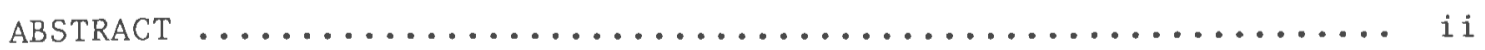

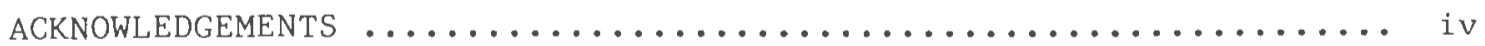

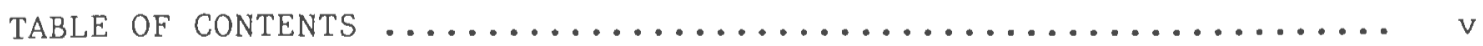

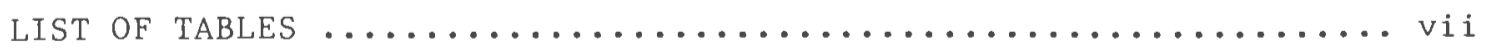

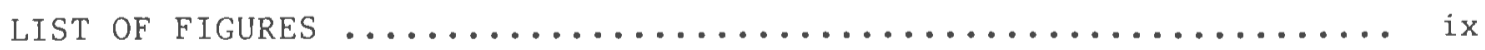

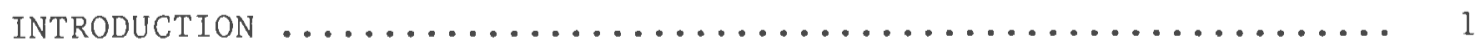

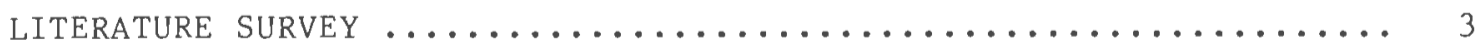

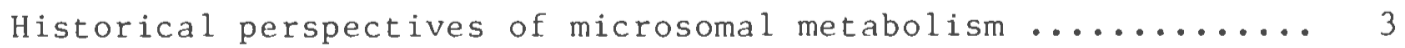

Components of the microsomal MFO system .................

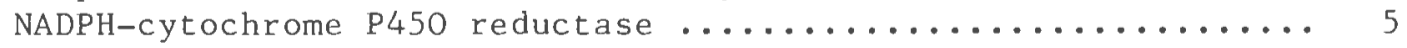

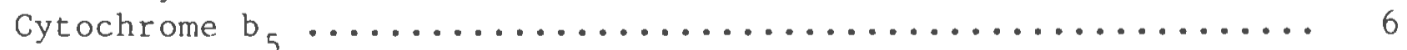

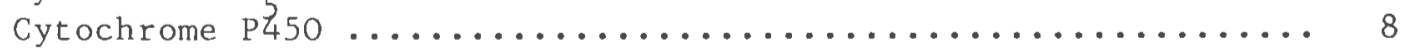

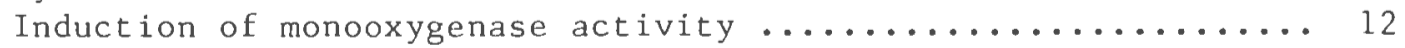

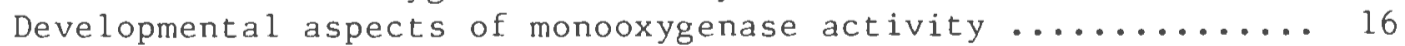

Heterogeneity of cytochrome $\mathrm{P} 450 \ldots \ldots \ldots \ldots$

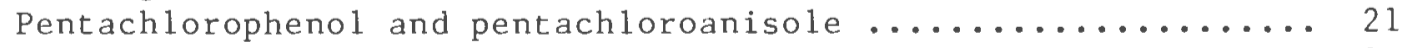

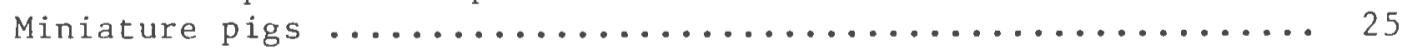

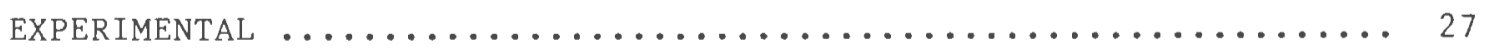

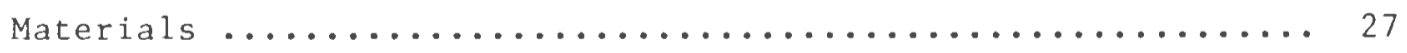

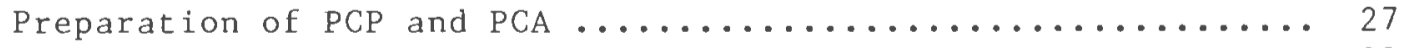

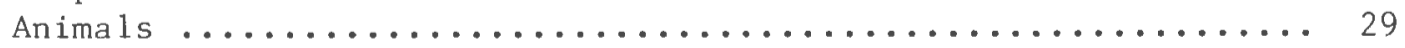

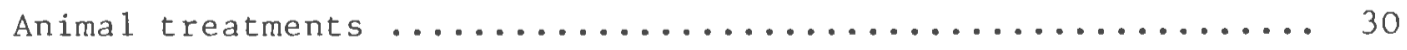

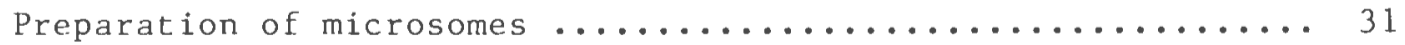

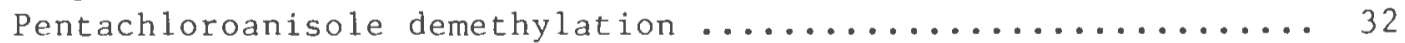

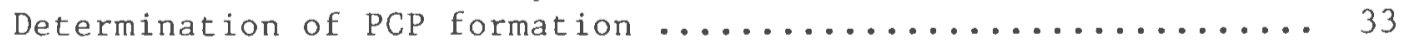

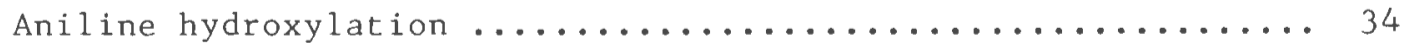

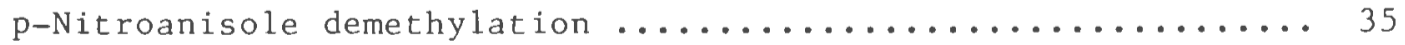

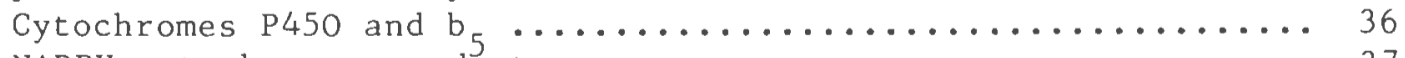

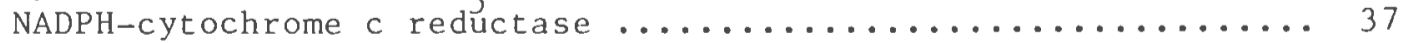

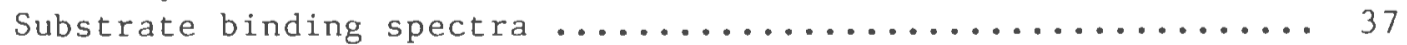

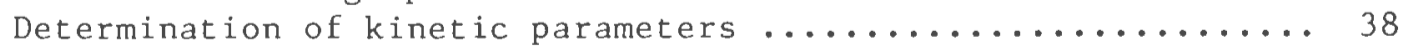

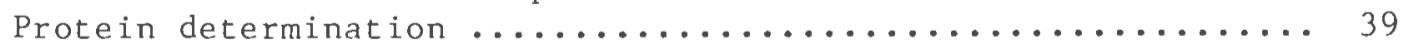

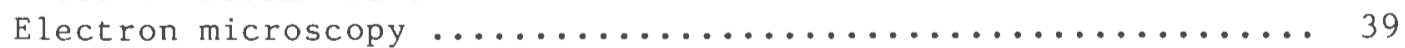

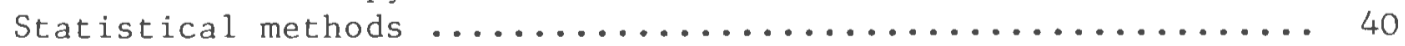


In vitro metabolism of pentachloroanisole ............. 42

Development of the MFO system in growing miniature pigs ..... 48 Effects of PCA, PCP and phenobarbital on MFO parameters in

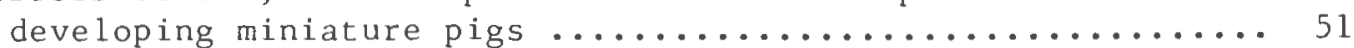

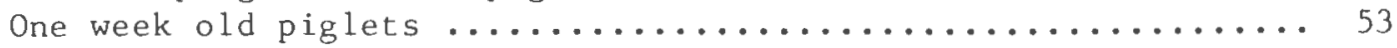

Treatment effects on hepatocellular morphology ........... 56

Biochemical effects in four week old piglets ............. 60

Biochemical effects in eight week old piglets ............ 65

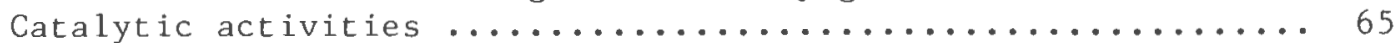

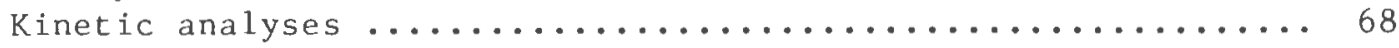

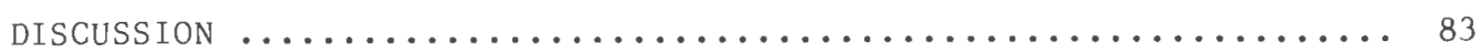

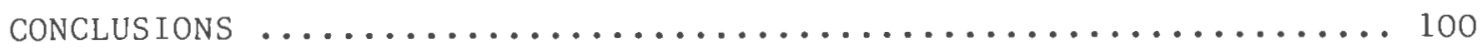

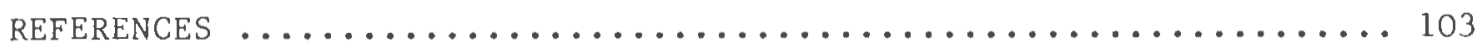

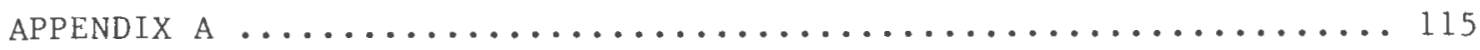

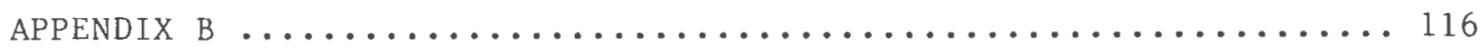




\section{LIST OF TABLES}

Table

1. Characterization of PCA demethylation by miniature pig hepatic microsomal enzymes .................... 43

2. Postnatal development of three microsomal mixed-function monooxygenase activities in miniature pigs ............. 50

3. Postnatal development of cytochrome $P 450$, cytochrome $b_{5}$, and NADPH-cytochrome $c$ reductase in miniature pigs ......... 52

4. Effects of PCA, PCP, and phenobarbital on microsomal enzyme activities in one week old miniature pigs .......... 54

5. Effects of PCA, PCP, and phenobarbital on cytochrome P450, $b_{5}$, and cytochrome $c$ reductase in one week old miniature

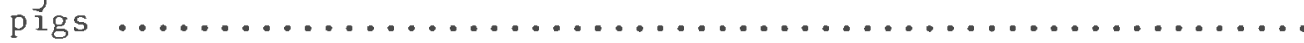

6. Effects of PCA, PCP, and phenobarbital on microsomal enzyme

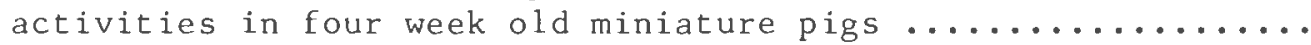

7. Effects of PCA, PCP, and phenobarbital on cytochromes P450, $b_{5}$, and cytochrome $c$ reductase in four week old miniature pigs

8. Effects of PCA, PCP, and phenobarbital on microsomal enzyme activities in eight week old miniature pigs ............. 66

9. Effects of PCA, PCP, and phenobarbital on cytochromes P450, $b_{5}$, and cytochrome $c$ reductase in eight week old miniature

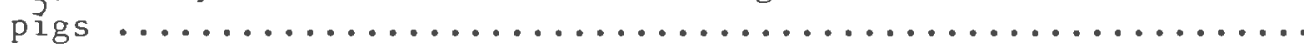

10. Catalytic activity of PCA demethylase as a function of age and treatment

11. Catalytic activity of aniline hydroxylase as a funcion of age and treatment

12. Catalytic activity of nitroanisole demethylase as a function of age and treatment

13. Summary of the kinetic parameters for the two forms of

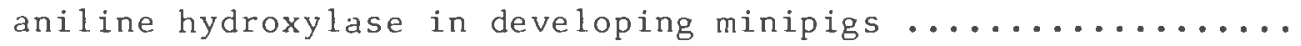

14. Summary of the kinetic parameters of the two forms of aniline hydroxylase in phenobarbital induced, developing minipigs ..... 
15. Comparison of the kinetic parameters for the two forms of aniline hydroxylase in uninduced, PCA, and phenobarbital treated minipigs at four weeks of age $\ldots \ldots \ldots \ldots \ldots \ldots \ldots \ldots$

16. Comparison of the kinetic parameters for the two forms of PCA demythylase in uninduced and phenobarbital induced

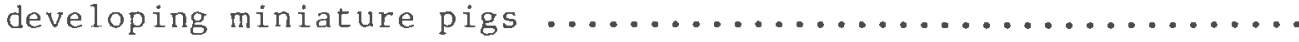


1. High-pressure liquid chromatograms for the analysis of

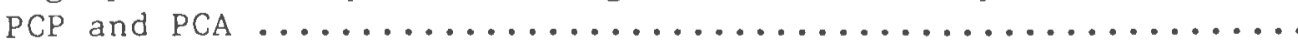

2. Lineweaver-Burke plots of PCA demethylation in hepatic microsomes from phenobarbital and uninduced minipigs ........

3. Typical substrate binding spectra observed following addition of PCA to miniature pig microsomal suspensions ............

4. Double-reciprocal plot for the determination of the spectral dissociation constant $\left(K_{s}\right)$ for PCA in phenobarbital induced

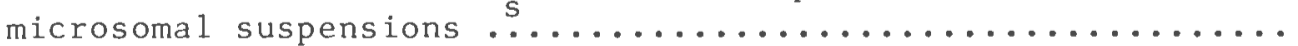

5. Electron photomicrograph of hepatic parenchymal cells from

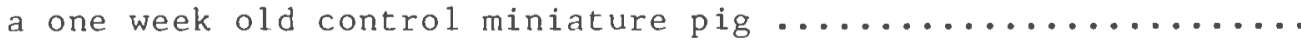

6. Higher power electron photomicrograph of an hepatic cell from

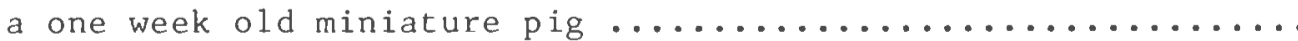

7. Electron photomicrograph of hepatic cells from a phenobarbital

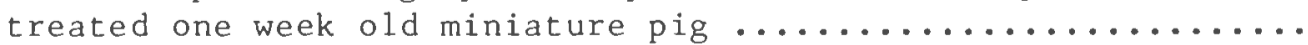

8. Electron photomicrograph of hepatic cells from a PCP treated

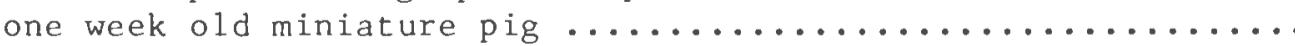

9. Electron photomicrograph of hepatic cells from PCA treated

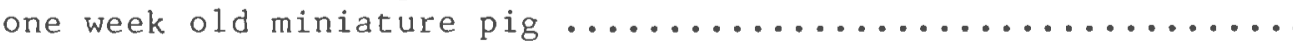

10. Eadie-Hofstee plot of aniline hydroxylase activity in microsomes

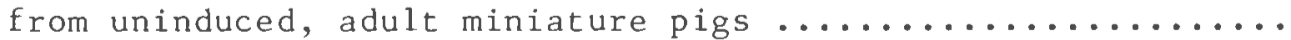

11. Plot of $\mathrm{v}$ (observed) against $\mathrm{v}$ (calculated) based on biphasic kinetic analysis of aniline hydroxylase activity ...........

12. Developmental profiles for the two forms of aniline hydroxylase

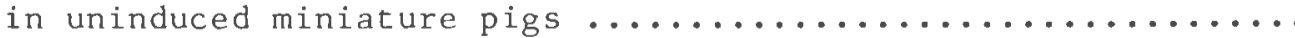

13. Eadie-Hofstee plot of PCA demethylase activity in microsomes

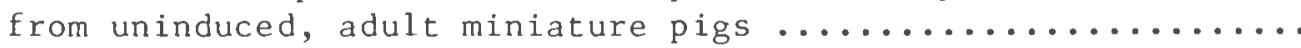




\section{INTRODUCTION}

In recent years, research in perinatal toxicology has gained substantial impetus and is now considered by many an important facet for the complete evaluation of chemical hazards to man. The increased interest in developmental toxicity studies has grown from both theoretical considerations and practical experience. In pharmacology, it has long been recognized that an effect in the infant cannot always be predicted by extrapolation of adult response. Yet, with the exception of teratology studies, the vast majority of toxicological research is conducted in relatively mature animals. Since the human infant is often unavoidably exposed to the same chemical milieu as the adult population, responses of the neonate need to be examined and defined.

It appears that within this framework, perinatal enzymology may play a central role. Chemically induced perturbations of enzyme ontogenetic profiles, alterations in isoenzyme patterns, or other modifications to key metabolic pathways may result in subtle biochemical lesions in the absence of apparent morphological or functional abnormalities. Furthermore, such changes may have profound effects on maturational processes or future health.

One enzyme system, the microsomal mixed-function monooxygenase (MFO) system, plays a critical role in the metabolism of foreign compounds such as drugs, pesticides and carcinogens. The enzyme system also has important homeostatic functions through its metabolism of steroids, heme, fatty acids and a number of other endogenous substrates. 
Additionally, the multicomponent enzyme system, in many cases, is extremely sensitive to induction by exogenous chemicals. This adaptive mechanism, once thought to be strictly beneficial for the detoxification of xenobiotics, has received much attention over the last decade with the knowledge that many chemicals, particularly carcinogens, require metabolic activation prior to exhibiting their detrimental effects.

This study attempts to examine temporal changes in the response of hepatic microsomal enzymes to xenobiotic induction during early postnatal life in miniature pigs. The effects of the environmental contaminants, pentachlorophenol (PCP) and pentachloroanisole (PCA) on the levels and activity of various MFO parameters are investigated with emphasis on age dependent differences in the response to induction. The in vitro metabolism of PCA is characterized and subsequently utilized in activity measurements. Due to its well established potent, comprehensive inductive effects, phenobarbital is used as a positive control for comparisons. Finally, alterations in cytochrome P450 subpopulations are examined as a determinant for age and treatment effects. 
LITERATURE SURVEY

\section{Historical perspectives of Microsomal Metabolism}

The metabolism of foreign compounds by hepatic microsomes was first described by Mueller and Miller (1949). These investigators showed that both the oxidative N-demethylation and the reduction of the azo linkage of aminoazo dyes were catalyzed in vitro by microsomes derived from rat liver homogenates. In 1955, Brodie and coworkers extended these initial studies by utilizing various drugs as substrates, and after compiling the research efforts from numerous laboratories (Brodie et al., 1958) proposed that the microsomal fraction of cells was responsible for a vast number of reactions involved in drug metabolism. The reactions had a strict requirement for both molecular oxygen and pyridine nucleotides as reducing agents, which lead to the classification of this enzyme system as a mixed-function oxidase (Mason, 1957) or monooxygenase (Hayaishi, 1962). Further direct support for this terminology was provided by Posner et al. (1961) who showed that the oxygen molecule inserted into a hydroxylated product was derived from ${ }^{18} \mathrm{O}_{2}$ and not water.

Although investigators in the early 1950 s had successfully isolated and characterized various individual components of microsomes, a 
direct connection to drug metabolizing capacity remained obscure. In the latter part of the decade, Klingenberg (1958) and Garfinkel (1958) reported that an additional component, a cytochrome not yet accounted for, existed in microsomes. The ability of this cytochrome to undergo unique spectral changes in the presence of carbon monoxide led to the early name of "CO Binding Pigment". Omura and Sato (1964) further characterized this new cytochrome and labeled it Cytocrhome P450 due to the location of the Soret peak of the reduced, carbon monoxide complexed material. The reactivity of Cytochrome $\mathrm{P} 450$ with carbon monoxide provided a powerful tool for experimentation linking microsomal electron transport to drug metabolism. Estabrook et al., (1963) provided firm evidence that Cytochrome $P 450$ was a crucial component for hydroxylation reactions in adrenal cortex particles and subsequently extablished its role as the "terminal oxidase" of the microsomal drug-metabolizing enzyme system (Cooper et al., 1965).

In 1968, Lu and Coon successfully solubilized and resolved the enzyme system into fractions containing Cytochrome P450, NADPHCytochrome P450-Reductase, and a heat stable factor, subsequently shown to be phosphatidylcholine. The ability to reconstitute catalytic activity toward a variety of drug, steroid and fatty acid substrates was a major milestone and opened the way for more refined approaches to mechanistic and functional studies.

In the two decades following the initial studies of microsomal mediated metabolism an extremely large body of literature has been generated from research in the areas of pharmacology, toxicology, biochemistry, endocrinology, molecular biology and genetics. 


\section{Components of the Microsomal MFO System}

The microsomal fraction of liver contains at least three flavoproteins; NADPH-Cytochrome P450-Reductase, NADH-Cytochrome $b_{5}$-Reductase and Amine Oxidase, two heme proteins; Cytochrome P450 and Cytochrome $b_{5}$, and a non-heme iron protein; Stearyl-CoA Desaturase. In the presence of the microenvironment of the smooth endoplasmic reticulum these components work efther independently or in concert in an electron transfer capacity. The following discussion will be limited to those components investigated in the present study.

\section{NADPH-Cytochrome P450-Reductase}

NADPH-Cytochrome P450-Reductase (NADPH Dehydrogenase. EC 1.6.2.4) was first observed in whole liver extracts by Horecker (1950). Phillips and Langdon (1962) and Williams and Kamin (1962) identified the microsomal fraction as the origin of this enzyme and upon purification revealed that the protein is capable of reducing a wide variety of both one and two electron acceptors. The nomenclature for this enzyme varies between laboratories and is dependent on both the acceptor used and the condition for the assay. Artificial acceptors such as cytochrome $c$ and ferricyanide are routinely utilized due to the ease of measurement, the extended linearity and the higher turnover in these assays. Although Cytochrome $\mathrm{P} 450$ is known to be the native acceptor, the term NADPH-Cytochrome $c$ Reductase is often used interchangeably. One major difference is that phosphatidylcholine is required for 
reduction of Cytochrome $\mathrm{P} 450$ in reconstituted systems but not for electron transfer to artificial acceptors (Strobel and Digman, 1978).

The mechanism by which the enzyme transfers electrons to Cytochrome $\mathrm{P} 450$ has been extensively investigated. It has been demonstrated that the protein contains equimolar amounts of FAD and FMN (Yasukochi and Masters, 1976). Vermillion and Coon (1978), using FMN-depleted reductase demonstrated that the enzyme containing only FAD remains capable of being readily reduced by NADPH and suggested that the FMN moiety probably interacts directly with Cytochrome P450. Although conclusive evidence for the exact mechanism is still lacking, the overall sequence of electron transfer from NADPH to FAD to FMN to P450 is consistent with the observed biphasic reduction kinetics of the enzyme. Furthermore, this scheme appears to be thermodynamically favorable as a function of reduction potential differences of the two flavin moieties (Oprian et al., 1979).

In addition to its essential role in transferring reducing equivalents to Cytochrome $\mathrm{P} 450$, the reductase has also been reported to have P450-independent catalytic activity. Hernandez et al., (1967) showed that Cytochrome $c$ Reductase catalyzed the reduction of azo dyes without benefit of P450. Furthermore, the participation of this flavoprotein in the initiation of microsomal NADPH-dependent lipid peroxidation has been reported (Pederson et al., 1973).

\section{Cytochrome B5}

Cytochrome $b_{5}$ was originally isolated from microsomes by Strittmatter and Velick (1956). In addition to purifying and 
characterizing this cytochrome the investigators also purified a flavoprotein specific for NADH which transferred electrons to Cytochrome $b_{5}$ (Strittmatter and Velick, 1956a). Although the physiological function of this enzyme system was not apparent at that time, approximately a decade later Holloway and Wakil (1970) implicated Cytochrome $b_{5}$ in microsomal fatty acid desaturation reactions. It is now well established that this microsomal electron transport system is composed of NADH-Cytochrome $b_{5}$-Reductase, Cytochrome $b_{5}$ and a cyanide-sensitive terminal desaturase which functions to convert Steryl-CoA to 0leyl-CoA (Prasad and Joshi, 1979).

Less well established has been the role of these components with respect to the "drug-metabolizing" enzyme system. The synergistic effect of NADH on NADPH-dependent reactions led early investigators to postulate a permissive role for Cytochrome $b_{5}$. With the knowledge that Cytochrome $\mathrm{P} 450$ mediated oxidations required two separate electron transfers, it was suggested that the second electron may be denoted via Cytochrome $b_{5}$ (Estabrook and Cohen, 1969). Lu and coworkers (1974) and Imai and Sato (1977) demonstrated that in reconstituted metabolic systems, Cytochrome $b_{5}$ was not an obligatory component for activity, although in both studies synergistic effects were seen. It was also suggested by Lu et al. (1974) that the role of Cytochrome $b_{5}$ may be dependent on such factors as tissue, sex, age and the particular substrate utilized. More recently, Imai (1979), using various purified forms of Cytochrome $\mathrm{P} 450$, showed that Cytochrome $\mathrm{b}_{5}$ was required for maximal activity with some forms of P450, but had little or no effect 
on other forms in reconstituted systems. Sugiyama (1979) reported the purification of a unique form of Cytochrome P450 from rabbit liver. This form of $P 450$ had a high affinity for Cytochrome $b_{5}$ and required its presence for reconstitution of catalytic activity with nitroanisole as substrate. Further support for the role of Cytochrome $b_{5}$ in P450-dependent reactions has come from the finding that in addition to MADH-Cytochrome $b_{5}$-Reductase, NADPH Cytochrome P450 Reductase can efficiently reduce Cytochrome $b_{5}$ (Enoch and Strittmatter, 1979). Thus it appears that Cytochrome $\mathrm{b}_{5}$ serves a central role in microsomal electron transport by interacting with two separate reductases, a desaturase and some forms of Cytochrome P450.

\section{Cytochrome $\mathrm{P} 450$}

Cytochrome $\mathrm{P} 450$ is the dominant heme protein in microsomes. The mammalian liver is the richest source of the hemoprotein, however, Cytochrome $\mathrm{P} 450$ is also found in kidney, lung, skin, intestinal tract, adrenal gland, placenta, ovary and blood platelets (Hodgson and Dauterman, 1980). cytochrome $\mathrm{P} 450$ as the terminal oxidase of the MFO system displays functional heterogeneity in the various tissues, yet although many of the extrahepatic tissues are capable of supporting low levels of xenobiotic metabolism, empirically, the liver is the major site for such metabolism. The Cytochrome $P 450$ in kidney, for example, appears to be quite active in the omega oxidation of fatty acids (Masters et al., 1980), while the P450 in adrenal gland mitochondria is mainly responsible for the metabolism of steriod hormones (Sih, 1969). 
The ability of Cytochrome $\mathrm{P} 450$ to serve as the terminal oxidase of the MFO system lies in its ability to bind substrate, undergo reversible oxidation state transitions, bind molecular oxygen and activate it for subsequent insertion into the substrate molecule. The binding of substrate by $\mathrm{P} 450$ results in measurable spectral perturbations. Remmer et al. (1966) and Schenkman et al. (1967) described characteristic absorbance changes upon addition of various compounds to microsomal suspensions. There are primarily two major and one minor types of spectra observed dependent on the compound utilized. A Type I difference spectrum is characterized by an absorption maximum between $385-390 \mathrm{~nm}$ and a minimum at approximately $420 \mathrm{~nm}$. A Type II spectrum is characterized by a peak at about $430 \mathrm{~nm}$ and a broad trough between $390-410 \mathrm{~nm}$. A third type of difference spectrum was also described as a reverse Type I. This spectrum is characterized by a peak at $420 \mathrm{~nm}$ and a trough between $385-390 \mathrm{~nm}$ and thus appears to be a mirror image of a Type I spectrum.

Whereas Type I producing compounds represent a large, structurally diverse group including drugs, pesticides and steriods, Type II compounds tend to be primary amines, pyridines and imidazole compounds (Mailman et a1., 1974). Gigon and coworkers (1968) found that the reduction of Cytochrome P450 by NADPH-Cytochrome P450-Reductase was accelerated in the presence of Type I compounds while unchanged or decreased in the presence of Type II compounds. These results correlated well with the fact that Type I compounds were generally better substrates for $\mathrm{P} 450$ dependent oxidation than Type II compounds and 
further indicated that the substrate binding preceded reduction in the dominant reaction pathway.

In conjunction with optical difference spectra studies, electron paramagnetic resonance (EPR) spectroscopy had shown that Cytochrome P450 can exist in a high-spin $\left(\mathrm{Fe}^{3+}\right.$ heme: $\left.\mathrm{S}=5 / 2\right)$, a low-spin $\left(\mathrm{Fe}^{3+}\right.$ heme: $S=1 / 2$ ) or most commonly in a mixed spin state (Jefcoate, 1978). A Type I change correlates with an increase in high-spin character upon binding of the substrate, while a Type II change reflects a conversion of native high-spin $P 450$ to a low-spin complex of the heme and the 1igand. In this respect, two modes of compound interaction with $\mathrm{P} 450$ are now recognized as "substrate" binding and "ligand" binding (Testa and Jenner, 1981).

From the integration of diverse physical and chemical studies, a structural model of the active site of Cytochrome P450 has been proposed (Lipscomb and Gunsalus, 1973; Rein et al., 1976).

In these models, the active site contains an iron protoporphyrin IX moiety in a large, relatively accessible hydrophobic pocket in the apoprotein. The heme is loosely anchored to the site by a combination of hydrophobic forces and covalent bonds to the central iron ion. The fifth iron ligand has been reported to be a thiolate anion contributed by a cycteine residue of the protein (Dolphin et al., 1979). This anionic mercaptide linkage has been implicated for both the unique specral properties of this cytochrome and in having important electronic effects on oxygen activation in the normal cycle of catalysis (Collman and Sorrell, 1975). The sixth axial ligand 
has been reported to be either oxygen, in the form of water or a hydroxyl group from a proximal amino acid (Griffin and Peterson, 1975) or nitrogen in the form of histidine. Although conclusive evidence is lacking, it is generally accepted that the sixth linkage is relatively weak, but functions to hold the heme iron in a square octahedral, hexacoordinated configuration. Displacement of the weak bond by stronger ligands such as amines and pyridines results in a heme-ligand complex typified by a Type II spectrum and low-spin cytochrome. The "locking" of Cytochrome P450 into a low-spin state appears to be responsible for some of the inhibitory actions exerted by such compounds (Testa and Jenner, 1981).

In contrast to ligand binding, substrate binding involves mainly hydrophobic interactions between non-polar regions of the protein and the substrate. This binding results in a dissociation of the native sixth ligand linkage and a change in the configuration of the heme molecule from octahedral, hexacoordinated to square pyramidal, pentacoordinated (White and Coon, 1980). This change also results in a conversion to a high-spin state, which increases the redox potential of the system and creates a more favorable electron flow sequence to Cytochrome P450 (S1ingar et al., 1979).

The mechanism of binding and subsequent activation of molecular oxygen by Cytochrome $\mathrm{P} 450$ is quite complex and has recently been reviewed (White and Coon, 1980). Essentially, following the binding of oxygen to the reduced P450-substrate complex, a second electron transfer results in the creation of peroxide anion. This reactive 
protein-complexed intermediate then reacts with substrate to form a hydroxylated compound and water. In addition to this mechanism, evidence has accumulated indicating that in some cases, Cytochrome P450 acts in an oxidase or peroxygenase capacity resulting in the production of hydrogen peroxide or other peroxy compounds. The homolytic cleavage of the oxygen-oxygen bond may lead directly to insertion of a hydroxyl group into a substrate independent of the $\mathrm{NADPH} / \mathrm{O}_{2}$ pathway (Coon, 1981).

\section{Induction of Monooxygenase Activity}

Conney and Burns (1959) first demonstrated the phenomenon of drug induced synthesis of liver microsomal enzymes. This finding served to substantiate a number of earlier assumptions concerning the MFO system and became a powerful tool for the study of induced enzyme synthesis in general. Extensive reviews on MFO induction have been published (Conney, 1967; Mannering, 1968).

Historically, inducers of MFO have fallen into one of two categories. One group, containing numerous drugs and xenobiotics of diverse chemical structure, is best typified by phenobarbital. The other class consists primarily of polycyclic aromatic hydrocarbons of which 3-methylcholanthrene is generally recognized as the prototype (Conney, 1967). The effects of these two types of inducers are similar in some respects in that they lead to increased protein synthesis, as determined by amino acid incorporation both in vivo and 
in vitro (Kato et al., 1965; Gelboin, 1964). The increase in protein synthesis can be blocked by the metabolic inhibitor, ethionine (Conney et al., 1956), and at the level of translation by puromycin, however, the inhibition by Actinomycin $D$ indicates that induction by both types of inducers involves DNA-dependent RNA synthesis (Nebert and Gelboin, 1969). There are however, major differences between the two classes of inducers.

Phenobarbital is a much more comprehensive inducer of MFO components than 3-MC. Among the effects produced by phenobarbital are an increase in both the total liver protein and the specific protein content in microsomes (Conney et al., 1960), increased levels of Cytochrome P450, Cytochrome $\mathrm{b}_{5}$, NADPH-Cytochrome P450 Reductase, and numerous Cytochrome P450-dependent reactions (Kuriyama et al., 1969; Conney, 1967). In addition, a marked proliferation of the smooth endoplasmic reticulum can be observed by electron microscopy (Fouts and Rogers, 1965) which is consistent with the observed increase in microsomal protein and phospholipid content following induction (Orrenius and Ericsson, 1966).

In contrast to phenobarbital, 3-MC and cogeners induce fewer components of microsomes. There are, however, two major qualitative changes observed in microsomes following 3-MC treatment. A shift in the wavelength of the reduced $C O$ peak to $448 \mathrm{~nm}$ and a substantial Increase in the activity of Aryl Hydrocarbon Hydroxylase, have been associated with the de novo synthesis of a new hemoprotein, Cytochrome P448 (Alvares et al., 1967; Kuntzman et al., 1969). 
A third class of inducers, the polychlorinated biphenyls, came to interest during the 1970 s as a result of their increasing contamination of the environment (Alvares et al., 1973). These compounds, typified by Aroclor 1254, exhibited potent inductive effects which were consistent with both phenobarbital and 3-MC effects. On further examination, it was concluded that this combined effect was probably due to the complex mixture of isomers in various preparations (Stonard and Greig, 1976).

Although most inducers of MFO usually require multiple administrations with fairly high doses to produce their maximal effect, the extremely toxic compound 2,3,7,8-tetrachlorodibenzo-p-dioxin (TCDD) was found to be an inducer of the 3-MC type and was more potent than any other inducer on a dose-per-unit body weight basis (Poland and Glover, 1974). Lucier et al. (1975) demonstrated that a single oral dose of TCDD at $3 \mathrm{\mu g} / \mathrm{kg}$ to pregnant rats caused marked elevations in both maternal and progeny hepatic MFO parameters. These effects were still present months later.

Although the number of xenobiotics capable of induction is quite large they have in the past been conveniently placed into one of the two classes. It is, however, becoming evident as assay capabilities and separation techniques expand, that many compounds exhibit unique induction properties. The effects of pregnenolone-16-a-carbonitrile (Elshourbagy and Guzelian, 1980) and isosafrole (Ryan et al., 1980) cannot be definitively categorized as either 3-MC or phenobarbital type of induction. 
The mechanism(s) by which inducers lead to increased synthesis of MFO components remains somewhat obscure. The documented increase in DNA-dependent RNA synthesis during the induction process has led investigators to propose that inducers play some role as derepressors of regulatory or other genes (Nebert et al., 1981). One early theory to account for the ability of such a diverse structural group of compounds to invoke similar effects was proposed by Marshall and McLean (1971). These authors suggested that induction was mediated through an "endogenous factor", which was normally inactivated by Cytochrome P450. Compounds capable of binding to $\mathrm{P} 450$ would block inactivation, resulting in increased cellular levels of the factor and subsequent induction. This theory is supported by the empirically derived evidence that a very large proportion of inducers are either substrates or inhibitors of $\mathrm{P} 450$ capable of producing Type I binding spectra (Mannering, 1969). Identification of a specific "endogenous factor" however, has yet to be accomplished.

The discovery of a hepatic cytosolic "species" in mice, which stereospecifically and reversibly bound TCDD, led to the postulation of a specific receptor for the induction of Aryl Hydrocarbon Hydroxylase (Poland et al., 1976). This receptor was shown to bind a variety of halogenated dibenzo- dioxins and furans with different affinity which closely correlated with their potencies as inducers. Furthermore, although the inductive polycyclic aromatic hydrocarbons competed with TCDD for binding, phenobarbital, pregnenolone-16-a-carbonitrile and steroid hormones displayed no specific binding. This cytosolic 
species, now termed the Ah receptor, is recognized as the major product of regulatory gene(s) in the murine Ah locus (Nebert et al., 1981). The receptor has also been detected in rats and rabbits (Kahl et al., 1980). Excellent reviews of the research on the Ah locus and genetic control of induction have recently been published (Nebert et al., 1981, 1982). Of great interest has been Nebert's comparison of the Cytochrome $\mathrm{P} 450$ and immune systems and his hypothesis that mammalian tissues have the genetic capacity to produce hundreds or thousands of inducible forms of $\mathrm{P} 450$ in response to different chemical stimuli.

\section{Developmental Aspects of Monooxygenase Activity}

Since the first reports by Jondorf et al. (1959) and Fouts and Adamson (1959), investigators of the perinatal development of MFO activity have flourished in the literature. Extensive reviews by Short et al. (1976), Neims et al. (1976) and most recently Klinger et al. (1981) have indicated that although variations exist between laboratories with respect to species, sex and substrates utilized, the general patterns of development are similar in most mammalian species. Essentially the monooxygenases are apparently absent or barely detectable in fetal organs, especially in the fetal liver, until just before birth. After birth, in most species, development of specific microsomal components and metabolic pathways generally follow one of three profiles: (1) activity rises rapidly from birth and 
plateaus at maturity, (2) activities peak shortly after birth, often exceeding adult levels, and subsequently decrease to adult levels, or (3) activity remains low during early postnatal development and rises rapidly coincident with the onset of sexual maturity.

A number of factors have been postulated to explain the deficiency of MFO activity during late fetal and early postnatal life. Wilson (1969) suggested that high levels of somatotropin during development inhibited MFO. Soyka and Long (1972) found that progesterone inhibited MFO in vitro and suggested that this maternally derived inhibitor was responsible for decreased activity in fetal and neonatal animals. Short et al. (1976) and Kuenzig et al. (1975) implicated the immaturity of hepatocellular morphology, especially the absence of smooth endoplasmic reticulum in the fetus and neonate, as a primary determinant for low MFO activity. Both groups demonstrated a good correlation between age related development of smooth endoplasmic reticulum and increases in hepatic drug metabolic activity. Other factors, including the presence of endogenous $\mathrm{P} 450$ ligands or age related phospholipid differences in microsomal membranes, have recently been discounted as responsible for the age differences in biotransformation (Klinger et al., 1981). Furthermore, these authors suggested that qualitative differences in Cytochrome $\mathrm{P} 450$, or in the ratio of different $P 450$ subpopulation may be responsible for the many variations observed in developmental profiles.

Induction of monooxygenase activity during perinatal development appears to be highly dependent on both the inducer and species utilized. In laboratory animals with long gestation periods, such as the 
guinea pig, phenobarbital type inducers are effective in increasing MFO activity in the late gestational fetus (Kuenzig et al., 1975). Species less developed at birth, such as the rat, are generally refractory to phenobarbital induction in utero (Guenther and Mannering, 1977; Cresteil et al., 1979), but rapidly become responsive after birth. Shubert and Netter (1981) have further demonstrated that the onset of inducibility is independent of parturition, but is largely determined by the time passed since conception. In contrast, inducers of Cytochrome P448, such as TCDD and 3-MC, are quite effective transplacental inducers (Guenther and Mannering, 1977; Lucier et al., 1975). Early studies on the postnatal inducibility of MFO activity indicated that younger animals were more responsive to phenobarbital induction when measured as percent increase of specific activity over controls (Basu et al., 1971). Although such studies did not receive a great deal of attention at that point in time, more recently interest has been rekindled with the knowledge of the heterogeneity of Cytochrome P450. Atlas et al. (1977) showed that various P450 (P448) subspecies follow different developmental patterns in rabbit, as well as altered sensitivity to induction. Cresteil and coworkers (1979) reported age dependent changes in the catalytic activity of aniline hydroxylation and nitroanisole demethylation as a function of induction by either phenobarbital or 3-MC. Klinger et al. (1981) has summarized a number of reports showing greater enhancement of MFO by phenobarbital in young rats. The conclusion that is beginning to 
emerge from these studies is that the neonate is not only quantitatively different from the adult in its capacity to metabolize compounds, but may be qualitatively different in its response to induction.

\section{Heterogeniety of Cytochrome P450}

Species differences in the rates of metabolism of several narcotics (Axelrod, 1956) and the induction of specific metabolic pathways at the expense of others in a single species (Conney et al., 1959) led to the early proposal of more than one liver microsomal drug metabolizing system. With the discovery that Cytochrome P450 was the terminal oxidase of the enzyme system (Cooper et al., 1965) numerous Investigations focused on determining whether the broad substrate specificity, the equally diverse number of metabolic reactions, and the induced alterations in specific catalytic activities could be accounted for by a single Cytochrome P450.

Early approaches to resolving the question of multiple forms of P450 were based on manipulations of various biochemical and biophysical properties of the enzyme in microsomal suspensions. The different, selective effects of phenobarbital and 3-MC induction have been well documented (Conney, 1967) and previously discussed. Similarly, in vitro inhibition studies have centered around the use of selective inhibitors of various reactions and forms of P450. SKF 525A, a potent Inhibitor of drug metabolism, was utilized to demonstrate differences between the forms of Cytochrome $\mathrm{P} 450$ in control and phenobarbital 
induced microsomes and that in 3-MC treated animals (Sladek and Mannering, 1969). It was generally accepted during this period that phenobarbital caused only a quantitative increase in the form of Cytochrome P450 normally present in uninduced microsomes, however, Grasdalen et al. (1975) demonstrated that phenobarbital induced microsomes displayed different characteristics from controls and indicated that metyrapone was more selective for the former while SKF 525A was more selective for uninduced form(s). Jonen et al. (1974) also indicated that metyrapone had a greater affinity for phenobarbital induced P450. Thus the early evidence indicated that phenobarbital induction led to qualitative as well as quantitative changes in microsomes. Napthoflavone (7,8-Benzoflavone) strongly inhibits many reactions induced by 3-MC (Burke et al., 1977), yet stimulates the activity of native and phenobarbital induced Cytochrome P450 (Cinti, 1978). Tetrahydrofuran has recently been shown to be a potent inhibitor of a form of $\mathrm{P} 450$ found in uninduced microsomes, but has little or no effect in phenobarbital induced forms of $P 450$ (Hultmark et a1., 1979). An extremely thorough review of the types of mechanisms of $P 450$ inhibitors was recently published (Testa and Jenner, 1981).

Further evidence for the presence of multiple forms of Cytochrome P450 in liver microsomes has been deduced from kinetic studies with various substrates. Although the metabolism of many compounds appears to follow normal Michalis-Menten kinetics, with resulting linear double reciprocal plots, a number of substrates such as aniline (McCoy, 1980), aminopyrine (Kotake, 1981) 7-ethoxycoumarin (Greenlee 
and Poland, 1978; Boobis et al., 1981) and phenacetin (Boobis et al., 1981) have been shown to exhibit biphasic kinetic profiles indicative of multiple enzymes acting on the same substrate (Segel, 1975). Multiple forms have also been implicated (Shiverick and Neims, 1979) for the developmental changes observed in the hydroxylation of testosterone at the $6 B, 7 \alpha$ and $16 \alpha$ positions in rats (Conney et al., 1969).

The ability to solubilize and resolve microsomal enzyme components (Lu and Coon, 1968), has enabled a finer approach to studying the multiplicity of Cytochrome P450. A number of criteria have been utilized and include determination of molecular weights by SDS-PAGE, differences in spectral characteristics, differences in catalytic activities of purified forms, immunological properties, peptide mapping, and amino acid sequencing (Lu and West, 1980). By assimilating the research from numerous laboratories, the authors have indicated that thus far, depending on treatment, there are five to seven forms of $\mathrm{P} 450$ that have been isolated from rabbit, five to six forms from rat, four to six forms from mice, and at least two forms from pigs. An undetermined number may be present in human liver microsomes.

\section{Pentachlorophenol and Pentachloroanisol}

Pentachlorophenol (PCP) and the lower chlorinated phenols, tetraand tri- chlorophenol have been used as fungicides, herbicides, insecticides, and precursors in the synthesis of other pesticides since the early 1930s. The literature on PCP is abundant. A review of the toxicology and occurrence of PCP in the environment up to 1967 was 
published by Bevenue and Beckman (1967). More recently, Ahlborg and Thunberg (1980) compiled an extensive review of the literature from 1967 on, including some aspects not covered by the previous authors.

The acute toxicity of PCP has generally been attributed to the uncoupling effect of the compound on oxidative phosphorylation (Weinbach, 1954). The clinical symptoms associated with acute poisoning, including increased respiratory rate and volume, progressive neuromuscular weakness and increased body temperature are consistent with such a mechanism of action. Of greater concern, however, are the potential chronic effects of chlorinated phenols. The occurrence of PCP in water and the food chain (Ahlborg and Thunberg, 1980) coupled with the detection of this compound in the urine of a diverse population of non-occupationally exposed persons, suggests that PCP is quite ubiquitous in the environment.

Subacute and chronic toxicity studies (Knudsen et al-; Schwetz et al., 1977) have led to variable and inconsistent results, which have now been attributed to differences in the purity of the PCP preparations utilized (Ahlborg and Thunberg, 1980). Specifically, the presence of chlorinated dibenzodioxins and dibenzofurans in tecnical grades of PCP, and the documented wide spectrum of toxic manifestations of these agents (Kimbrough, 1972) precludes analysis of specific cause and effect relationships. Goldstein and coworkers (1977) demonstrated that technical grade PCP produced hepatic porphyria and dramatic increases in microsomal drug metabolizing activity in an eight month feeding study in female rats. The qualitative and quantitative 
nature of these effects were consistent with the effects of a number of chlorinated dioxins. In the same study, purified PCP was shown to be devoid of any hepatic effects with the exception of a moderate Increase in glucuronyl transferase activity at the highest dosage level. This study implied that many of the hepatic and extrahepatic effects reported in earlier studies were probably due to contaminants. Kimbrough and Linder (1975) reported that purified PCP, in addition to increasing liver size, produced an enlargement of hepatocytes, a slight increase in smooth endoplasmic reticulum and lipid vacuoles. The cause of these effects, however, is not known.

In contrast to studies on enzyme induction, a number of investigators have examined the potential for PCP and other chlorinated phenols to inhibit MFO activity. Arrhenius et al., (1977) showed that in vitro, PCP selectively inhibited the C-oxygenation of dimethylaniline (P450-dependent) thus favoring the N-oxygenation (P450Independent). The author concluded that these results were due to either a specific attack on the $\mathrm{P} 450$ enzyme or a disturbance in the transfer of electrons to P450. Carlson (1978) reported inhibition of EPN detoxification and nitroanisole demethylation in vitro by various trichlorophenol isomers. The observed inhibition appeared to be noncompetitive and was not demonstrated in microsomes obtained from treated animals. It thus appears that PCP and cogeners may be similar to various other phenols and alcohols in their interaction with Cytochrome P450 (cf Testa and Jenner, 1981). Furthermore, a competitive aspect for inhibition may be consistent with the finding that PCP is 
a substrate for Cytochrome P450 (P448) mediated dechlorination (Ahlborg, 1978).

Pentachloroanisol (PCA), the methyl ether of PCP, has been found in lake sediments and fish tissues (Kuehl et al., 1978), in shellfish (Miyazaki, 1981) and in the blood and milk of cows exposed to commercial grades of PCP (Firestone et al., 1979). The occurrence of PCA in the environment has been attributed solely to the degradation of PCP by microorganisms in soil and wood (Kaufman, 1978). Cserjesi and Johnson (1972) reported the capacity of three species of Trichoderma to methylate PCP in liquid cultures. Curtis et al. (1972) reported that feeding chickens maintained on shavings from wood treated with chlorophenols produced meat and eggs displaying a musty taint. The same group (Curtis et al., 1974) established that the methylating action of certain fungi present in poultry litter was responsible for the occurrence of chlorinated anisoles.

Despite these findings, pentachloroanisole has not received much attention in the toxicological literature. Glickman and coworkers (1977) studied the uptake, distribution and elimination of PCP and PCA in rainbow trout. Their results indicated that PCA is more readily bioaccumulated, more persistent, and that the presence of PCP-glucuronide in the bile of PCA treated fish indicated some demethylation of the compound in vivo. The same group (Vodicnik et al., 1980) undertook similar experiments in female mice. The results of this study, however, indicated that the pattern of distribution and 
elimination of PCA was similar to that for PCP in rodents. They concluded that PCA must be demethylated prior to excretion and that this step was probably rate limiting for clearance.

\section{Miniature Pigs}

The development of a strain of genetically small pigs was initiated at the Hormel Institute of the University of Minnisota in 1949 (England, 1954). Since then, other breeds of miniature pigs have been established in the United States and abroad.

The use of the pig in biomedical research received much attention in the 1960 s by virtue of its similarities to the human in renal, cardiovascular, and digestive tract anatomy and physiology, dental characteristics, eye structure, and skin morphology. In addition to these traits, the pig is capable of developing many human pathological conditions including atherosclerosis, gastric ulcer and obesity (Pond and Houpt, 1978). The young pig has found greatest utility in studies of nutrition. Since the digestive physiology and nutrient requirements of newborn pigs is remarkably similar to human infants, baby pigs have been used to develop and evaluate some human infant formulas (Book and Bustard, 1974). Although the pig has received increasing popularity as a laboratory model, housing and handling constraints continue to restrict its use to larger, well equipped facilities.

The use of the swine in drug toxicity studies was advocated by Earl et al. (1964). Investigators of drug metabolism pathways in miniature pigs, however, have been extremely limited. In an attempt to 
find a suitable "metabolic" replacement for the dwindling supply of rhesus monkeys, Litterst et al. (1976) conducted a comparative study using the miniature pig as one of five species. Based on an arbitrary scale, the authors concluded that the miniature pig was the most comparable species. Freudenthal et al. (1976) further characterized some parameters of the MFO system in miniature pigs ranging in age from two to eight months. They concluded that the two month old pig demonstrated adult levels of activity. Early postnatal development of the MFO system has been reported for the domestic, Duroc pig (Short and David, 1970; Short and Stith, 1973), however to date similar studies in the miniature pig have not been found in the literature. 


\section{EXPERIMENTAL}

\section{Materials}

Pentachlorophenol ( $99 \%$ ) was purchased from Aldrich Chemical Company (Milwaukee, WI). The stock material was subjected to further purification as described below. Pentachloroanisole was synthesized from the purified PCP as below. Sodium Phenobarbital was purchased from Mallinkrodt Chemical Works (St. Louis, MO).

NADP, NADPH, NADH, Glucose-6-Phosphate and Glucose-6-Phosphate Dehydrogenase were purchased from PL Biochemicals, Inc. (Milwaukee, WI). Aniline hydrochloride was purchased from Fisher Scientific (Silver Spring, MD). Sigma Chemical Company (St. Louis, MO) was the supplier of cytochrome $c$ (Type III) and p-nitrophenol standard solution. Eastman-Kodak (Rochester, NY) was the supplier of p-nitroanisole and p-aminophenol.

All other reagents utilized throughout the investigation were analytical grade or better.

\section{Preparation of PCP and PCA}

Pentachlorophenol (Aldrich 99\%) was further purified in an attempt to remove trace residual of non-phenolic contaminants. Twenty grams of PCP, Aldrich $99 \%$ were dissolved in $100 \mathrm{mls}$ methanol in a 1.0 liter 
separatory funnel. Fifty mls of $2.5 \mathrm{~N} \mathrm{NaOH}$ were added, followed by $200 \mathrm{mls}$ distilled water. The contents were extracted four separate times with $100 \mathrm{mls}$ petroleum ether, which was discarded after each extraction by aspiration. The aqueous layer was then acidified with $20 \mathrm{mls}$ concentrated $\mathrm{HCl}$. The resulting white precipitate was transferred to a Buchner funnel and vacuum filtered. The remaining material was washed copiously with distilled water and then transferred to a clean container and dried overnight in a vacuum oven. The procedure decolorized the starting material (yellow to white) and the final product gave a melting point of $187-190^{\circ}$, consistent with a purified standard. ${ }^{1}$ Further analysis for the presence of contaminating materials was kindly provided by Mr. Ron Thomas of the Office of Pesticide Programs, US EPA, Beltsville, MD. A summary of this analysis is provided in Appendix A.

Pentachloroanisole was synthesized by methylating PCP using diazomethane ( $P$. Sapienza and G. Ikeda, personal comm.). Ten grams of pur1fied PCP were dissolved in a small volume of methanol. A three-fold molar excess of diazomethane, prepared using a Diazald Kit (Aldrich Chemical Company, Milwaukee, WI) was added to the PCP-methanol solution. The solution was then evaporated unter nitrogen. The resulting material was then recrystallized with hot $95 \%$ ethanol. Activated charcoal was added to aid in decolorizing. The solution was filtered

\footnotetext{
${ }^{1}$ Purified standards of pentachlorophenol and pentachloroanisole were provided by the Division of Chemistry, Bureau of Foods, Food and Drug Administration.
} 
while hot to remove the charcoal and again after cooling. The resulting PCA was dried overnight in a vacuum oven. The newly synthesized PCA had a melting point of $106-107^{\circ}$ which agreed with a purified standard. Thin layer chromatographic analysis using Benzene:MeOH (95:5) showed a single spot ( $\operatorname{Rf} 0.91$ ) indentical to the PCA standard. No PCP ( $R f$ 0.47 was detected in the sample. Further analysis for contaminants was conducted as above.

\section{Animals}

The miniature pigs utilized in this study were a cross of Hanford and Hormel strains belonging to FDA's Beltsville Research Facility. Sows were bred at a swine breeding facility operated by Environmental Consultants, Inc., Suffolk, Virginia. Bred sows were transferred to the Beltsville Research Facility at approximately the beginning of their third trimester ( 70 days of gestation), where they were maintained until farrowing. From the 109 th day of gestation, sows were housed in individual pens containing sterilized corn cob bedding and equipped with an overhead heat lamp. Within 24 hours of birth, piglets were assigned a unique identification number and received $1 \mathrm{cc}$ iron dextran (Nomemic; Burns-Biotec, Omaha, NB). Piglets were maintained with the sow for $96 \pm 12$ hours after birth at which time they were removed to individual stainless-steel metabolism cages in a specially designed neonatal nursery. The temperature and humidity in the nursery were maintained at approximately $90^{\circ} \mathrm{F}$ and $40 \%$, respectively, during the first few weeks and thereafter the temperature was reduced at 
a rate of $2-5^{\circ} \mathrm{F}$ per week to a minimum of approximately $72^{\circ} \mathrm{F}$. A twelve hour light/dark cycle was maintained through the entire study.

Weaned piglets were fed a diet of whole cow's mild obtained from the USDA facility (Beltsville, MD). Milk diet was supplemented with $0.4 \%$ of a multivitamin mixture (Dawes STRESSEZ). During the first few weeks in the nursery, piglets received amounts of milk equal to approximately $20 \%$ of their body weight, divided into three equal portions at 8:00 A.M., Noon and 4:00 P.M. Milk was heated to room temperature prior to feeding. As animals increased in size and weight, diet was adjusted accordingly so that by eight weeks of age, piglets received approximately $30 \%$ of their body weight. Piglets that failed to thrive, as determined by weight gain and overall condition, were excluded from the study. Piglets were assigned to treatment groups based on a random division of littermates across the four experimental treatments. Each treatment group had equal numbers of male and female piglets.

\section{Animal Treatments}

Piglets were treated at 1 week, 4 weeks, or 8 weeks of age with either PCP (10 mg/kg in corn oil), PCA (10 $\mathrm{mg} / \mathrm{kg}$ in corn oil), Phenobarbital ( $10 \mathrm{mg} / \mathrm{kg}$ in water) or corn oil alone. Phenobarbital treated piglets received an equivalent volume of corn oil immediately after dosing. All dosages were adjusted such that $1 \mathrm{ml}$ of solution was administered per kilogram of body weight. Dosing was done by oral administration using a syringe fitted with a 19 ga stainless-steel stomach 
tube. Piglets were held securely with their mouths open and the tip of the stomach tube was placed to the rear of the oral cavity. After the contents of the syringe were ejected, the piglet was held until complete swallowing of the dose was evidenced.

Piglets were treated once a day at 8:00 A.M. for four consecutive days and sacrificed on the fifth day, approximately 24 hours after the final dose.

\section{Preparation of Microsomes}

Piglets were sacrificed by electrocution and then exsanguinated. Livers were removed and immediately placed into ice cold $0.02 \mathrm{M}$ Tris-HCL ( $\mathrm{pH} 7.4$ ) containing $1.15 \% \mathrm{KCl}$. After removing the gall bladders, the livers were blotted dry and weighed.

A portion of the liver, between five and seven grams, was thoroughly minced with scissors, and transferred to a glass PotterElvehjem homogenizing tube. Three volumes of $0.02 \mathrm{M}$ Tris-HCL were added and the contents homogenized with a teflon pestle attached to a variable speed motor. The homogenate was centrifuged for 15 minutes at $10,000 \mathrm{RPM}$ in a Sorvall $\mathrm{RC} 2-\mathrm{B}$ refrigerated centrifuge at $4^{\circ} \mathrm{C}$. The resulting supernatant was filtered through one layer of sterilized gauze to remove the floating fat layer and then centrifuged at $105,000 \times 8$ in a Beckman L2-65B ultracentrifuge. The supernatant was removed by aspiration and the microsomal pellet was resuspended in buffer and centrifuged again at $105,000 \times \mathrm{g}$ for 30 minutes. The 
"washed" microsomal pellet was then gently resuspended with sufficient $0.02 \mathrm{M}$ Tris-HCl buffer to give a final protein concentration of approximately 4-6 mg per $\mathrm{ml}$. Microsomal suspensions were kept on ice until utilized.

\section{Pentachloroanisole Demethylation}

The in vitro metabolism of pentachloroanisole was determined by measuring the formation of the demethylated by-product, formaldehyde, according to the method of Nash (1953). Assays were performed in $25 \mathrm{ml}$ erlenmeyer flasks and consisted of the following in $0.1 \mathrm{M}$ Tris-HC1 (pH 7.4): NADP $(0.8 \mathrm{mM})$; glucose-6-phosphate $(5.0 \mathrm{mM}), \mathrm{MgCl}_{2}(5.0 \mathrm{mM})$, glucose-6-phosphate dehydrogenase (1.9 Units) and semicarbazide $(1.0 \mathrm{mM})$.

Stock substrate was prepared by suspending PCA in $0.1 \mathrm{M}$ Tris-HCl which contained $2.5 \mathrm{mg} / \mathrm{ml}$ Tween 80 and the mixture was sonicated for 5 minutes. The resulting milky white suspension appeared evenly dispersed and was vortexed prior to each addition to incubation mixtures. Substrate blanks were run for each individual sample and received an equal volume of the Tween 80 solution without PCA. Final PCA concentration in the assay was $0.5 \mathrm{mM}$.

Flasks containing cofactors and substrate (or blank) were preincubated for 10 minutes at $37^{\circ} \mathrm{C}$ to allow temperature equilibration. The reaction was initiated by the addition of microsomes (approximately 2-3 $\mathrm{mg}$ protein) and the mixtures (in a total volume of $2.5 \mathrm{ml}$ ) 
were incubated aerobically, with vigorous shaking in a Dubenoff Metabolic shaking incubator for 10 minutes. The reaction was terminated with $0.5 \mathrm{mls}$ of $50 \%$ TCA and the protein precipitated by centrifugation. A $1.0 \mathrm{ml}$ aliquot of the clear supernatant was transferred to a clean test tube and $0.5 \mathrm{mls}$ of Nash reagent $(3.9 \mathrm{M}$ Ammonium acetate; $0.039 \mathrm{M}$ acetylacetone) was added. The resulting colored product was measured in an Abbott Bichromatic Analyzer (ABA-100) using a peak wavelength of $415 \mathrm{~nm}$ and sideband wavelength of $450 \mathrm{~nm}$. An internal calibration factor, previously determined from formaldehyde standards, was utilized and results were obtained directly as nMoles HCHO/ml. Activity was calculated by subtracting substrate blank values from their corresponding sample value, which was then converted to nMoles $\mathrm{HCHO} / \mathrm{min} / \mathrm{mg}$ protein.

\section{Determination of PCP Formation}

Proof of the formation of pentachlorophenol (PCP) as a result of the demethylation of PCA was established qualitatively as follows: The PCA demethylation assay (above) was modified slightly such that the final volume was $1.0 \mathrm{ml}$. Assays were conducted in screw cap culture tubes and contained $0.2 \mathrm{mM}$ PCA and microsomes from phenobarbital treated piglets. The reaction was terminated after 20 minutes by the addition of $1.0 \mathrm{ml} 6 \mathrm{~N} \mathrm{HCl}$, followed by $5.0 \mathrm{mls}$ hexane. Tubes were vortexed for 1 minute and then centrifuged to separate the aqueous and organic layers. The hexane phase was removed to a clean glass vial and the extraction was repeated. The combined hexane extracts 
were evaporated to dryness under a stream of nitrogen at room temperature. Analysis for PCP (and PCA) was performed using a Waters Associates Liquid Chromatograph. The HPLC parameters were as follows: Solvent - McOH:H $\mathrm{H}_{2} \mathrm{O}$ Acetic Acid (80:19:1), Flow Rate - $1.3 \mathrm{ml} / \mathrm{min}$, Column - C-18 (reverse phase), UV Detector - $254 \mathrm{~nm}$ (P. Sapienza, personal communication). The residue was taken up in $0.1 \mathrm{mls}$ of solvent and $20 \mathrm{ul}$ were injected into the chromatograph. A standard containing both PCA and PCP was run immediately prior to the sample.

\section{Aniline Hydroxylation}

The para-hydroxylation of aniline was determined by measuring the formation of the product, p-aminophenol, according to the method of Imai et al. (1965). Incubation conditions were identical to those for PCA demethylation except semicarbazide was omitted. Aniline-HCl, dissolved in $0.1 \mathrm{M}$ Tris- $\mathrm{HCl}$, was added to give a final concentration of $5.0 \mathrm{mM}$. Blanks received buffer alone. Reactions were terminated after 10 minutes by the addition of $1.5 \mathrm{mls} 50 \%$ TCA and the protein precipitated by centrifugation. To a $1.0 \mathrm{ml}$ aliquot of the clear supernatant, $0.5 \mathrm{mls}$ of $10 \% \mathrm{Na}_{2} \mathrm{CO}_{3}$ was added to neutralize the acid. One $\mathrm{ml}$ of $2 \%$ phenol in $0.2 \mathrm{~N} \mathrm{NaOH}$ was then added to each tube and the color allowed to develop at $37^{\circ} \mathrm{C}$ for 40 minutes. The resulting colored product was read in an Abbott Bichromatic Analyzer using a $650 \mathrm{~nm}$ primary and $550 \mathrm{~nm}$ sideband wavelength filter. An internal calibration factor, previously determined from p-aminophenol standards was utilized and 
results were obtained directly as nMoles pAP/ml. Activity was converted to nMoles $\mathrm{pAP} / \mathrm{min} / \mathrm{mg}$ protein.

\section{p-Nitroanisole Demethylation}

The activity of p-Nitroanisole demethylase was determined by a modification of the procedure described by Netter and Seidel (1964) in which the production of p-nitrophenol is followed directly in the incubation mixture at $420 \mathrm{~nm}$ at $\mathrm{pH} 7.8$.

The modified assay was performed in an Abbott Bichromatic Analyzer as follows: The reagent vial contained $\mathrm{MgCl}_{2}$, glucose-6phosphate and glucose-6-phosphate dehydrogenase in $50 \mathrm{mM}$ Tris-HCl (pH 7.6). Sample cups contained microsomal suspension, and multicuvette compartments contained either buffer or NADP (20 ul). The contents of the reagent vial and the multicuvette were maintained at $37^{\circ} \mathrm{C}$. Reactions were initiated by an automated sampling system. At timed intervals, $10 \mathrm{ul}$ aliquots of sample (microsomes) were drawn and dispensed together with $250 \mathrm{ul}$ cofactor $\mathrm{mix}$ (reagent) into individual compartments of a multicuvette. The final concentrations in a total volume of $0.28 \mathrm{mls}$ were: NADP $(0.62 \mathrm{mM})$, glucose-6-phosphate $(5.0 \mathrm{mM})$, glfose-6-phosphate dehydrogenase (0.9 Units), $\mathrm{MgCl}_{2}(5.0 \mathrm{mM})$ and p-nitroanisole $(1.2 \mathrm{mM})$. The total amount of microsomal protein in each assay was approximately 40-60 ug.

Each individual sample was run in the presence and absence of NADP and the absorbance differences recorded at 5 minute intervals at 
$415 \mathrm{~nm}$ and $450 \mathrm{~nm}$. Activity was determined by subtracting the NADP blank value from its corresponding sample value and comparing that value to a p-nitrophenol standard curve generated along with the assay. Activity was converted to nMoles pNP/min/mg protein.

\section{Cytochromes $\mathrm{P} 450$ and $\mathrm{B}_{5}$}

The content of Cytochrome $\mathrm{P} 450$ in microsomes was determined according to the method of Omura and Sato (1964). Microsomes were diluted in $0.1 \mathrm{M}$ Potassium Phosphate Buffer ( $\mathrm{pH} 7.5$ ) to a protein concentration of about $1-2 \mathrm{mg} / \mathrm{ml}$. A few milligrams of solid sodium dithionite were added, the contents mixed and $3 \mathrm{mls}$ of the microsomal suspension were pipetted into each of two cuvettes. The cuvettes were placed into a Beckman Acta CII Split-beam Spectrophotometer and a baseline of equal light absorbance was recorded by scanning from 500 to $400 \mathrm{~nm}$. The contents of the sample cuvette were then gently bubbled with carbon monoxide for 40 seconds and returned to the spectrophotometer. The difference spectra was recorded after 3 minutes (500$400 \mathrm{~nm}$ ) and again after 5 minutes. The amount of Cytochrome P450 was calculated by using a millimolar extinction coefficient of $91 \mathrm{mM}^{-1}$ $\mathrm{cm}^{-1}$ for the absorbance difference at $450-490 \mathrm{~nm}$.

The content of Cytochrome $b_{5}$ was determined by the method outlined by Estabrook and Werringloer (1978). Fresh microsomes, at the same concentration used for $\mathrm{P} 450$ determinations, were placed into each of two cuvettes. After establishing a baseline, $10 \mathrm{ul}$ of a $15 \mathrm{mM}$ 
solution of $\mathrm{NADH}$ were added to the sample cuvette and the contents mixed wel1. The reference cuvette received 10 ul of buffer. Cytochrome $\mathrm{b}_{5}$ was calculated from the absorbance difference between $426 \mathrm{~nm}$ and $409 \mathrm{~nm}$ using the millimolar extinction coefficient of $185 \mathrm{mM}^{-1} \mathrm{~cm}^{-1}$.

\section{NADPH - Cytochrome c - Reductase}

The rate of reduction of cytochrome $c$ was measured, as outlined by Mazel (1969) by following the increase in absorbance at $550 \mathrm{~nm}$ due to the appearance of reduced cytochrome c. Cuvettes contained in a final volume of three mls; 0.15 umoles cytochrome $c, 3.0$ umoles $\mathrm{KCN}$, and approximately $0.2-0.4 \mathrm{mg}$ microsomal protein in $0.1 \mathrm{M}$ Potassium Phosphate buffer $(\mathrm{pH} 7.6)$. The reaction was initiated by the addition of 0.45 umoles NADPH to the sample cuvette and was followed for approximately 1 minute at room temperature in a Beckman Acta CII Spectrophotometer. Activity was calculated from the change in absorptance for $1 \mathrm{~min}$ using the extinction coefficient of $18.5 \mathrm{mM}^{-1} \mathrm{~cm}^{-1}$ of reduced cytochrome c at $550 \mathrm{~nm}$ (Gigon et al., 1968).

\section{Substrate Binding Spectra}

Microsomes, in $0.1 \mathrm{M}$ potassium phosphate buffer, were pipetted Into each of two cuvettes and placed into a Beckman Acta C11 Spectrophotometer. PCA, dissolved in methanol $(20 \mathrm{mg} / \mathrm{ml})$ was added to the sample cuvette in 1 ul increments. Equal volumes of methanol were added to the reference cuvette. After each addition, the difference 
spectra was recorded by scanning from $460 \mathrm{~nm}$ to $360 \mathrm{~nm}$. The spectral dissociation constant $\left(K_{s}\right)$ and maximum absorbance change were determined from double-reciprical plots of $1 / \mathrm{S}$ versus $1 / \mathrm{ABS}$ (386-420 nm).

\section{Determination of Kinetic Parameters}

Kinetic profiles for aniline hydroxylation and PCA demethylation were determined in control and phenobarbital treated pigs at $1,4,8$, and 16 weeks of age. Piglets were treated with phenobarbital (10 mg/kg) for four days by gavage. Controls received equal volumes of saline. Within each age and treatment group, microsomes were derived from a pool of three livers, with the exception of the 16 week old groups where microsomes were obtained from a pool of two pigs.

Assays for PCA demethylation and aniline hydroxylation were conducted as previously described, modified to be conducted in $16 \mathrm{x}$ $125 \mathrm{~nm}$ disposable test tubes in a final volume of $1.0 \mathrm{ml}$. Substrate concentrations ranged from 0.01 to $4.0 \mathrm{mM}$ for $\mathrm{PGA}$ and 0.005 to $5.0 \mathrm{mM}$ for aniline. Generally, 9-11 different concentrations were run in duplicate in addition to pooled blanks. Assays were run for either 10 minutes (control) or 5 minutes (phenobarbital) and contained approximately $1 \mathrm{mg}$ microsomal protein from either source. Further, at all ages, one high and one low substrate concentration were run concurrently to establish linearity with time. In all cases where substrate consumption exceeded $5 \%$, average velocities were utilized (Segel, 1975). Reactions were terminated by the addition of 200 ul of $50 \%$ TCA 
and determination of formaldehyde (PCA demethylation) and p-aminophenol (Aniline hydroxylation) was conducted as before.

Kinetic parameters were determined using Eadie-Hofstee plots (V vs. V/S). After graphing the data, linear regression analysis was conducted using those points corresponding to low substrate concentration. The slope and intercept of the line represent the apparent $\mathrm{K}_{\mathrm{m}}$ and $V_{\text {max }}$, respectively, for the high affinity component. The velocities due to the low affinity component were obtained by subtracting the $V_{\max }$ for the high-affinity component from the total velocity at high substrate concentrations. Linear regression analysis for the new values $\left(V_{2}\right.$ vs. $\left.V_{2} / S\right)$ gave the apparent $K_{m 2}$ and $V_{\max 2}$ for the low affinity component.

\section{$\underline{\text { Protein Determination }}$}

Protein content was determined by the method of Lowry et al. (1951) using bovine serum albumin as the protein standard. The intensity of the characteristic blue color was read using an Abbott BIchromatic Analyzer with a primary wavelength of $650 \mathrm{~nm}$.

\section{Electron Microscopy}

The effects of PCA, PCP, and phenobarbital on hepatic ultrastructure were determined by electron microscopy in 1 week old piglets. At the time of sacrifice, thin (approximately $4 \mathrm{~mm}$ ) sections of liver were obtained from one animal in each treatment group. The liver 
sections were blotted and placed into a formaldehyde-glutaraldehyde fixative (Karnovsky, 1965). Samples were immediately transferred to Dr. Werner Seibel of the Department of Anatomy, University of Maryland Dental School, Baltimore, MD. All further steps in the processing of tissue and electron microscopy were kindly done by Dr. Seibel. The methods utilized appear in Appendix B.

\section{Statistical Methods}

The statistical analyses for this study were performed using the Statistical Analysis System (SAS), of the SAS Institute, Inc. Cary, NC. The following analyses were performed: Levine's Test for Homogeneity of Variance, Analysis of Variance (one-way classification; balanced and unbalanced design), Duncan's Multiple Range test, Least Square Means, Wilcoxin Rank-Sums Analysis, Non-parametric Student's Newman-Keuls test, Students $t$ test (balanced and unbalanced design Control vs. Phenobarbital).

The scheme depicted below was followed:

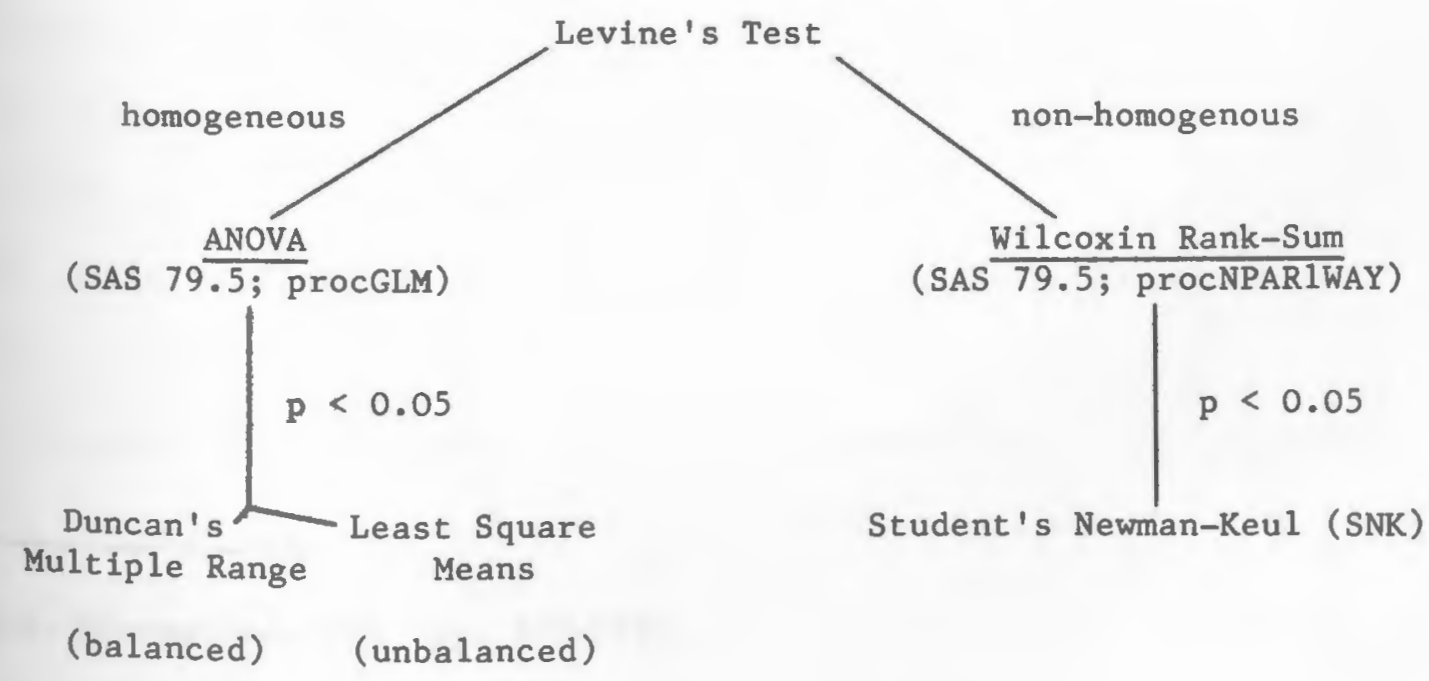


Additional statistical methods

Simple Linear Regression

Outlier Analysis ${ }^{1}$

$$
y=a+b x \text { (regression equation) }
$$$$
r^{2}=\frac{(\Sigma x y)^{2}}{\Sigma x^{2} \Sigma y^{2}} \quad \begin{aligned}
& \text { (regression } \\
& \text { coefficient })
\end{aligned}
$$

$$
G_{1}=\frac{\left(y_{2}-y_{1}\right)}{\left(y_{N}-y_{1}\right)}
$$

${ }^{1}$ U.S. Pharmacopea XVI (pp. 873-874). 
RESULTS

In Vitro Metabolism of Pentachloroanisole

Since pentachlorophenol has been detected in biological fluids of fish (Glickman et a1., 1977) and of mice (Vodicnik et al., 1980) treated with pentachloroanisole, PCA was investigated as a substrate for the microsomal mixed-function monooxygenase system. The demethylation reaction, one of the many diverse pathways involved in xenobiotic metabolism, is easily measured since the by-product, formaldehyde, can be conveniently quantitated colorimetrically. In the case of PCA, the quantity of formaldehyde formed should represent the stoichiometric conversion of the substrate to PCP.

In order to establish monooxygenase involvement, cofactor requirements were determined as well as the effects of various MFO inhibitors. The results of these experiments are shown in Table 1 . In the absence of NADPH, microsomes were totally incapable of demethylating PCA. Furthermore, the presence of carbon monoxide in the reaction mixture resulted in strong inhibition (95\%) of activity. NADH as the sole electron donor was capable of supporting a low level of activity and produced a synergistic effect when added to the complete system. At equimolar concentrations, metyrapone produced the strongest inhibition ( $91 \%$ ) while SKF 525A and 7,8-Benzoflavone (ANF) inhibited the reaction $70 \%$ and $20 \%$, respectively. 
TABLE 1. Characterization of PCA demethylation by miniature pig hepatic microsomal enzymes. ${ }^{a}$

Reaction Mixture

$\%$ Total Activity

Complete $e^{b}$

$100 \%$

- NADPH

0

- NADPH + NADH $(0.5 \mathrm{mM}) \quad 8.2$

$\begin{array}{ll}\text { Complete + NADH } & 105\end{array}$

Complete + Carbon Monoxide 4.6

SKF $525 \mathrm{~A}^{\mathrm{C}}$

+ Metyrapone $\quad 9$

$+7,8$-Benzof lavone (ANF) 80

activity was measured as the rate of formaldehyde production in microsomes from phenobarbital induced minipigs as detailed in Materials and Methods.

${ }^{b}$ Activity in the complete system was 5.45 nmoles/min/mg protein. ${ }^{c}$ The final concentration of all inhibitors was $5 \times 10^{-5} \mathrm{M}$. 
In order to verify that the formaldehyde produced in the assay was a result of the oxidative demethylation of PCA to PCP, some incubation mixtures were subjected to organic extraction and the residues were analyzed by HPLC. Using the HPLC parameters described in the Methods section, PCA had a retention time of 5.2 minutes and PCP had a retention time of 3.8 minutes. A typical chromatogram of a mixed PCA/PCP standard is shown in Figure $1(a)$, while the results from an incubation extract are shown in Figure 1(b). An additional peak at 2.3 minutes was not identified, however, it may represent additional metabolism of PCP.

Preliminary kinetic analysis of PCA demethylation was conducted using microsomes from uninduced and phenobarbital treated, mature minipigs. Kinetic parameters were determined from Lineweaver-Burke plots shown in Figure $2(\mathrm{a} \& \mathrm{~b})$. The apparent $\mathrm{K}_{\mathrm{m}}$ for both uninduced and phenobarbital induced microsomes, 0.052 and $0.047 \mathrm{mM}$, respectively, are relatively similar. The maximum velocities, however, differ by a factor of 10. The $V_{\max }$ for phenobarbital induced microsomes is 4.9 nmoles $/ \mathrm{min} / \mathrm{mg}$ protein compared to $0.45 \mathrm{nmoles} / \mathrm{min} / \mathrm{mg}$ protein in controls.

In conjunction with catalysis of PCA, the interaction of the substrate with cytochrome $\mathrm{P} 450$ was investigated using difference spectroscopy. Pentachloroanisole when added to microsomal suspensions produced a typical Type I binding spectrum with a peak absorbance at $385 \mathrm{~nm}$ and a trough at $419 \mathrm{~nm}$ (Figure 3). Of particular interest, however, is the inability of the compound to produce discernable spectral changes when added to uninduced microsomal preparations. 
FIGURE 1. High-Pressure Liquid Chromatograms for the Analysis of PCP and PCA.
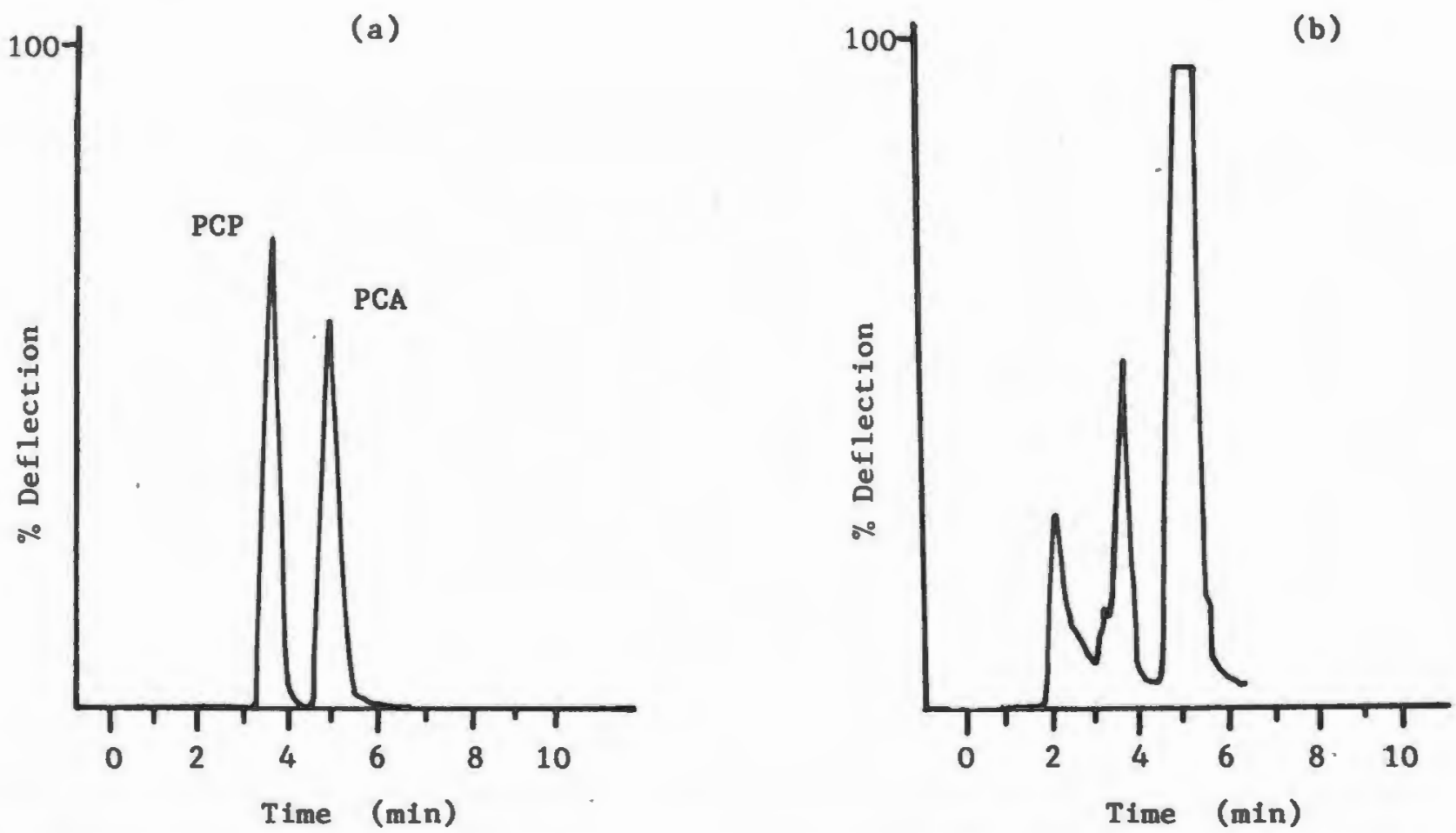

a) HPLC parameters and incubation extraction procedures are described in Materials \& Methods.

b) Retention times are 3.8 minutes (PCP) and 5.2 minutes (PCA).

c) Typical chromatograms depicted are for (a) standard solution and (b) incubation extracts. 
FIGURE 2. Lineweaver-Burke Plots of PCA Demethylation in Hepatic Microsomes from Phenobarbital (a) and Uninduced (b) Minipigs.

a) Incubation mixtures for PCA demethylase were identical to that described in Materials and Methods with the exception that PCA was solubilized in acetone prior to addition to the Tween 80 mixture. Final PCA concentrations ranged from 0.05 to $1.0 \mathrm{mM}$.

b) Microsomes were obtained from a pool of three livers from mature (16-17 weeks old) miniature pigs. Phenobarbital was administered at $10 \mathrm{mg} / \mathrm{kg} \mathrm{P.O.} \mathrm{for} \mathrm{four} \mathrm{consecutive} \mathrm{days.}$ 

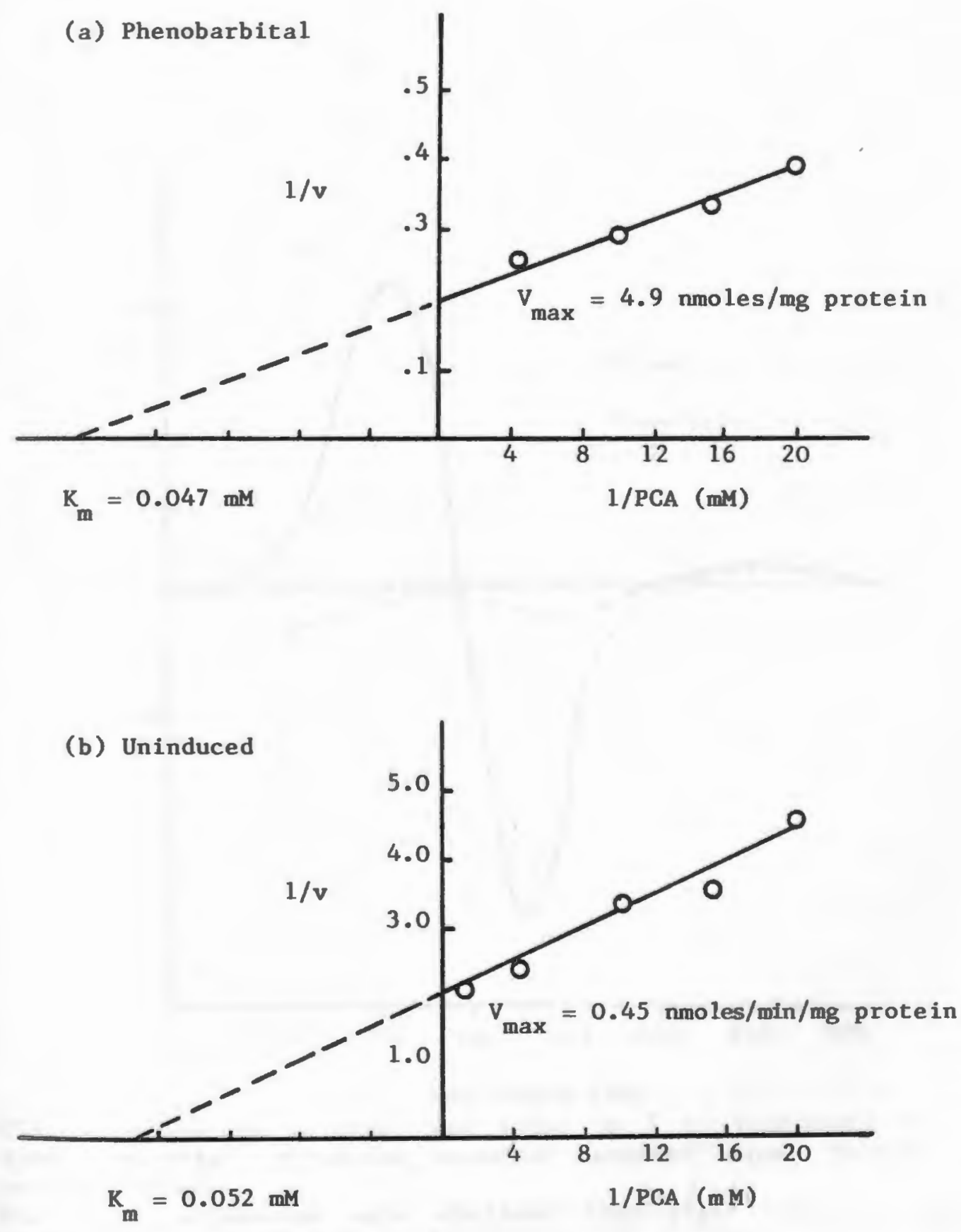
FIGURE 3. Typical Substrate Binding Spectra Observed Following Addition of PCA to Miniature Pig Microsomal Suspensions.

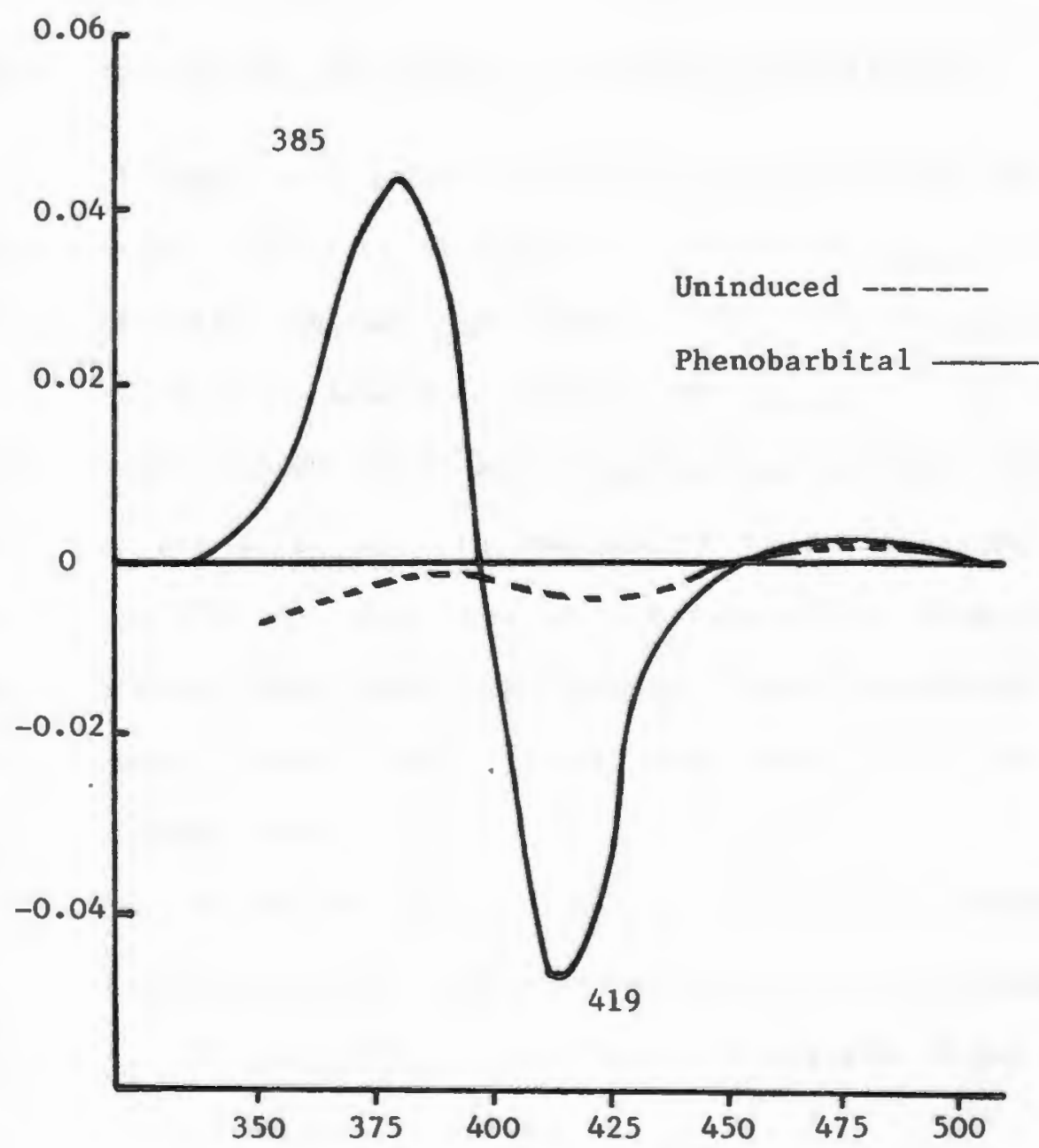

Wavelength ( $\mathrm{nm}$ )

a) PCA, dissolved in methanol was added in 1 ul increments to the sample cuvette. Reference cuvette received equal volumes of methanol alone.

b) Microsomal suspension were obtained from eight week old pigs. Phenobarbital was administered as previously described.

c) The observed spectra is characteristic of "Type I" binding with $\lambda \max$ at $385 \mathrm{~nm}$ and $\lambda$ min at $419 \mathrm{~nm}$. 
Using phenobarbital induced microsomes, PCA was readily titrated to apparent saturation. Double reciprocal plots of $1 /\{\mathrm{PCA}\}$ vs. $1 / \triangle \mathrm{Abs}$. (peak to trough) yielded values of $0.014 \mathrm{mM}$ for the spectral dissociation constant $\left(K_{s}\right)$ and a maximum peak to trough absorbance change $\left(A_{\max }\right)$ of 0.035 per milligram of protein (Figure 4 ).

\section{Development of the MFO System in Growing Miniature Pigs}

In order to assess the pattern of postnatal development of the hepatic MFO system, a variety of parameters were measured in 1,4 , and 8 week old minipigs. Two reaction pathways, the aromatic hydroxylation of aniline and the O-demethylation of p-Nitroanisole were investigated since these pathways have well characterized in other laboratory species and are often used in assessments of MFO function. The 0-demethylation of PCA was also used as a parameter for comparison. In all cases, optimal assay conditions were previously determined and the reactions were within linear ranges with respect to time and protein concentrations used.

The specific activities as a function of age are shown in Table 2. In all cases maximal levels are attained by four weeks of age. Furthermore, the activities in one week old piglets ranged from 65 to $80 \%$ of the eight week old activity.

The concentrations of cytochromes $\mathrm{P} 450$ and $\mathrm{b}_{5}$ and the activity of NADPH cytochrome-c Reductase were also determined in developing minipigs. The concentration of microsomal cytochrome P450 increased in linear manner from 0.57 nmoles/mg protein in one week old piglets 
FIGURE 4. Double-Reciprocal Plot for the Determination of the Spectral Dissociation Constant $\left(K_{s}\right)$ for PCA in Phenobarbital Induced Microsomal Suspensions.

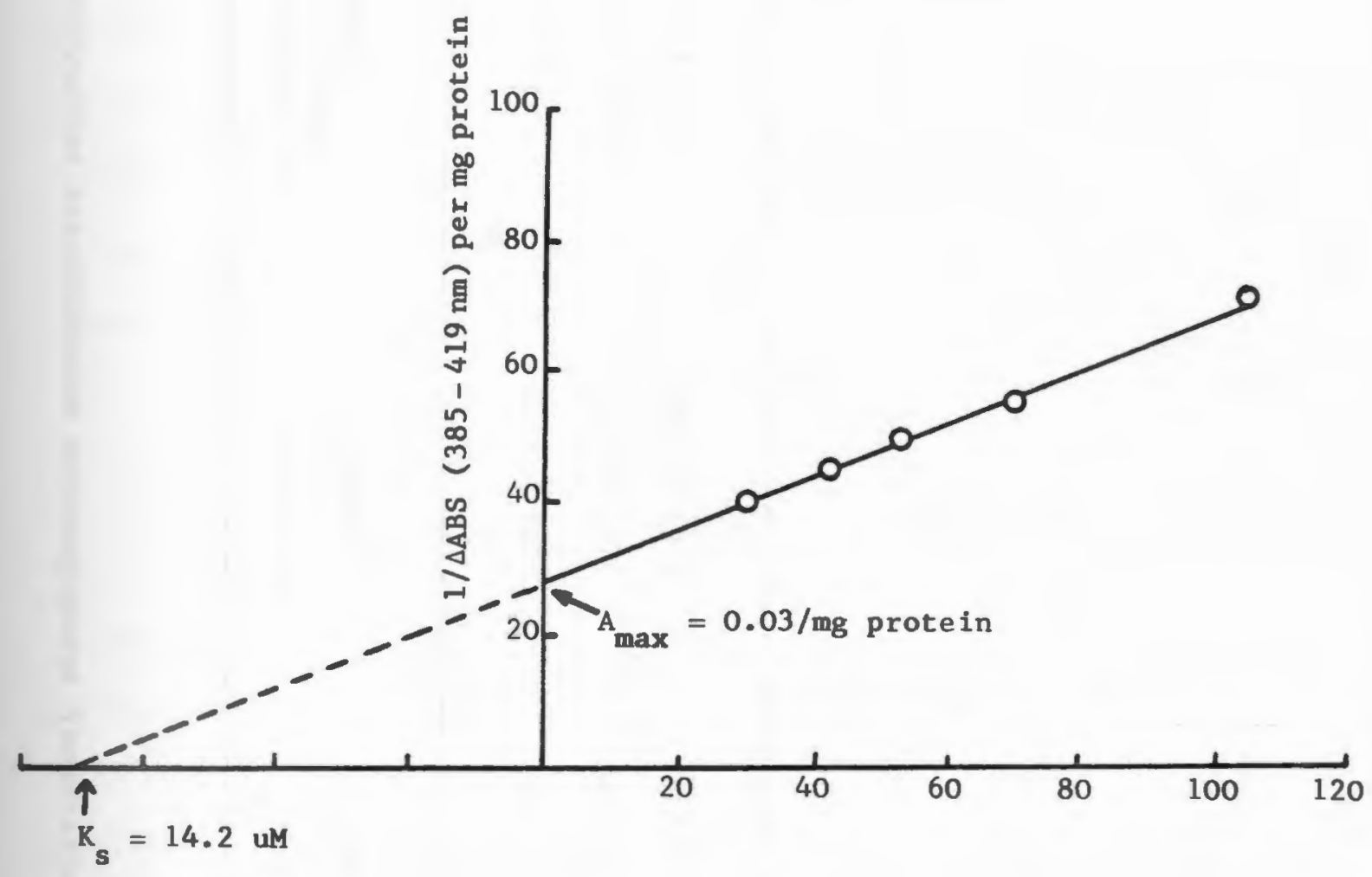

a) Each point represents the reciprocal of the peak-to-trough absorbance difference (as shown in Figure 3) as a function of PCA concentration.

b) Values of $K_{S}$ and $A_{\max }$ are for eight week old, phenobarbital induced minipigs. 
TABLE 2 Postnatal development of three microsomal mixed-function monooxygenase activities in miniature pigs.

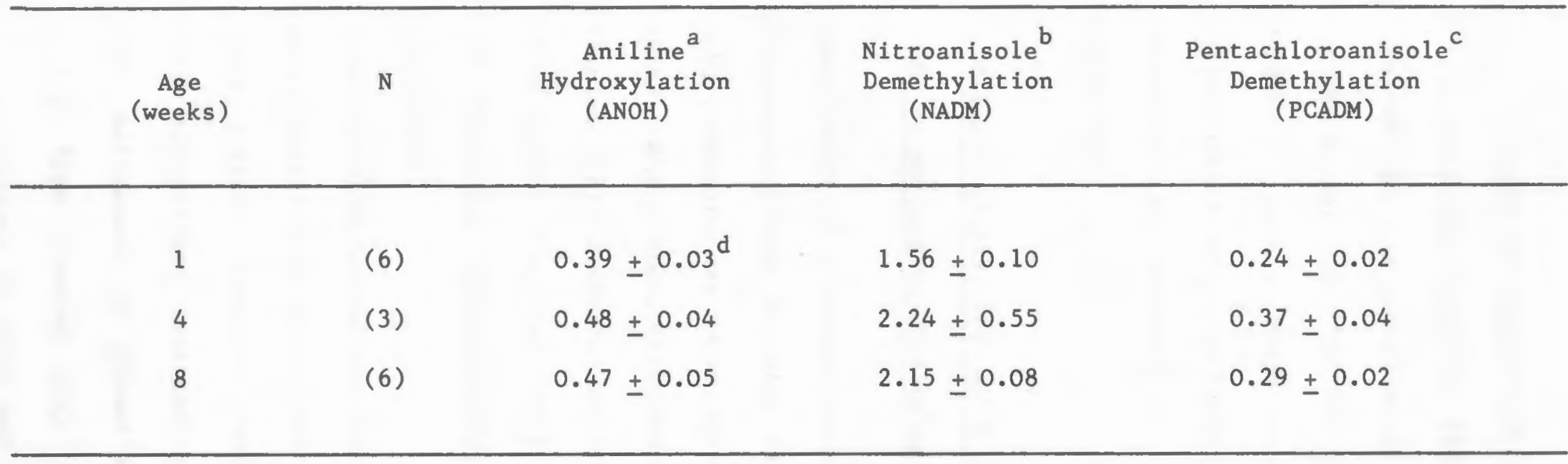

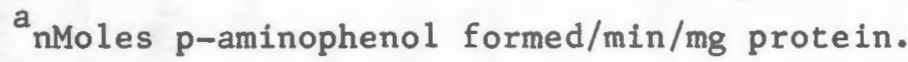

b nMoles p-nitrophenol formed/min/mg protein. nMoles formaldehyde formed $/ \mathrm{min} / \mathrm{mg}$ protein. Values are mean \pm S.E.M. 
to 1.00 nmoles/mg protein in eight week old piglets (Table 3). Cytochrome $\mathrm{b}_{5}$ concentration was equal to $\mathrm{P} 450$ concentration in one week old piglets, however the concentration of cytochrome $b_{5}$ reached maximum by four weeks of age and remained constant to eight weeks. The activity of NADPH cytochrome-c Reductase appears to follow a similar pattern as the activities shown in Table 2. There is an increase from one to four weeks of age, followed by a slight decrease in activity at eights weeks of age.

Effects of PCA, PCP and Phenobarbital on

MFO Parameters in Developing Miniature Pigs

Since a vast number of compounds metabolized by the hepatic mixedfunction monooxygenase system are also capable of inducing the enzyme system, pentachloroanisole was investigated for its induction potential. Furthermore, since pentachlorophenol is the product of microsomal demethylation, this compound was also investigated in order to determine if the parent compound (PCA) or the metabolite (PCP) was responsible for induction. Phenobarbital was utilized in this study as a positive control.

At the dose of $10 \mathrm{mg} / \mathrm{kg} /$ day for four days, PCA and PCP produced no overt signs of toxicity in any of the age groups. Similarly, phenobarbital treated piglets remained alert and active. All piglets, during treatment situations, consumed their normal ration of milk diet and either maintained or gained weight. At the time of the sacrifice, livers from treated pigs were inspected grossly and appeared normal with respect to color and texture. 


\begin{tabular}{lllll}
\hline 1 & $(6)$ & $0.57 \pm 0.04^{\mathrm{d}}$ & $0.56 \pm 0.04$ & $110.3 \pm 5.1$ \\
4 & $(3)$ & $0.81 \pm 0.05$ & $0.76 \pm 0.003$ & $165.5 \pm 1.8$ \\
8 & $(6)$ & $1.00 \pm 0.04$ & $0.74 \pm 0.01$ & $151.6 \pm 6.8$ \\
\hline
\end{tabular}

$a_{\text {nMoles }} \mathrm{P} 450 / \mathrm{mg}$ protein.

$\mathrm{b}_{\text {nMoles }} \mathrm{b}_{5} / \mathrm{mg}$ protein.

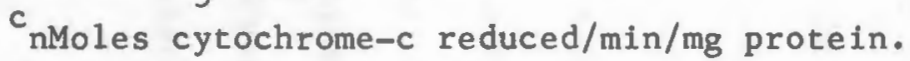

¿alues are mean \pm S.E.M. 


\section{One Week old Piglets}

The effects of PCA, PCP and phenobarbital on MFO activity in one week old piglets varied with respect to the parameter measured and the degree of induction. A comparison of the specific activities for aniline hydroxylase (ANOH), nitroanisole demethylase (NADM) and PCA demethylase (PCADM) is shown in Table 4. PCA produced a small, yet significant $41 \%$ increase in $\mathrm{ANOH}$ activity and a somewhat larger (67\%) increase in NADM activity. Of particular interest, however, is the disproportionate three-fold increase in the activity of the enzyme catalyzing PCA's own metabolism. In contrast to PCA's effects, microsomes from PCP treated piglets showed no change in PCADM and ANOH activities. PCP treatment did have a minor effect on NADM ( $50 \%$ over controls). The effects of phenobarbital on the three enzyme activities were consistent with its strong comprehensive inductive effects. ANOH and NADM activities were increased 5.5- and 9-fold, respectively, over controls. A dramatic 14-fold increase in PCADM was observed.

The observed increases in the different enzyme activities are paralleled by an increase in the concentration of cytochrome $\mathrm{P} 450$ in microsomes from treated pigs. Phenobarbital produced a three-fold increase in P450 (Table 5), while PCA and PCP produced much smaller, but significant increases in the concentration of the hemoprotein. The wavelength of maximum absorbance in all microsomal preparations was $450 \mathrm{~nm}$. The microsomal concentration of cytochrome $b_{5}$ and the activity of NADPH-cytochrome-c Reductase are also shown in Table 5. 
Table 4. Effects of PCA, PCP, and phenobarbital on microsomal enzyme activities in one week old miniature pigs.

$\begin{array}{ccc}\text { Aniline } & \text { Nitroanisole } & \text { Pentachloroanisole }^{\mathrm{e}} \\ \text { Hydroxylase } & \text { Demethylase } & \text { Demethylase }\end{array}$

$\begin{array}{llll}\text { Control (6) } & 0.39 \pm 0.03 & 1.56 \pm 0.10 & 0.24 \pm 0.02 \\ \text { PCA (6) } & 0.55 \pm 0.03 * & 2.60 \pm 0.24 * & 0.72 \pm 0.09 * \\ \text { PCP (5) } & 0.44 \pm 0.04 & 2.35 \pm 0.21 * & 0.27 \pm 0.03 \\ \text { Phenobarbital (6) } & 2.15 \pm 0.23 * * & 13.96 \pm 1.99 * * & 3.37 \pm 0.28 * \star\end{array}$

a PCA, PCP, and phenobarbital were administered at $10 \mathrm{mg} / \mathrm{kg} / \mathrm{day}$ P.O. for four consecutive days.

${ }^{b}$ Miniature pigs were seven days of age at the onset of treatment.

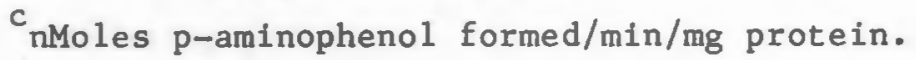

$\mathrm{d}_{\text {nMoles }}$-nitrophenol formed/min/mg protein.

enMoles formaldehyde formed $/ \mathrm{min} / \mathrm{mg}$ protein.

Numbers in parentheses are the number of values used to calculate the mean \pm S.E.M.

* Significantly different from control ( $p<0.05$ ) Duncan's Multiple Range Analysis.

**Significantly different from control ( $p<0.05$ ) Student's t test. 
TABLE 5. Effects of PCA, PCP, and phenobarbital on cytochromes $P 450, b_{5}$, and cytochrome-c Reductase in one week old miniature pigs.

Treatment

$$
\text { Cytochrome }
$$

Cytochrome ${ }^{c}$

$\mathrm{b}_{5}$

\section{Cytochrome-c ${ }^{d}$}

Reductase

$\begin{array}{lllll}\text { Control (6) } & 0.57 \pm 0.01(450 \mathrm{~nm})^{e} & 0.56 \pm 0.04 & 110.3 \pm 5.1 \\ \text { PCA (6) } & 0.76 \pm 0.04 *(450 \mathrm{~nm}) & 0.75 \pm 0.05 * & 144.2 \pm 12.1 * \\ \text { PCP (6) } & 0.85 \pm 0.06 *(450 \mathrm{~nm}) & 0.70 \pm 0.03 & 120.6 \pm 4.5 \\ \text { Phenobarbital (6) } & 1.67 \pm 0.12 *(450 \mathrm{~nm}) & 0.77 \pm 0.03 * * & 145.2 \pm 11.7 \star *\end{array}$

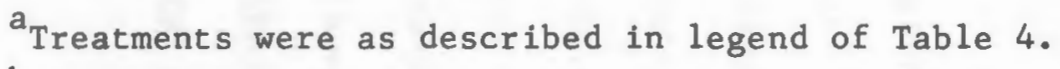

$\mathrm{b}_{\text {nMoles/mg protein. }}$

$c_{\text {nMoles/mg protein. }}$

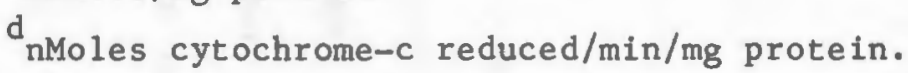

ebserved wavelength of maximum absorbance in the reduced-co difference spectra.

All values are the mean \pm S.E.M. for the number of observations in parentheses.

* Significantly different from control ( $<$ < 0.05) Duncan's Multiple Range Analysis.

**Significantly different from control ( $p<0.05$ ) Student's $t$ test. 
Phenobarbital produced similar increases in $b_{5}$ and the reductase ( $37 \%$ and $32 \%$, respectively) over controls. It is interesting to note that PCA produced almost identical increases in both parameters and these correlated with the increase in $\mathrm{P} 450$ concentration in that treatment group.

\section{Treatment Effects on Hepatocellular Morphology}

Since induction of cytochrome $\mathrm{P} 450$ and related metabolic activities by phenobarbital has been associated with hepatocellular changes in smooth endoplasmic reticulum content, electron microscopy was used in an attempt to correlate biochemical and morphological effects. Furthermore, qualitative similarities in the induction profiles of phenobarbital and PCA suggested that the latter compound may be a "phenobarbital type" of inducer.

Figure 5 shows a low power electron micrograph of a liver parenchymal cell from a one week old control piglet. The liver cells are characterized by a round nucleus, rough endoplasmic reticulum and an abundance of glycogen. A high power micrograph (Figure 6) better illustrates that the endoplasmic reticulum in these cells is primarily RER although vesicles of smooth ER occur intermittantly (insert).

In contrast, phenobarbital results in a marked proliferation of smooth endoplasmic reticulum (Figure 7). Although RER is present, vesicles of agranular endoplasmic reticulum (SER) appear to predominate in the cytoplasm. Similarly, PCP and PCA appear to shift the 
FIGURE 5. Electron Photomicrograph of Hepatic Parenchymal Cells from a One Week Old Control Miniature Pig.

Details of the fixation and staining procedures appear in Appendix B.

Legend: Nucleus (N), Mitochondria (M), Rough Endoplasmic Reticulum (R), Smooth Endoplasmic Reticulum (S), Glycogen (G).

Magnification X6,000. 


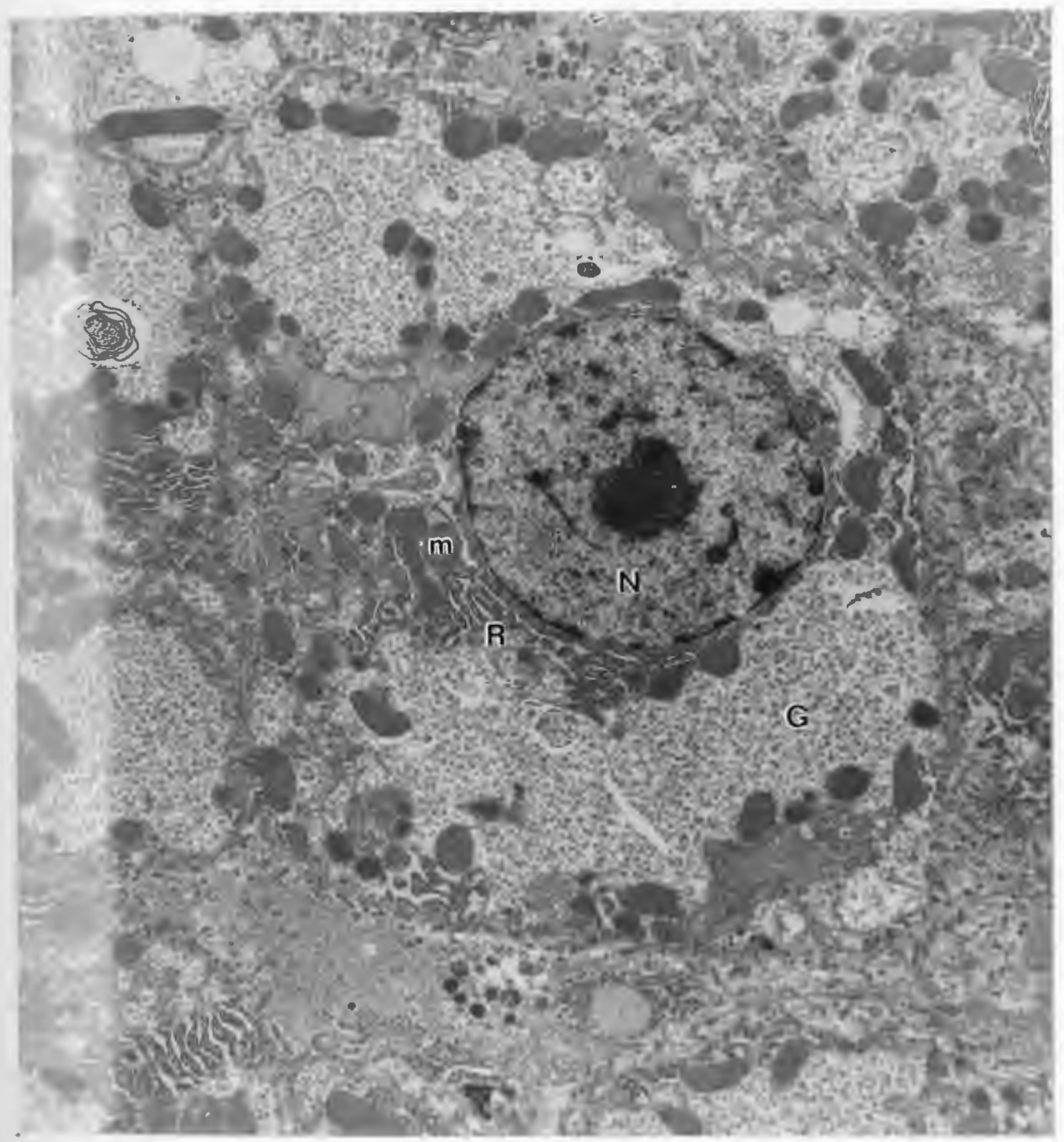


FIGURE 6. Higher Power Electron Photomicrograph of an Hepatic Cell from a One Week 01d Control Miniature Pig.

Legend: see Figure 5.

Magnification X22,500 (Insert: X15,000). 


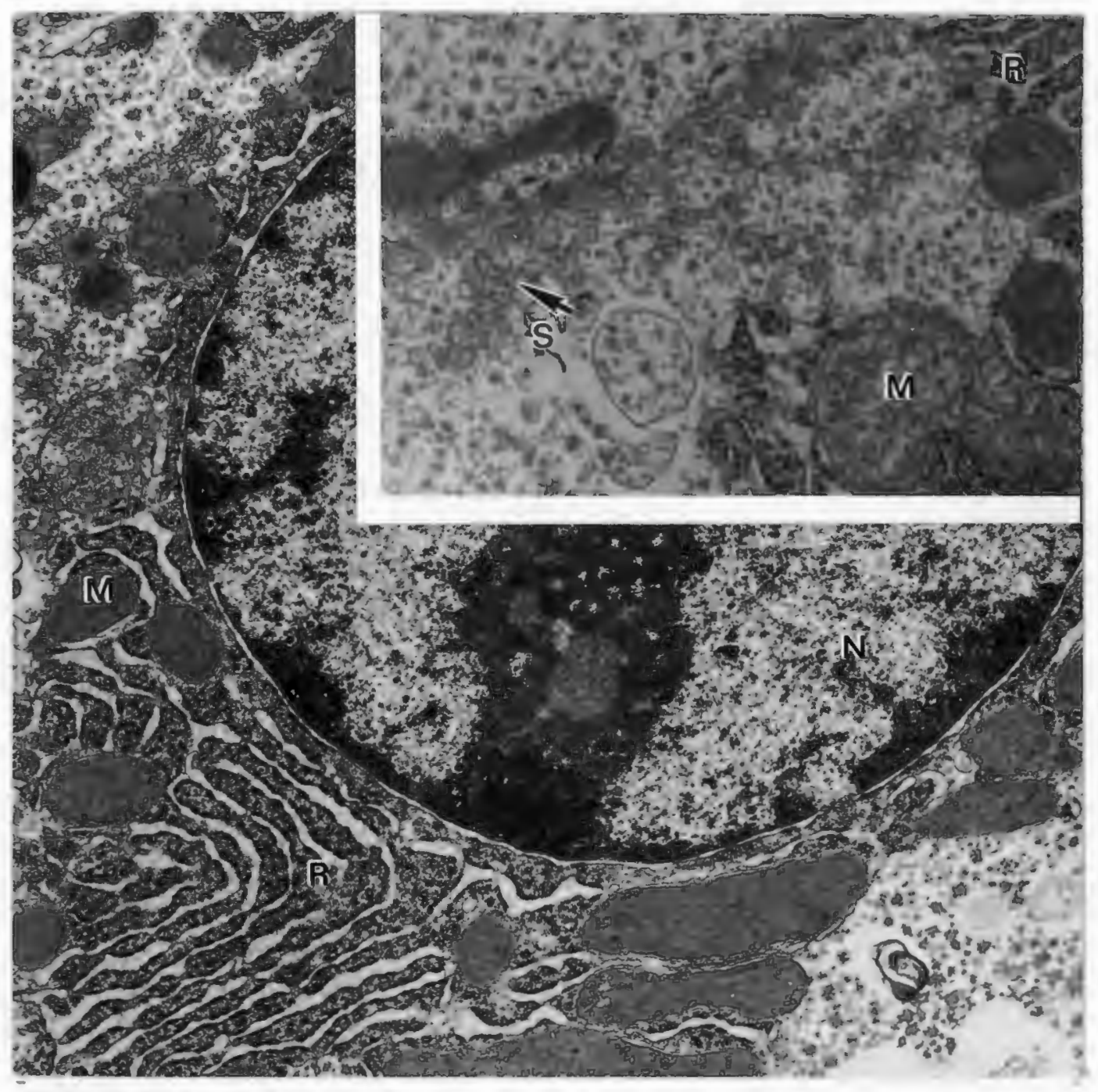


FIGURE 7. Electron Photomicrograph of Hepatic Cells from a Phenobarbital Treated One Week Old Miniature Pig.

Legend: see Figure 5.

Magnification X12,500. 


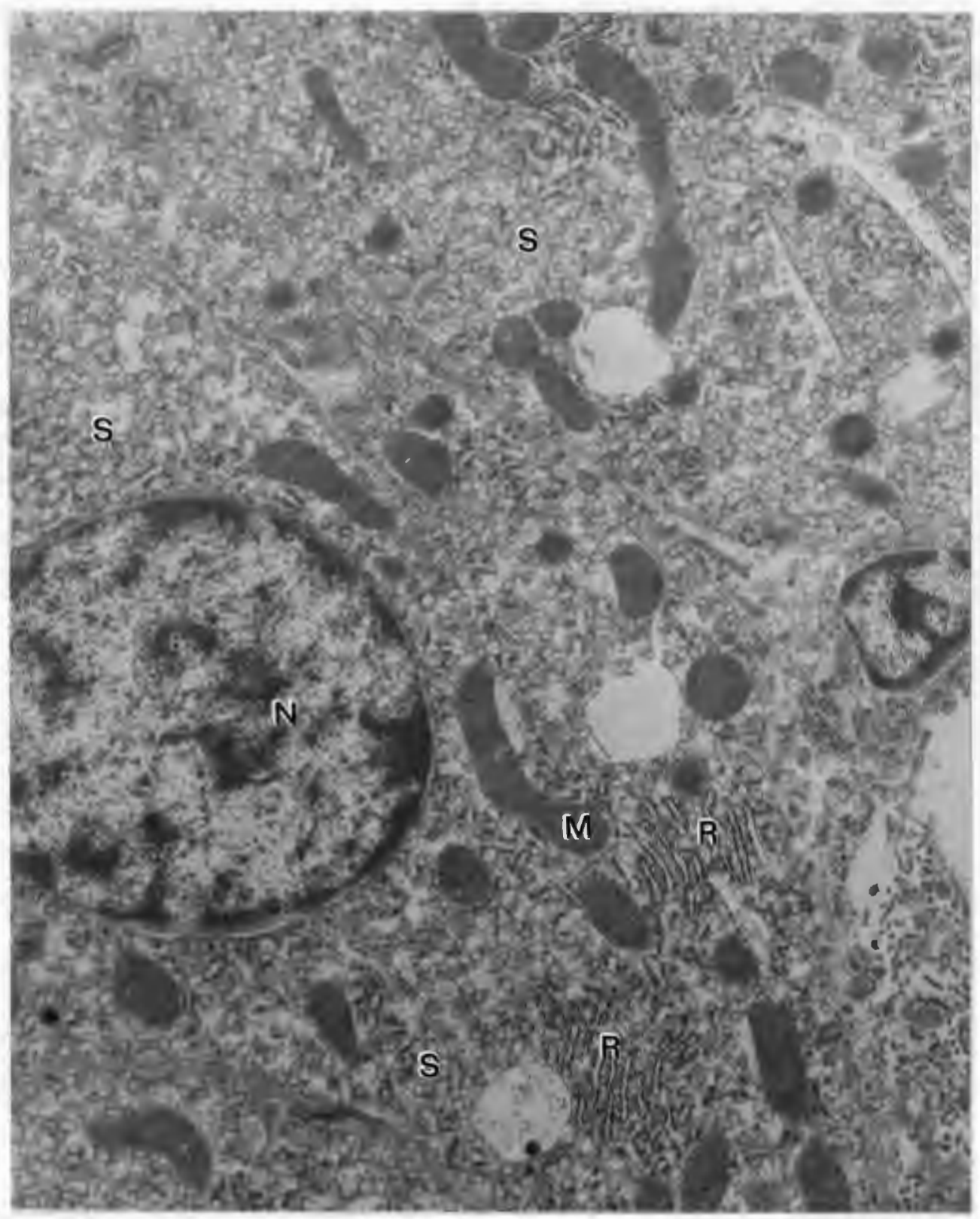


predominance of endoplasmic reticlum from rough to smooth (Figures 8 \& 9). It should be noted that in the latter two cases, regions of RER appear more dispersed in the cytoplasm rather than arranged in parallel stacks as observed in controls and phenobarbital treated piglets.

\section{Biochemical Effects in Four Week Old Piglets}

The effects of the various treatments in four week old piglets are shown in Tables 6 and 7. Due to the smaller number of animals used per treatment group and the occurrence of aberrant values in some parameters, statistical significance could not be demonstrated for the relatively small changes produced by either PCA or PCP. A similar trend in the induction patterns of the two compounds, however, is apparent, with PCA producing small increases in ANOH and NADM activity and its major effect on its own metabolism (Table 6). PCP, as in one week old piglets, appears to increase only NADM activity.

Phenobarbital treatment in four week old piglets results in significant increases in all' six parameters measured. ANON, NADM, and PCADM were $4.5,5.4$ and 15 -fold, respectively, greater than control activities (Table 6).

The levels of cytochrome $\mathrm{P} 450, \mathrm{~b}_{5}$ and cytochrome c Reductase were not significantly changed by PCA or PCP, however, phenobarbital again produced a 3-fold increase in $P 450$ and significant, albeit smaller increases in the other two parameters (Table 7). 
FIGURE 8. Electron Photomicrograph of an Hepatic Cell from a PCP Treated One Week old Miniature Pig.

Legend: see Figure 5.

Magnification X11,250. 


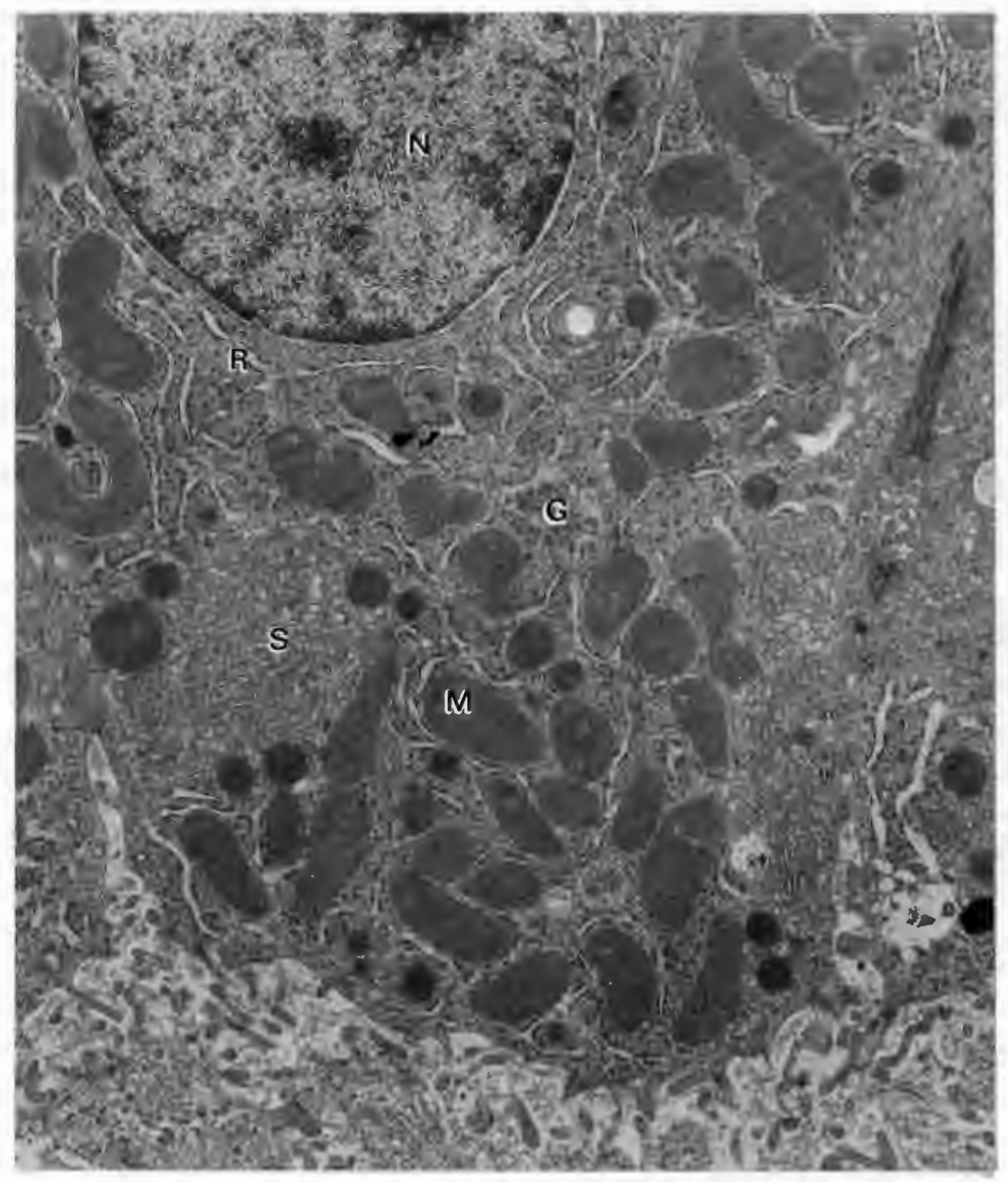




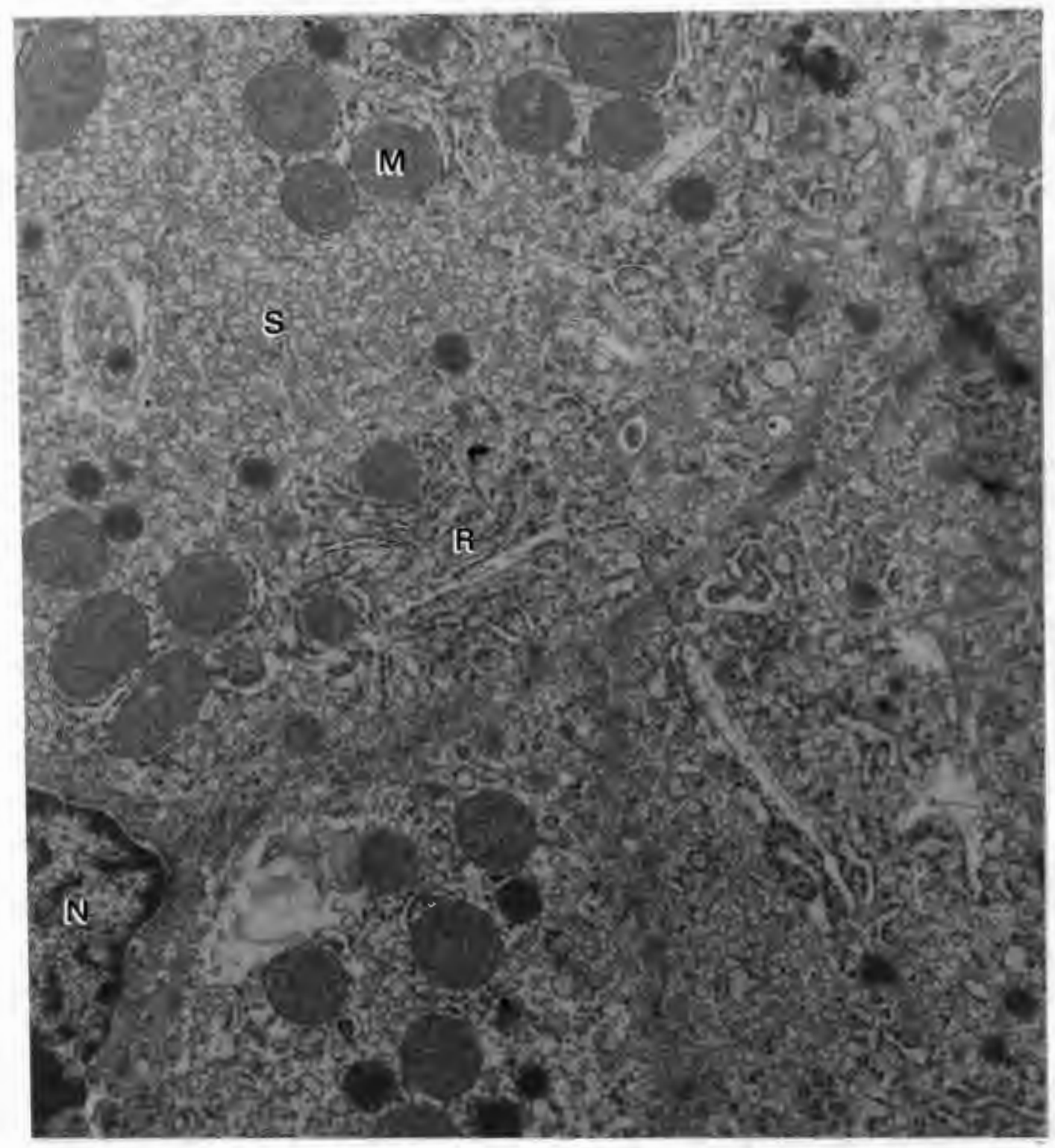




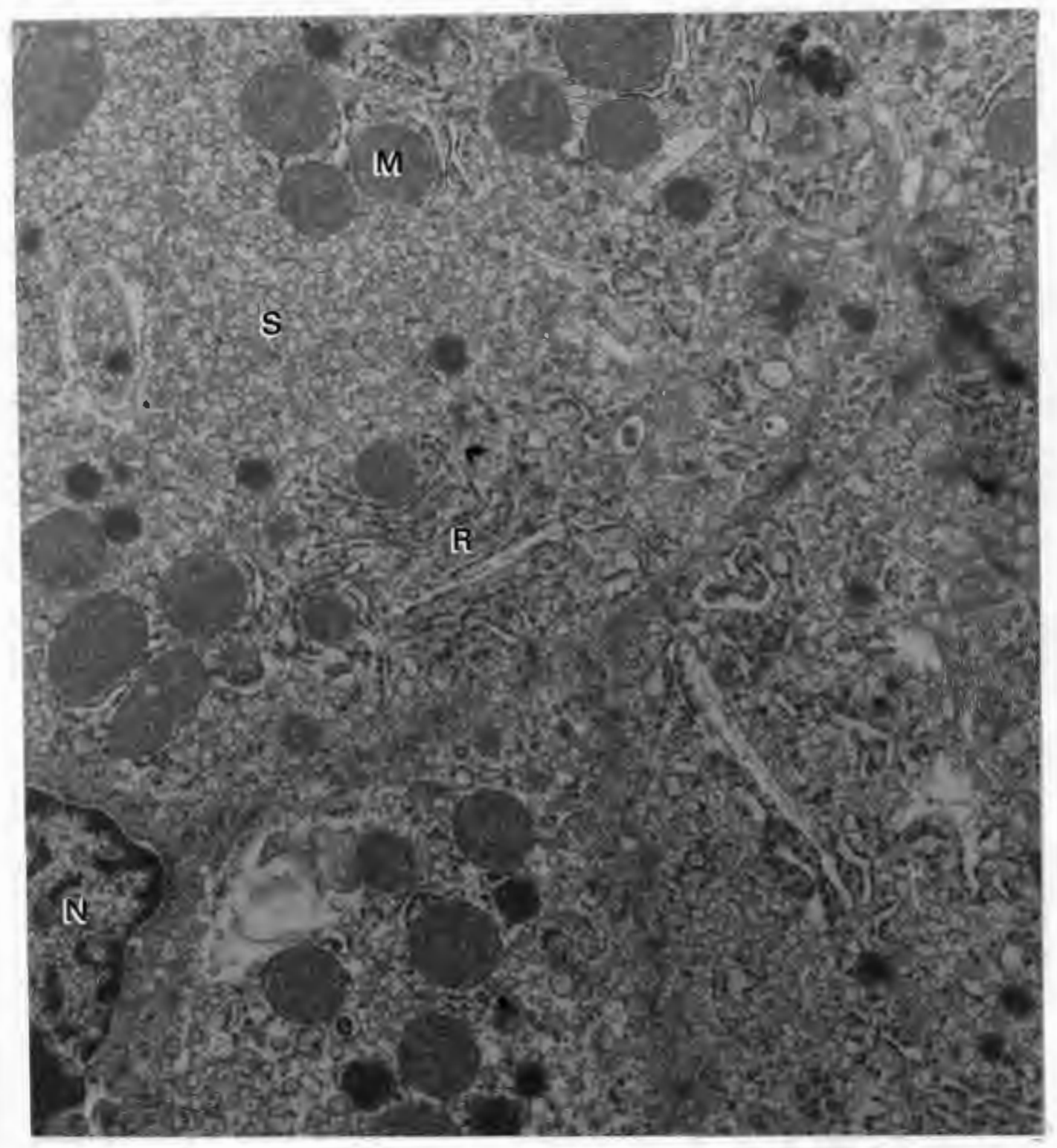


TABLE 6. Effects of PCA, PCP, and phenobarbital on microsomal enzyme activities in four week old miniature pigs.

$\begin{array}{ccc}\text { Aniline } & \text { Nitroanisole } & \text { Pentachloroanisole } \\ \text { Hydroxylase } & \text { Demethylase } & \text { Demethylase }\end{array}$

$\begin{array}{llcc}\text { Control (3) } & 0.48 \pm 0.04 & 2.24 \pm 0.55 & 0.37 \pm 0.04 \\ \text { PCA (3) } & 0.67 \pm 0.03 & 3.09 \pm 0.28 & 0.80 \pm 0.16 \\ \text { PCP (3) } & 0.56 \pm 0.07 & 3.25 \pm 0.20 & 0.46 \pm 0.14 \\ \text { Phenobarbital (3) } & 2.16 \pm 0.32 * * & 12.09 \pm 1.57 * * & 5.60 \pm 0.32 * \star\end{array}$

a Treatments are described in Materials and Methods section.

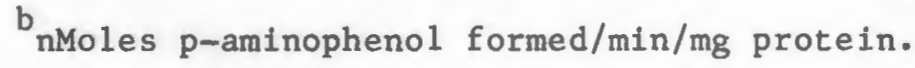

c nMoles p-nitrophenol formed/min/mg protein.

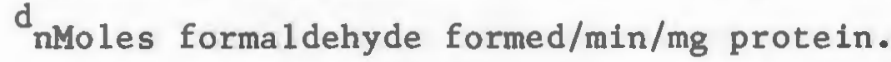

All values are the mean \pm S.E.M. for the number of observations in parentheses.

**Significantly different from control ( $p<0.05)$ Student's t test. 
TABLE 7. Effects of PCA, PCP, and phenobarbital on cytochromes P450, $b_{5}$, and cytochrome-c Reductase in four week old miniature pigs.

\begin{tabular}{|c|c|c|c|}
\hline Treatment & $\begin{array}{c}\text { Cytochrome } \\
\text { P450 }\end{array}$ & Cytochrome $^{c}$ & $\begin{array}{c}\text { Cytochrome-c } \\
\text { Reductase }\end{array}$ \\
\hline
\end{tabular}

$\begin{array}{llll}\text { Control (3) } & 0.81 \pm 0.04 & 0.76 \pm 0.003 & 165.5 \pm 1.8 \\ \text { PCA (3) } & 0.92 \pm 0.05 & 0.74 \pm 0.03 & 148.5 \pm 6.8 \\ \text { PCP (3) } & 1.10 \pm 0.02 & 0.85 \pm 0.04 & 152.7 \pm 4.7 \\ \text { Phenobarbital (3) } & 2.63 \pm 0.06 * * & 0.93 \pm 0.05 * * & 187.3 \pm 5.4 * *\end{array}$

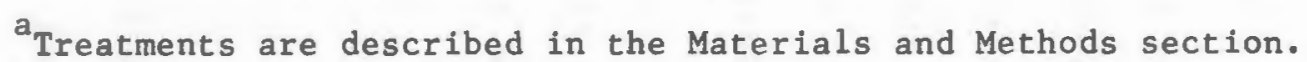

b nMoles/mg protein.

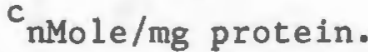

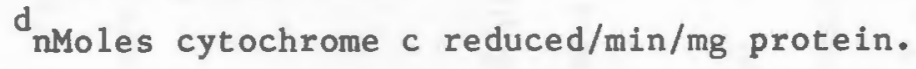

All values are the mean \pm S.E.M. for the number of observations in parentheses.

**Significantly different from control ( $p<0.05)$ Student's $t$ test. 


\section{Biochemical Effects in Eight Week Old Piglets}

The results in eight week old piglets were for the most part similar to those in younger animals (Tables 8 \& 9), however, the extent of induction by PCA appears to be less than that in one week old piglets. Although PCA produces a significant $35 \%$ increase in NADM activity, this is approximately half the increase (67\%) observed in the younger animals. Similarly, PCA treatment produced only a $75 \%$ increase in its own metabolism (PCADM) as compared to a 3-fold increase in the one week old group. ANOH activity is no longer significantly different from controls. PCP treatment, as with the earlier groups, had no significant effect on ANOH, however, unlike the younger animals the compound did produce a small increase in PCADM.

The effects of phenobarbital compared relatively well with those seen in the two previous age groups. PCADM activity was approximately 13-fold greater and ANOH 4.6-fold greater than controls (Table 8). NADM activity, however, was increased 4.7-fold by phenobarbital which is approximately half the 9-fold increase observed in one week old piglets.

As with the four week old piglets, the only significant increases in cytochrome $\mathrm{P} 450, \mathrm{~b}_{5}$ and Reductase in eight week old piglets were produced by phenobarbital (Table 9).

\section{Catalytic Activities}

The relative ease by which cytochrome $\mathrm{P} 450$ can be quantitated in microsomal suspensions imparts the ability to analyze data from 
TABLE 8. Effects of PCA, PCP, and phenobarbital on microsomal enzyme activities in eight week old miniature pigs.

$\begin{array}{ccc}\text { Treatment } & \text { Aniline } & \text { Nitroanisole } \\ \text { Hydroxylase } & \text { Demethylase } & \text { Pentachloroanisole }^{\mathrm{d}} \\ & \text { Demethylase }\end{array}$

$\begin{array}{llll}\text { Control (6) } & 0.47 \pm 0.05 & 2.15 \pm 0.08 & 0.29 \pm 0.02 \\ \text { PCA (6) } & 0.60 \pm 0.03 & 2.94 \pm 0.24 * & 0.51 \pm 0.03 * * \\ \text { PCP (6) } & 0.53 \pm 0.07 & 2.92 \pm 0.31 * & 0.41 \pm 0.02 * * \\ \text { Phenobarbital (6) } & 2.14 \pm 0.18 * * * & 10.13 \pm 0.43 * * * & 3.85 \pm 0.40 * * *\end{array}$

$a_{\text {Treatments }}$ are described in Materials and Methods section.

$\mathrm{b}$

nMoles p-aminophenol formed/min/mg protein.

c nMoles p-nitrophenol formed/min/mg protein.

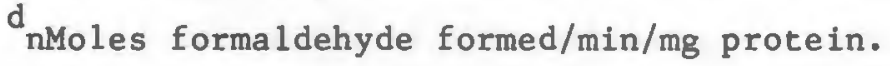

All values are the mean \pm S.E.M. for the number of observations in parentheses.

* Significantly different from control ( $p<0.05$ ) Student Newman-Keuls test.

** Significantly different from control ( $p<0.05$ ) Duncan's Multiple Range test.

$* * *$ Significantly different from control $(p<0.05)$ Student's t test. 
TABLE 9. Effects of PCA, PCP, and phenobarbital on cytochromes P450, $b_{5}$, and cytochrome-c Reductase in eight week old miniature pigs.

$\begin{array}{ccc}\text { Treatment } & \text { Cytochrome } & \text { Cytochrome } \\ \text { P450 } & b_{5} & \text { Cytochrome-c }^{d} \\ & \text { Reductase }\end{array}$

$\begin{array}{llcc}\text { Control (6) } & 1.00 \pm 0.04 & 0.74 \pm 0.01 & 151.6 \pm 6.8 \\ \text { PCA (6) } & 1.08 \pm 0.06 & 0.83 \pm 0.03 & 163.9 \pm 8.3 \\ \text { PCP (6) } & 1.15 \pm 0.06 & 0.75 \pm 0.04 & 142.9 \pm 5.0 \\ \text { Phenobarbital (6) } & 3.71 \pm 0.24 * & 1.04 \pm 0.05 * & 201.7 \pm 7.0 *\end{array}$

areatments are described in Materials and Methods section.

$b_{\text {nMoles/mg protein. }}$

c nMoles/mg protein.

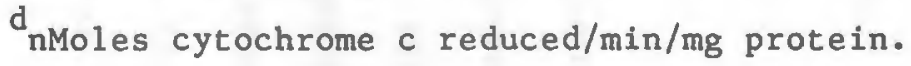

All values are the mean \pm S.E.M. For the number of observations in parentheses.

* Significantly different from control ( $p<0.05$ ) Student's $t$ test. 
enzyme assays in terms of "molecular" or "catalytic" activity. This method is particularly useful for determining changes in the specificity of induced form(s) of cytochrome P450. Catalytic activities, expressed as nmoles product/min/nmole P450, for PCADM as a function of age and treatment are shown in Table 10. Consistent with its relatively large effect on PCA metabolism, phenobarbital produced a 5.2-fold increase in catalytic activity in one week old piglets. PCA treatment also produced a significant 2-fold increase in catalytic activity in the youngest age group. Although there are no significant changes in controls as a function of age, an age related decrease in catalytic activity was observed in PCA and phenobarbital induced pigs. Catalytic activity in eight week old piglets is less than half the one week old activity for each respective group.

Similar, yet less pronounced alterations in catalytic activity were observed for ANOH (Table 11) and NADM (Table 12). In both cases, however, only phenobarbital produced any significant effects.

\section{Kinetic Analysis}

Changes in various catalytic activity profiles following chemical induction of the MFO system have generally been associated with either an increase in the concentration of a substance specific form of cytochrome $\mathrm{P} 450$ or alterations in the relative proportions of various subpopulations of the hemoprotein. To further investigate the age related changes in catalytic activities as well as the nature of the large effect produced by phenobarbital on PCA metabolism, kinetic 
TABLE 10. Catalytic activity of PCA demethylase as a function of age and treatment.

$\underline{\mathrm{AGE}}$

$\begin{array}{llll}\text { Treatment } & 1 \text { Week } & 4 \text { Week } & \text { Week }\end{array}$

$\begin{array}{llll}\text { Control } & 0.41 \pm 0.04(5) & 0.46 \pm 0.06(3) & 0.29 \pm 0.01 \text { (6) } \\ \text { PCA } & 0.94 \pm 0.08(6)^{\dagger} 0.88 \pm 0.20(3) & 0.48 \pm 0.03(6)^{\text {† }} \\ \text { PCP } & 0.32 \pm 0.05(5) & 0.42 \pm 0.12(3) & 0.35 \pm 0.02(6) \\ \text { Phenobarbital } & 2.15 \pm 0.28(5)^{5} & 2.12 \pm 0.10(3)^{\S} & 0.91 \pm 0.04(5)^{5 \Upsilon}\end{array}$

${ }^{a}$ Catalytic activity is expressed as nMoles formaldehyde formed/min/ nMole cytochrome $\mathrm{P} 450$.

Values are the mean \pm S.E.M. for the number of observations in parentheses.

${ }^{t_{P}}<0.05$ vs. age matched controls (Duncan's Multiple Range).

${ }^{5} \mathrm{P}<0.05$ vs. age matched controls (Student's t test).

${ }^{\top} \mathrm{P}<0.05$ vs treatment matched one week olds (Least Square Means). 
TABLE 11. Catalytic activity of aniline hydroxylase as a function of age and treatment.

\begin{tabular}{|c|c|c|c|c|c|}
\hline \multirow[b]{2}{*}{ Treatment } & \multicolumn{5}{|c|}{ AGE } \\
\hline & 1 Week & & 4 Week & & 8 Week \\
\hline Control & $0.66 \pm 0.06(5)$ & 0.59 & \pm 0.09 & (3) & $0.48 \pm 0.06(6)$ \\
\hline PCA & $0.75 \pm 0.03(6)$ & 0.74 & \pm 0.07 & (3) & $0.56 \pm 0.03(6)$ \\
\hline PCP & $0.54 \pm 0.05(5)$ & 0.51 & \pm 0.05 & (3) & $0.46 \pm 0.05(6)$ \\
\hline Phenobarbital & $1.28+0.06(6)^{\dagger}$ & 0.82 & \pm 0.06 & $(3)^{5}$ & $0.60 \pm 0.07(6)^{5 \tau}$ \\
\hline
\end{tabular}

acatalytic activity is expressed as nMoles p-aminophenol formed/min/ nMole cytochrome $\mathrm{P} 450$.

Values are the mean \pm S.E.M. for the number of observations in parentheses.

${ }^{t_{P}}<0.05$ vs. age matched control (Student's t test).

${ }^{5} \mathrm{P}<0.05$ vs. treatment matched one week olds (Least Square Means).

$\mathbf{T}_{\mathrm{P}}<0.05$ vs. treatment matched four week olds (Least Square Means). 
TABLE 12. Catalytic activity of nitroanisole demethylase as a function of age and treatment.

$\underline{\mathrm{AGE}}$

Treatment

1 Week

4 Week

8 Week

$\begin{array}{llll}\text { Control } & 2.79 \pm 0.27(5) & 2.74 \pm 0.55(3) & 2.17 \pm 0.14(6) \\ \text { PCA } & 3.42 \pm 0.25(6) & 3.39 \pm 0.46(3) & 2.75 \pm 0.26(6) \\ \text { PCP } & 2.87 \pm 0.16(5) & 2.96 \pm 0.15(3) & 2.52 \pm 0.20(6) \\ \text { Phenobarbital } & 8.29 \pm 1.05(6)^{\dagger} 4.57 \pm 0.55(3)^{5} & 2.78 \pm 0.21(6)^{+59}\end{array}$

${ }^{a}$ Catalytic activity is expressed as nMoles p-nitrophenol formed/min/ nMole cytochrome P450.

Values are the mean \pm S.E.M. for the number of observations in parentheses.

${ }^{t_{P}}<0.05$ vs. age matched controls (Student's t test).

${ }^{\S} \mathrm{P}<0.05$ vs. treatment matched one week olds (Least Square Means).

$\mathbf{T}_{\mathrm{P}}<0.05 \mathrm{vs}$. treatment matched four week olds (Least Square Means). 
analyses were conducted. Based on the assumption that there are multiple forms of cytochrome $P 450$, which may differ in their affinities toward a particular substrate, it should be possible to detect the activities of different forms by kinetic anaylsis providing the affinity differences are large enough.

When aniline concentrations were varied from $5 \mathrm{uM}$ to $5 \mathrm{mM}$, a biphasic pattern was observed when plotted by the Eadie-Hofstee method (Figure 10). Kinetic constants for the two phases were determined as described in the Methods section. In adult ( 4 month old) uninduced pigs, the high affinity component had an apparent $\mathrm{K}_{\mathrm{m}}$ of 6.8 $u M$ and a $V_{\max }$ of 0.39 nmoles/min/mg protein. The low affinity component had an apparent $\mathrm{K}_{\mathrm{m}}$ of $0.74 \mathrm{mM}$ and a $\mathrm{V}_{\max }$ of $1.17 \mathrm{nmoles} /-$ $\mathrm{min} / \mathrm{mg}$ protein. Using these four kinetic parameters, theoretical values for velocity were calculated for the substrate concentrations utilized. The calculated velocities correlated extremely well $\left(r^{2}=\right.$ .99) with the experimentally derived velocities (Figure 11).

Similar analyses were conducted with microsomes from 1,4 , and 8 week old uninduced piglets. A summary of the kinetic constants are listed in Table 13. In uninduced microsomes, the high affinity component, designated Form I, remains relatively constant with respect to affinity and maximum velocity over the four ages. In contrast, the low affinity component, Form II, appears to undergo age dependent changes in both parameters.

The developmental profiles of the two forms of ANOH are depicted in Figure 12. In one week old piglets, Form I constitutes approximately $65 \%$ of the total activity. Between one and four weeks 
FIGURE 10. Eadie-Hofstee Plot of Aniline Hydroxylase Activity in Microsomes from Uninduced, Adult Miniature Pigs.

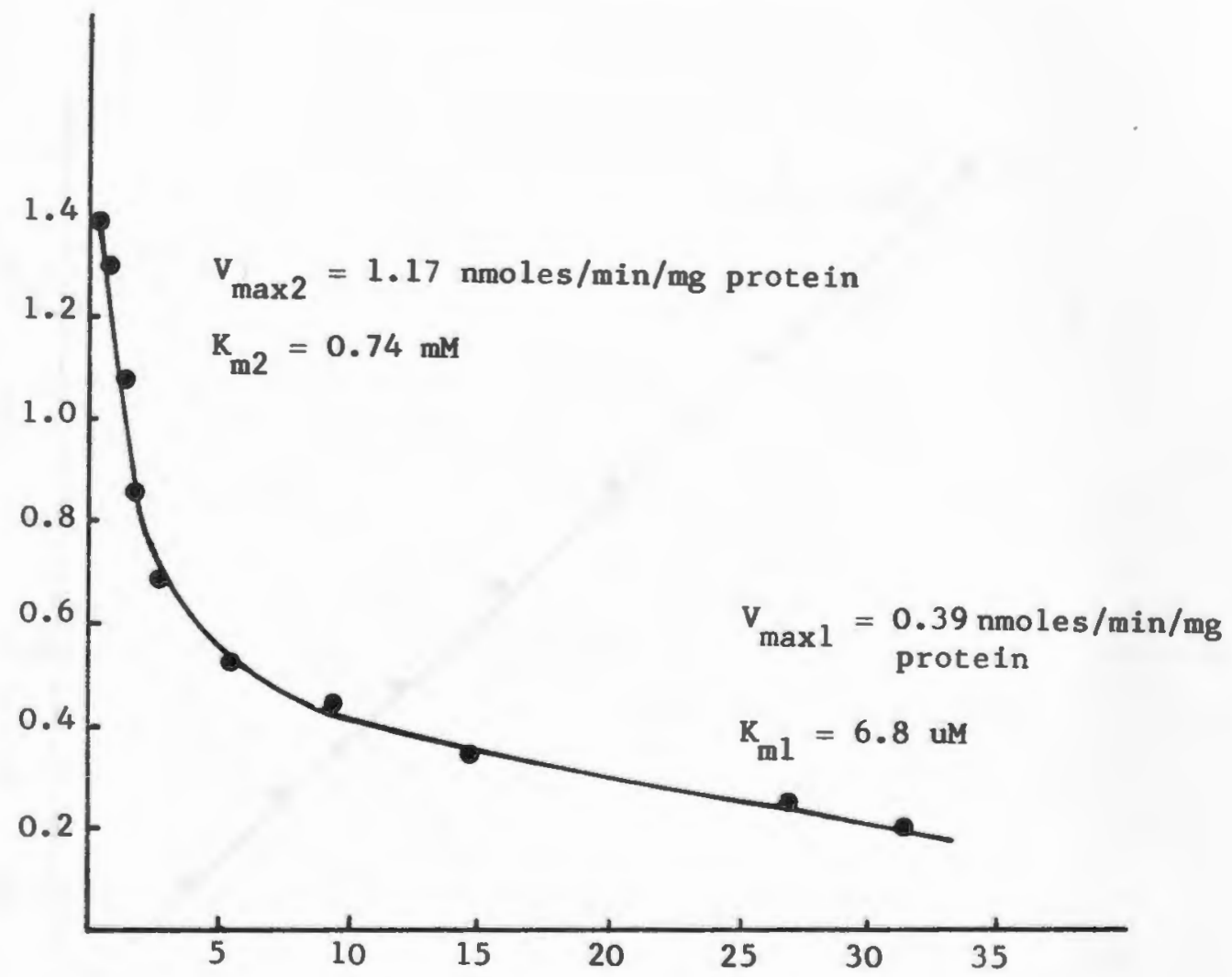

b) Details of the assay conditions and derivation of kinetic constants are described in Materials \& Methods.

b) Miniature pigs were 16 weeks old at the time of sacrifice. Microsomes were obtained from a pool of two livers.

c) Each point represents the average of duplicate determinations for the substrate concentration utilized. 
FIGURE 11. Plot of $v$ (observed) Against $v$ (calculated) Based on Biphasic Kinetic Analysis of Aniline Hydroxylase Activity.

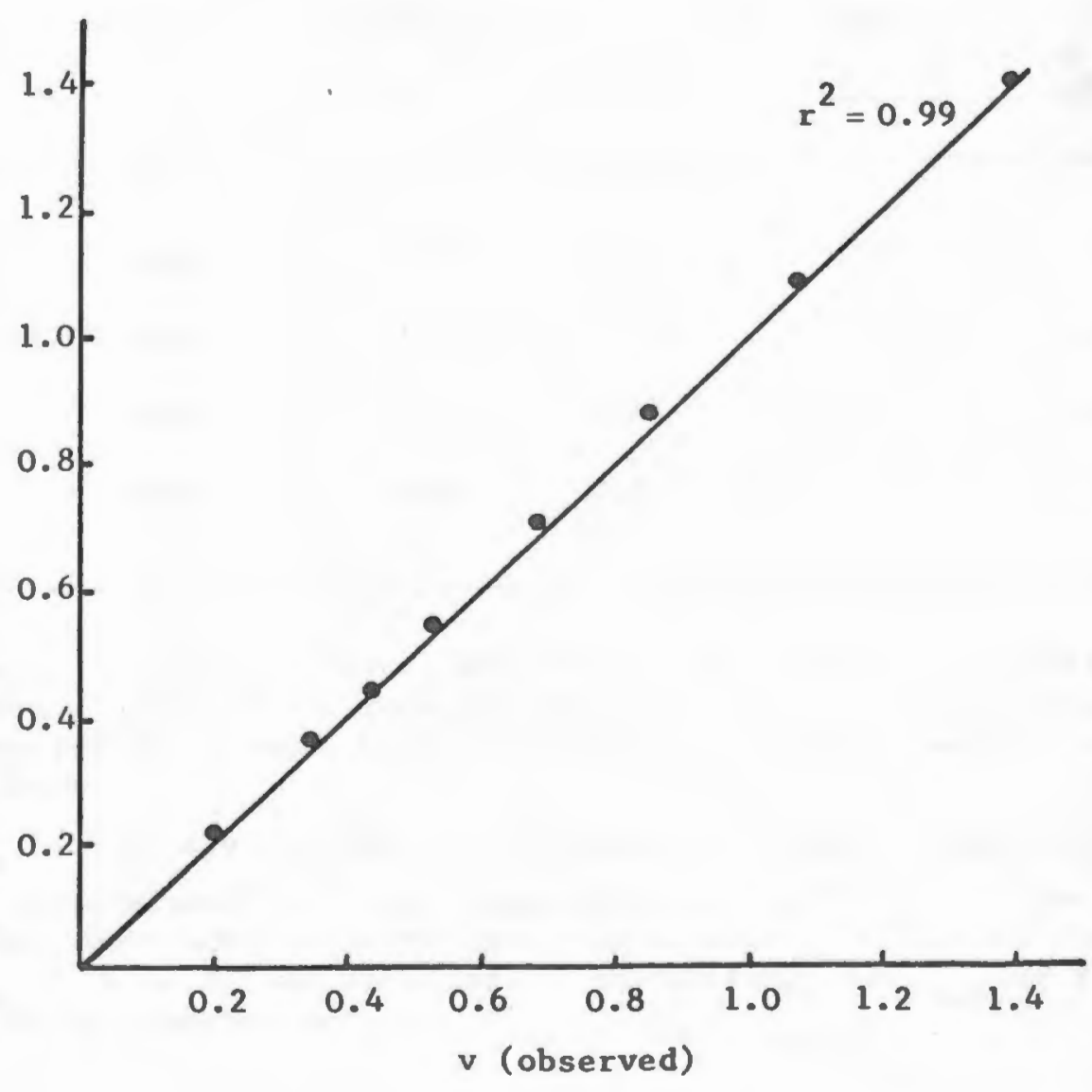

a) The observed velocity represents the total velocity $\left(v_{T}\right)$ at each aniline concentration from the experimental data shown in Figure 10.

b) Theoretical values of $v_{T}$ and $v_{T} / S$ were calculated using the estimates for the apparent $K^{T}$ and $V_{\max }$ of each component (Figure 10) and the substrate concentrations used in the assay. The values were substituted into the equation:

$$
v_{T}=v_{1}+v_{2}=\frac{v_{\max 1} S}{k_{m 1}+S}+\frac{v_{m a x} S}{K_{m 2}+S}
$$


TABLE 13. Summary of the kinetic parameters for the two forms of aniline hydroxylase in developing minipigs.

FORM I

FORM II

Age

Apparent

$\underline{\mathrm{K}_{\mathrm{m}}(\mathrm{uM})} \quad \underline{\underline{\max }}$

Apparent

$\mathrm{K}_{\mathrm{m}}(\mathrm{mM}) \quad \mathrm{V}_{\max }$

$\begin{array}{lllll}1 \text { Week } & 8.2 & 0.36 & \mathrm{ND}^{c} & 0.16 \\ 4 \text { Week } & 3.6 & 0.29 & 0.52 & 0.50 \\ 8 \text { Week } & 5.4 & 0.41 & 0.56 & 0.47 \\ 16 \text { Week } & 6.8 & 0.39 & 0.74 & 1.17\end{array}$

Kinetic parameters were determined as detailed in Materials and Methods. Experimental data was obtained from duplicate determinations on pooled microsomes from three pigs ( 1,4 and 8 weeks) or two pigs (16 weeks).

${ }^{b} v_{\max }$ is expressed as nMoles p-aminophenol formed/min/mg protein.

The predominance of the high-affinity activity in one week old piglets precluded accurate analysis of the $\mathrm{K}$ value for Form II. The $v_{\max }$ of Form II was obtained by subtracting the $V_{\max }$ of Form I from thex total observed velocity $\left(V_{\max 2}=V_{T}-V_{\max 1}\right)$. 
FIGURE 12. Developmental Profiles for the Two Forms of Aniline Hydroxylase in Uninduced Miniature Pigs.

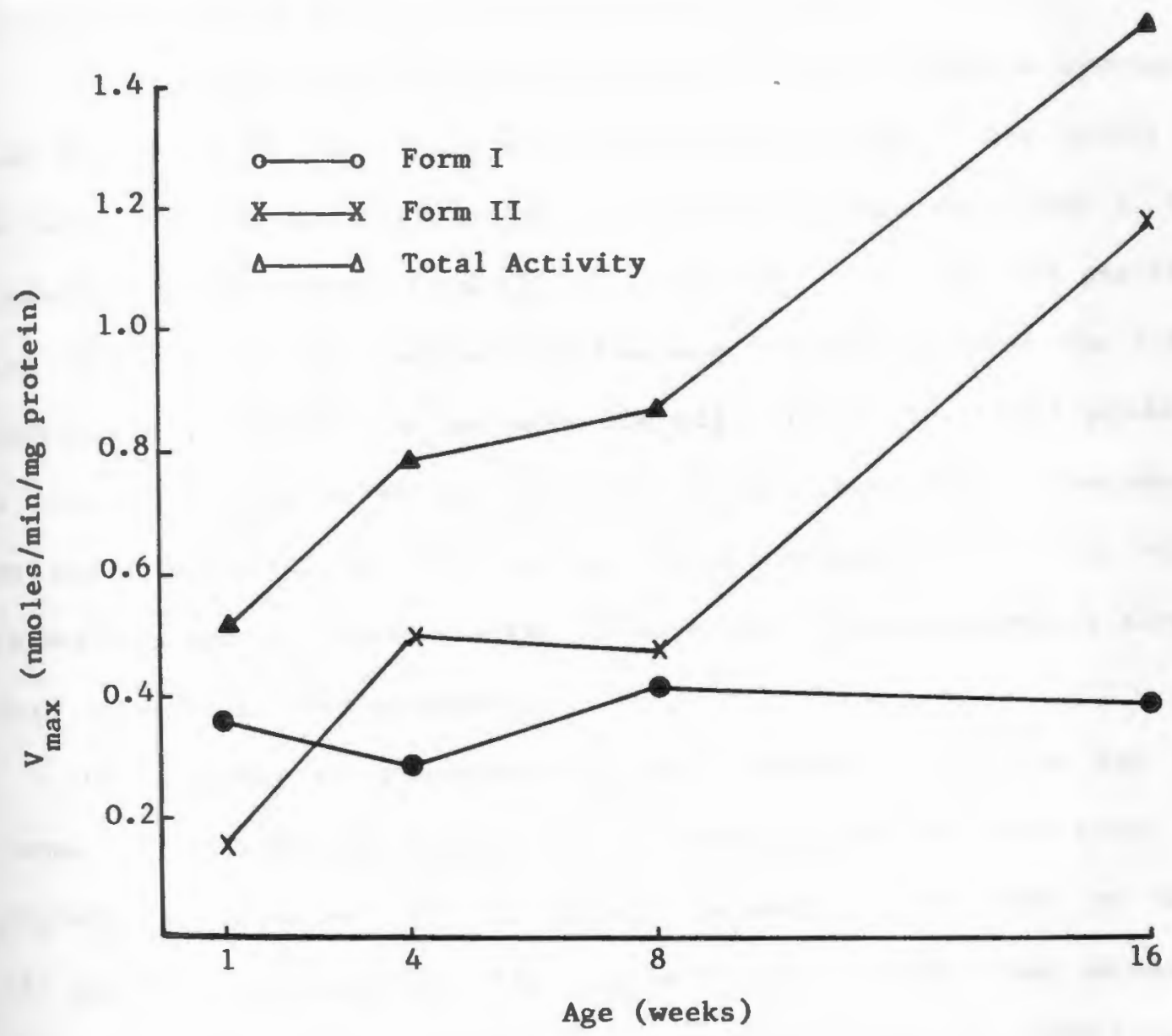

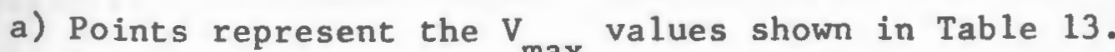

b) Total aniline hydroxylase activity is the sum of the $V_{\max }$ values for Form I and Form II. 
of age, the maximum velocity of Form II approximately triples while Form I remains relatively constant. At this point, Form II contributes to $65 \%$ of the total activity. There appears to be a leveling off in both components to eight weeks followed by a further 2.5-fold increase in the activity of Form II by sixteen weeks of age.

The effects of phenobarbital on the two forms of aniline hydroxylase are shown in Table 14. At all ages, phenobarbital has little or no effect on the activity of the high-affinity component, Form $I$. The low-affinity component, Form II, is increased at al1 ages. Of particular interest is the inverse relationship between age and the total increase in activity. In one week old piglets, phenobarbital produced a 12.8-fold increase in the activity of the low-affinity component. By eight weeks of age, the increase is approximately half that value (6.4-fold) and by sixteen weeks phenobarbital produces only a threefold increase in this component.

In addition to phenobarbital, the effects of PCA on the two forms of aniline hydroxylase were investigated in four week old piglets. A comparison of the kinetic parameters are shown in Table 15. As with phenobarbital, the high-affinity component was unchanged while the low-affinity component was slightly increased in PCA treated piglets. Furthermore, while phenobarbital does not appear to alter the apparent $K_{m}$ of the low-affinity component, PCA treatment reduced the apparent $\mathrm{K}_{\mathrm{m}}$ by approximately $50 \%$.

Similar kinetic analyses were conducted using PCA demethylase. As with aniline hydroxylase, Eadie-Hofstee plots appeared biphasic 
TABLE 14. Summary of the kinetic parameters of the two forms of aniline hydroxylase in phenobarbital induced, developing minipigs.

FORM I

Age

\section{Apparent}

$\mathrm{K}_{\mathrm{m}}$ (uM)

$\mathrm{v}_{\max } \quad \mathrm{v}_{\mathrm{pb}} / \mathrm{v}_{\mathrm{c}}$

FORM II

\section{Apparent}

$\mathrm{K}_{\mathrm{m}}(\mathrm{mM})$

$\begin{array}{rrrrrrr}1 \text { Week } & 11.3 & 0.35 & .97 & 0.93 & 2.04 & 12.8 \\ 4 \text { Week } & 6.9 & 0.24 & .83 & 0.58 & 2.26 & 4.5 \\ 8 \text { Week } & 6.2 & 0.29 & .71 & 0.55 & 2.99 & 6.4 \\ 16 \text { Week } & 19.5 & 0.35 & .90 & 0.94 & 3.40 & 2.9\end{array}$

${ }^{a}$ Kinetic parameters were determined as detailed in Materials and Methods. Experimental data was obtained from duplicate determinations on pooled microsomes from three pigs (1, 4, and 8 weeks) or two pigs (16 weeks).

${ }^{b}$ Phenobarbital was administered at $10 \mathrm{mg} / \mathrm{kg}$ P.O. for four consecutive days. ${ }^{c} v_{p b} / v_{c}$ is the ratio of the $v_{\max }$ for phenobarbital induced pigs to the $v_{\max }$ for uninduced pigs (Table 13 ). 
TABLE 15. Comparison of the kinetic parameters for the two forms of aniline hydroxylase in uninduced, $\mathrm{PCA}$ and phenobarbital treated minipigs at four weeks of age. ${ }^{a}$

\begin{tabular}{|c|c|c|c|c|}
\hline & FORM & & FORM & \\
\hline Treatment & $\begin{array}{l}\text { Apparent } \\
\mathrm{K}_{\mathrm{m}} \quad(\mathrm{UM}) \\
\end{array}$ & $\mathrm{v}_{\text {max }}$ & $\begin{array}{l}\text { Apparent } \\
\mathrm{K}_{\mathrm{m}} \text { (mM) } \\
\end{array}$ & $\mathrm{v}_{\text {max }}$ \\
\hline Control & 3.6 & 0.29 & 0.52 & 0.50 \\
\hline $\mathrm{PCA}^{\mathrm{C}}$ & 3.0 & 0.30 & 0.27 & 0.78 \\
\hline Phenobarbital ${ }^{b}$ & 6.9 & 0.24 & 0.58 & 2.26 \\
\hline
\end{tabular}

${ }^{\text {a }}$ Kinetic parameters were determined as detailed in Materials and Methods. Experimental data was obtained from duplicate determinations on pooled microsomes from three piglets in each treatment group.

${ }^{\text {b }}$ Phenobarbital was administered at $10 \mathrm{mg} / \mathrm{kg} \mathrm{P.O.} \mathrm{for} \mathrm{four} \mathrm{consecutive}$ days.

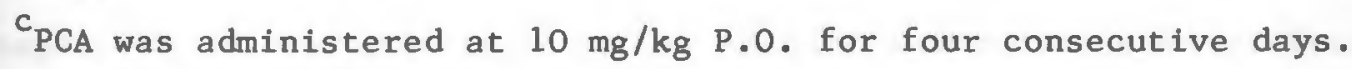


(Figure 13). In sixteen week old uninduced pigs, the high affinity component had an apparent $K_{m}$ of 40.1 uM and a $V_{\max }$ of 0.38 nmoles/min/mg protein. The low affinity component had an apparent $K_{m}$ of $3.1 \mathrm{mM}$ and $a V_{\max }$ of $1.32 \mathrm{nmoles} / \mathrm{min} / \mathrm{mg}$ protein. A summary of the kinetic constants for uninduced and phenobarbital induced microsomes at various ages is shown in Table. In the case of PCA demethylation, both the high and low-affinity components are increased by phenobarbital. Furthermore, while the apparent $K_{m}$ of the high-affinity component appears relatively unchanged by treatment, the apparent $\mathrm{K}_{\mathrm{m}}$ of the low-affinity form is markedly reduced.

When the data are arranged to illustrate age related increases in the two components as a result of phenobarbital induction (Table 16), it is interesting to note that while the low-affinity form is increased to a greater extent over basal levels, the magnitude of this increase remains relatively constant with age. In contrast, the magnitude of the increases in the high-affinity component produced by phenobarbital appears to decrease with age. In this respect, an interesting correlation exists between these data and that seen in Table 10 for catalytic activity of PCA demethylase. In Table 16, there appears to be a greater than $50 \%$ decrease in the magnitude of phenobarbitals effect between one and eight weeks of age (5.4-fold vs. 2.5-fold). Similarly, the catalytic activity of PCADM (Table 10) decreases from 2.15 to 0.91 between one and eight weeks of age in phenobarbital treated pigs. 
FIGURE 13. Eadie-Hofstee Plot of PCA Demethylase Activity in Microsomes from Uninduced, Adult Miniature Pigs.

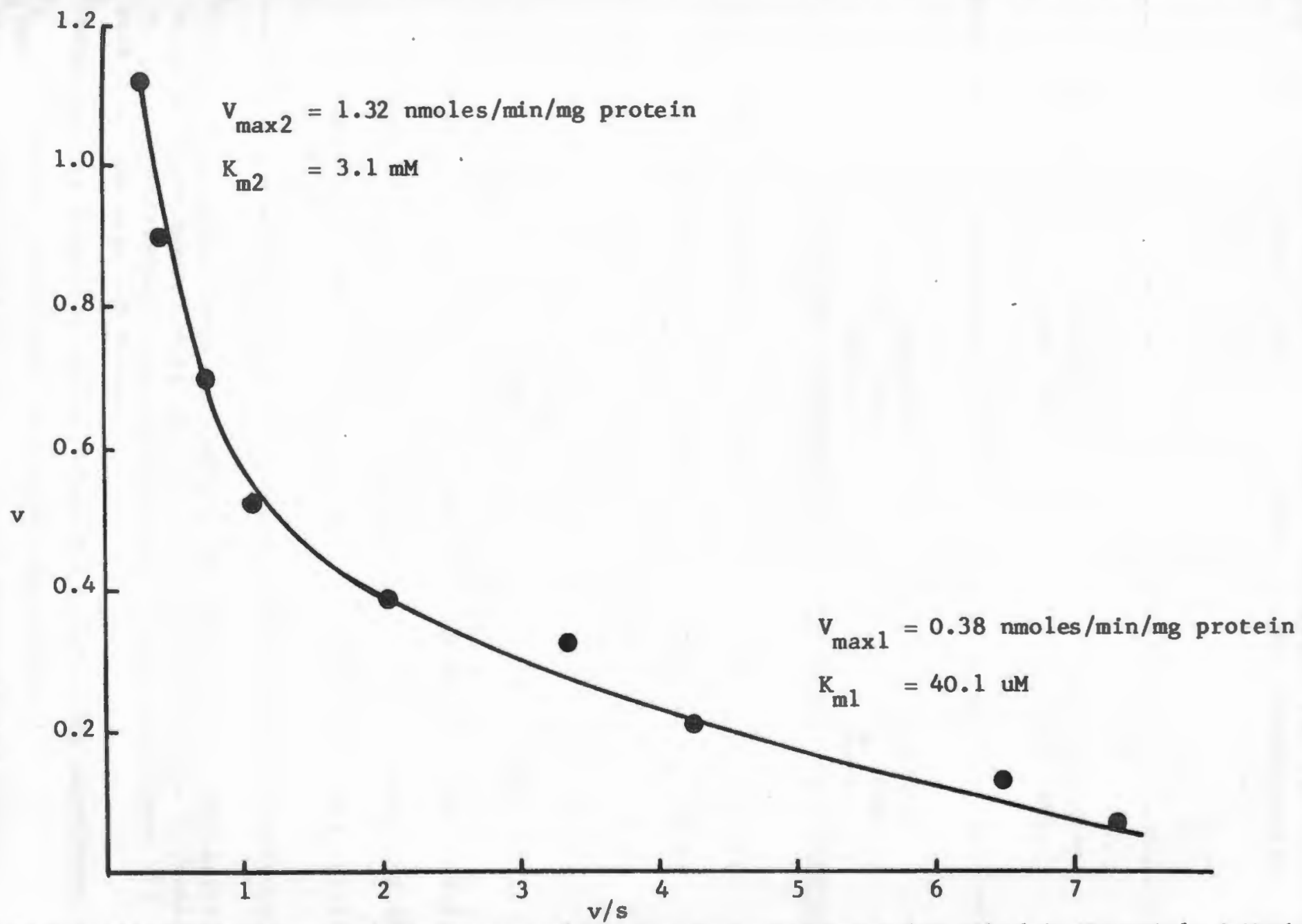

a) Details of the assay conditions and derivation of kinetic parameters are described in Materials \& Methods.

b) Miniature Pigs were 16 weeks old at the time of sacrifice. Microsomes were obtained from a pool of two livers.

c) Each point represents the average of duplicate determinations for the substrate concentration utilized. 
TABLE 16. Comparison of the kinetic parameters for the two forms of PCA demethylase in uninduced and phenobarbital induced developing miniature pigs.

$\begin{array}{cc}\text { Age } & \text { High Affinity } \\ \text { Component } & \text { Component }\end{array}$

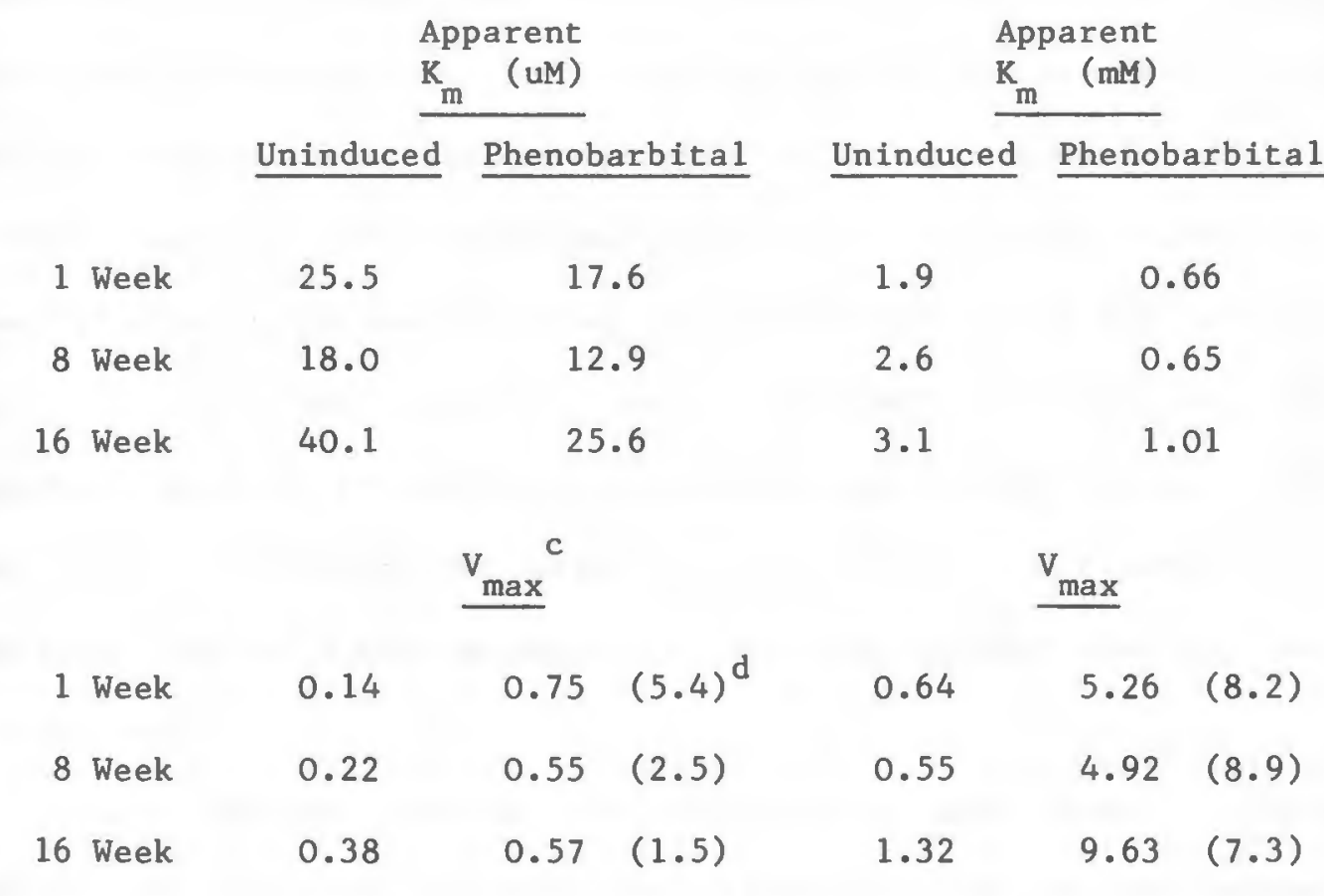

ainetic parameters were determined as detailed in Materials and Methods. Experimental data was obtained from duplicate determination on pooled microsomes from three pigs in each treatment ( 1 and 8 weeks) or two pigs ( 16 weeks).

${ }^{b}$ Phenobarbital induction was as described in previous experiments. $c_{v_{\text {max }}}$ is nMoles formaldehyde formed/min/mg protein.

Values in parenthesis are the ratio of phenobarbital induced activity $\left(V_{\max }\right)$ to uninduced activity. 


\section{DISCUSSION}

In support of those studies reporting the detection of pentachlorophenol in biological fluids following treatment with pentachloroanisole (Glickman et al., 1977; Vodicnik et al., 1980), the present investigation has shown that PCA is indeed a substrate for microsomal mixed-function oxidation. As evidenced by the requirement for NADPH and the inhibition by carbon monoxide and other documented inhibitors of MFO (Table 1), PCA is metabolized via a cytochrome P450-dependent demethylation reaction resulting in the formation of PCP (Figure 1). Since PCP has been shown to be metabolized to lower chlorinated compounds such as tetrachlorohydroquinone and trichlorophenol (Ahlborg and Thunberg, 1978), the peak at 2.3 minutes in Figure 1(b) may represent one of these metabolites, although further characterization is required.

These results present an interesting and ironic situation. Whereas it is often assumed that biodegradation of pesticides and other environmental contaminants renders them inactive, PCA represents one biodegraded product that can be reactivated to its parent compound, PCP, in species possessing the proper metabolic capacity. Furthermore, as indicated by Glickman et al. (1977), PCP exhibits a higher degree of bioaccumulation and is more persistent than PCP in fish. Thus, the compound may present a more difficult assessment with respect to contamination of the food chain. 
Initial kinetic analysis of PCA demethylation provided some interesting results. The activity in uninduced microsomes $(<0.5$ nmoles/min/mg protein) is much lower than that reported in the literature for other 0-demethylated substrates such as nitroanisole in various laboratory species. The possibility of species differences, however, has been discounted since a similarly low rate of PCA metabolism has been observed in uninduced rat liver (Agins et al., 1982). An unusually large increase in activity following phenobarbital induction, in this case greater than ten-fold, suggested the existence of a specific-inducible form of cytochrome $P 450$ that preferentially metabolized PCA. In support of this assumption are the sensitivity of PCA demethylation in phenobarbital induced microsomes to metyrapone inhibition (Table 1) and the results from substrate binding spectra (Figure 3). The inability to detect discernable spectral changes in uninduced microsomes is most likely a function of the low concentration or absence of the PCA specific form of cytochrome P450. Following phenobarbital induction, a binding spectra becomes readily apparent, which correlates with the increase in demethylase activity. Furthermore, the spectral dissociation constant $\left(\mathrm{K}_{\mathrm{s}}\right)$ of approximately $15 \mathrm{uM}$ indicates that PCA has a relatively high affinity for the inducible form of cytochrome P450 (Figure 4).

In conjunction with these findings, it is interesting to note that Hultmark and coworkers (1979) reported a similar situation for the metabolism of dichloro-p-nitroanisole in rats. Their results indicated that this chlorinated analogue of nitroanisole was demethylated quite poorly by uninduced microsomes and that phenobarbital 
induction resulted in a 24-fold increase in activity as well as increased sensitivity to metyrapone inhibition. Using the selectivity of various MFO inhibitors, the authors concluded that the forms of cytochrome 9450 metabolizing dichloro-p-nitroanisole in uninduced and phenobarbital induced microsomes were different. It would appear then, that the presence of chlorine atoms or the degree of chlorination alters the physio-chemical properties of these anisole in such a way that changes their interactions with various cytochrome $\mathrm{P} 450$ subpopulations.

The finding that PCA was a substrate for cytochrome P450dependent metabolism prompted an investigation of the compound as a potential inducer of the MFO system. Furthermore, since it has been reported that younger animals, in many cases, respond to a greater extent than their adult counterparts (Basu et al., 1971; Klinger et al., 1981) the present investigation attempted to focus on age related differences in induction.

The choice of the miniature pig for this study was based on a number of factors. The minipig is the largest, non-altricious animal giving multiple births. As such it is well suited for perinatal studies, because unlike the rat and most laboratory species, the neonate is mobile minutes after birth. This imparts the ability to wean and raise piglets with minimal effort and handing. Furthermore, the size of the neonate permits easy, direct oral administration of test compounds, thereby avoiding indirect maternal influences.

Although a large number of studies have been conducted on the postnatal development of the hepatic MFO system in various laboratory 
species, similar studies in the miniature pig have not appeared in the literature. Short and Davis (1970) reported that in the domestic Duroc pig, MFO activity rises rapidly and in a linear fashion from birth to approximately four weeks of age. From this point, activity either plateaus or continues to increase at a much reduced rate. Similar patterns have been reported for rabbits, rats and mice (Gram and Fouts, 1966). As seen in Tables 3 and 4, the developmental pattern of MFO in miniature pigs is consistent with those in other laboratory animals. Oxidative metabolism appears to reach maximum at four weeks of age. Furthermore, activities in the one week old piglet range from $65 \%$ to $80 \%$ of activity in eight week old pigs. Although the present investigation did not include newborns, values of 0.14 nmoles/mg protein for cytochrome $\mathrm{P} 450$ and $0.22 \mathrm{nmoles} / \mathrm{min} / \mathrm{mg}$ protein for aniline hydroxylase were obtained from piglets less than 24 hours old in a previous study (Agins, unpublished results). Thus when compared to the respective values in Tables 3 and 4 , it appears that the most rapid rate of development probably occurs between birth and one week of age.

Although early postnatal studies in minipigs are lacking, the results in eight week old pigs were able to be compared to two studies on MFO in Hanford Miniature pigs of similar age. Cytochrome P450 levels and aniline hydroxylase activity compared almost identically to values reported by Freudenthal et al. (1976) and Litterst et al. (1976). Furthermore, as reported in both studies, no sex differences in MFO activity were demonstrated. 
In one week old piglets, PCA produced significant increases in all parameters measured. The greatest increase, a three-fold increase in PCADM, suggests that as with phenobarbital, PCA induces a specific form a cytochrome P450. The smaller increases observed for ANOH and NADM suggest that the induced form of $P 450$ displays over-lapping substrate specificity in agreement with the literature. In this respect, it is generally accepted that some substrates are metabolized most efficiently by one form of cytochrome $\mathrm{P} 450$, yet can also be metabolized by other forms at much lower rates.

Although differing in magnitude, the qualitative nature of PCA's induction is quite similar to that of phenobarbital. In both cases, the greatest effect was seen in PCADM followed by NADM and then ANOH (Table 4). Similarly, PCA increased the microsomal concentration of cytochromes $\mathrm{P} 450$ and $\mathrm{b}_{5}$ and the activity of cytochrome $c$ reductase (Table 5). Interestingly, the increases in the latter two parameters were identical in both phenobarbital and PCA treated pigs. The increase in cytochrome $\mathrm{P} 450$ concentration in phenobarbital treated pigs, however, was much greater than in PCA treated animals. In explaining this apparent disparity (i.e. similar effects of the two compounds on some microsomal components and differences in others) an important issue requires clarification.

The increased concentration of microsomal proteins following treatment may be a result of an increased rate of synthesis, a decreased rate of degradation or a combination of both. In this respect, Kuriyama et a1. (1969) showed that the net increase in cytochrome c reductase following phenobarbital treatment was a 
function of both increased synthesis and decreased degradation. In contrast, the increased concentration of cytochrome $b_{5}$ seen after treatment was only due to a decrease in the rate of decay of this protein. The authors additionally showed that after a short lag, cytochrome $\mathrm{P} 450$ synthesis followed that of reductase.

Thus, it is likely that phenobarbital and PCA produce a true induction of reductase and P450. That differences exist in the magnitude of $\mathrm{P} 450$ induction would suggest that phenobarbital is a more efficient or stronger inducer. In view of the proposed heterogeneity of cytochrome $\mathrm{P} 450$ populations (Lu and West, 1980), however, the greater effect of phenobarbital may be a result of more than one form of cytochrome $\mathrm{P} 450$ induced.

In favor of this assumption, at least two forms of cytochrome P450 have been shown to be induced by phenobarbital in mice (Huang et al., 1976), rats (Bornheim and Franklin, 1982) and more closely related to the present study, pigs (Tsuji et al., 1980). In the latter study, the authors reported that at least two and possibly three forms of $\mathrm{P} 450$ were induced by phenobarbital in adult male pigs.

From the present results, it may be speculated that one form of phenobarbital inducible $\mathrm{P} 450$ may be intimately coupled with cytochrome c reductase (i.e. within the same genetic locus) while additional form(s) are not linked directly with this microsomal protein. Furthermore, the almost identical increases in $\mathrm{P} 450$ and reductase $(33 \%$ and $31 \%$, respectively) produced by $\mathrm{PCA}$, coupled with the qualitative similarities in relation to phenobarbital's effects, suggests that PCA induces one of the phenobarbital inducible forms. 
In addition to the biochemical effects produced by PCA and phenobarbital, morphological changes in hepatic ultrastructure were also comparable. While in the one week old control piglet, the major portion of endoplasmic reticulum is associated with ribosomes (Figures 5 and 6 ), both PCA and phenobarbital produced a substantial proliferation of smooth endoplasmic reticulum (Figures 7 and 8 ), consistent with the documented effect of phenobarbital on this organelle (Fouts and Rogers, 1965).

The effects of PCP are more difficult to explain. A significant increase in the cytochrome $\mathrm{P} 450$ content in one week old piglets is coupled only with a small increase in the activity of nitroanisole demethylase. A number of possibilities exist. Tsuji and coworkers (1980), in addition to demonstrating various phenobarbital forms of P450, reported that ethanol induced a form of $\mathrm{P} 450$ similar to a constitutive form. Furthermore, both forms exhibited the lowest activities toward the three substrates used in their study. In this respect, PCP may induce a similar form of $\mathrm{P} 450$ displaying limited activity towards the substrates used in this study.

A second possibility is that PCP, in view of its known membrane binding effects (Danner and Resnick, 1980), may interfer with the association of newly synthesized $P 450$ within the endoplasmic reticulum, rendering it relatively inactive. Whatever the mechanism, the present results confirm earlier studies which indicated that purified PCP is relatively devoid of hepatic MFO effects (Goldstein et a1., 1977). 
On a morphological basis, PCP did produce an increase in the cellular content of smooth ER (Figure 9). This finding while consistent with a study by Kimbrough and Linder (1975), would not appear to be consistent in view of the correlation between the biochemical and morphological data for PCA and phenobarbital.

Cresteil et al. (1980), however, proposed three effects of exogenous chemicals on endoplasmic reticulum: (1) induction of metabolic activities without proliferation of membranes as produced by polycyclic hydrocarbons, (2) simultaneous induction of enzyme activities and proliferation of membranes as produced by the total sequence of events involving phenobarbital, and (3) proliferation of membranes without apparent enzyme induction as produced by the parahydroxylated metabolite of phenobarbital. Therefore, the possibility exists that PCP produces the latter effect or some combination of the three. Caution should, however, be observed concerning the morphological results since the electron photomicrographs shown in Figures 5 through 9 are representative of only one animal per treatment group.

By eight weeks of age, the inductive effects of PCA were greatly diminished. However, in the absence of a significant increase in cytochrome P450, PCA demethylase activity continues to be significantly greater than controls. Although this would appear to be inconsistent with the necessary requirement for P450, Bornheim and Franklin (1982) warned that compounds might cause subtle changes within the subpopulations of cytochrome $P 450$ not necessarily evidenced by increases in microsomal cytochrome $\mathrm{P} 450$ concentrations. Furthermore, it is likely that synthesis of one form of cytochrome P450 may 
occur at the expense of others (Atlas et al., 1977). Thus, in eight week old pigs the rate of degradation of a constitutive form of $P 450$ may be offset by a similar rate in the synthesis of an inducible form such that the overall concentration of $\mathrm{P} 450$ appears unchanged in PCA treated animals. Furthermore, if the induced form were specific for PCA demethylation it would explain the significant increase observed in this parameter.

In view of the concept of various "isoenzymatic" forms of cytochrome $\mathrm{P} 450$, each differing in substrate specificity, the expression of results in terms of catalytic activities is finding increasing popularity in the literature.

When the specific activities for PCADM, ANOH, and NADM were recalculated to reflect catalytic activities, a number of interesting effects were observed with respect to age and treatment. PCA and phenobarbital increased the catalytic activity of PCA demethylase to the greatest extent. Thus, as suggested earlier, these compounds induce one or more forms of cytochrome $\mathrm{P} 450$ that preferentially catalyze PCA. Phenobarbital also increased the catalytic activity of nitroanisole demethylase, but to a lesser extent than in PCADM. Furthermore, while statistical significance could not be demonstrated, PCA treatment tended to increase catalytic activity for this substrate. These results would suggest that while PCA may be most efficiently metabolized by phenobarbital inducible forms of $\mathrm{P} 450$, nitroanisole is probably metabolized by a combination of constitutive and inducible forms. 
The finding that PCP does not significantly alter catalytic activities in any of the parameters, especially in nitroanisole demethylase where increases were observed in specific activities, lends some support to the suggestion that the compound may induce a constitutive form of $\mathrm{P} 450$.

The most striking effects, upon further examination of catalytic activity results, are the age related changes observed in induced pigs. While the catalytic activities for control animals remained relatively constant from one to eight weeks of age, the effects of PCA and phenobarbital appear to decrease in an age dependent manner. The eight week old values in all three parameters are less than $50 \%$ of the corresponding one week old catalytic activities in phenobarbital treated pigs. This would imply that the inducible, substrate specific form(s) of cytochrome $P 450$ represent a smaller percentage of the total P450 concentration in microsomes of eight week old pigs. This may be the result of either a decrease in the synthesis of a particular form or a diluting effect of increased synthesis of non-specific forms.

In support of this proposal, Thomas and coworkers (1980) reported that the major phenobarbital inducible form of $P 450$ (P450-b) in rats accounted for $70 \%$ of the total $\mathrm{P} 450$ in immature animals, while only $35 \%$ in adult microsomes. Furthermore, a minor form of P450 (P450-a) present in uninduced microsomes, was induced by both phenobarbital and $3-M C$ in immature, but not adult rats.

Since a number of investigations have suggested that biphasic Michaelis-Menten kinetics are indicative of more than one species of 
P450 catalyzing the same reaction (Greenlee and Poland, 1978; Boobis et al., 1981; McCoy, 1980), attempts were made to further investigate the possibility of age dependent changes in the induction of $\mathrm{P} 450$ subpopulations utilizing kinetic experiments. Based on the assumption that sufficiently large differences in affinities toward a particular substrate may enable detection of the activities of different 4450 forms, aniline concentrations were varied over three orders of magnitude. When plotted by the Eadie-Hofstee method, aniline hydroxylase activity could, in fact, be resolved into two kinetic components (Figure 10). While the affinities of the two forms differed by greater than 100-fold, the differences in maximum velocities varied by only three-fold. Furthermore, although the absolute values for the kinetic constants differ slightly, these results are in agreement with those reported by McCoy (1980) for aniline hydroxylase activity in hamster liver microsomes.

By conducting similar kinetic analyses at various ages, a developmental profile was obtained for the two forms of aniline hydroxylase activity (Figure 12). While the high-affinity component (Form I) remained relatively constant during development, the low affinity component (Form II) exhibited a biphasic nature, increasing from 1 to 4 weeks and then again between 8 and 16 weeks of age. Interestingly, between 1 and 4 weeks of age, there is a cross-over in the developmental pattern. Thus, there is an age dependent change in the contribution of the two forms to the total aniline hydroxylase activity. The high-affinity component constitutes $70 \%$ of total 
activity in one week old piglets while the low-affinity component contribute to $75 \%$ in the sixteen week old animal.

Based strictly on the kinetic data from uninduced pigs, it would be impossible to establish the relationships between the two components of aniline hydroxylase and various, well characterized forms of cytochrome P450. The selective induction of only one component of aniline hydroxylase activity by phenobarbital (Table 14), however, provided some basis for comparisons. That the high-affinity component was essentially unaffected by phenobarbital treatment suggested that this form may be cytochrome P448. Indeed, this 3-methylcholanthrene inducible form, synonomous with arylhydrocarbon hydroxylase (AHH), is not induced by phenobarbital. Furthermore, studies with various purified forms of cytochrome P450 (448), isolated from both rat (Ryan et al., 1979) and pig (Tsuji et al., 1980) have shown that aniline is most efficiently metabolized by cytochrome $\mathrm{P} 448$.

In contrast to its lack of effect on the high-affinity component, phenobarbital does increase the low-affinity activity. In comparing the apparent $\mathrm{K}_{\mathrm{m}}$ values observed in uninduced and induced microsomes (Tables 13 and 14), it would appear that phenobarbital's effect was strictly quantitative. In otherwords, phenobarbital induces the synthesis of a constitutive form of cytochrome P450. This, however, is contrary to the overwhelming evidence in the literature that phenobarbital induces forms of cytochrome 8450 distinctly different from the major form in uninduced animals. Therefore, a more tenable explanation is that the phenobarbital induced form is in fact qualitatively different from the constitutive form, but exhibits a similar affinity 
towards aniline. In this respect, Tsuji and coworkers (1980) reported that the major phenobarbital inducible form ( $4450 \mathrm{~B}$ ) purified from pig liver displayed identical catalytic activity as the form isolated from uninduced animals (P450 Cent). The two forms, however, were determined to be uniquely different proteins by a variety of other criteria. Additionally, the authors reported that one minor form of P450 ( 4450 A), induced by phenobarbital, exhibited a two-fold greater catalytic activity towards aniline than the major inducible form.

At this point, it is important to mention that while two aniline hydroxylase activities could be resolved in control and induced animals in this study, the possibility exists that the detection of additional kinetic species may be obscured by the predominance of a low-affinity/high-capacity enzyme or similarities in enzyme affinity towards a particular substrate. Thus, the observed activity of the low-affinity component in phenobarbital induced pigs may be the cumulative activities of more than one form of cytochrome P450. This possibility may help to explain the changes in the magnitude of phenobarbital's effect as a function of age (Table 14). As previously discussed, Thomas and coworkers (1980) described a minor form of cytochrome $\mathrm{P} 450$ ( $\mathrm{P} 450 \mathrm{a}$ ) which was induced by phenobarbital in immature, but not adult rats. If the minor inducible form in pig liver (P450 A) (Tsuji et al., 1980), which was more active towards aniline, is under similar temporal control, it could explain the greater effect of phenobarbital on one week versus older animals. Furthermore, the age-dependent induction of a more highly active form of aniline 
hydroxylase would explain the significant increase in catalytic activity in one week old piglets (Table 11) and the absence of a significant effect in older animals.

In view of the qualitative similarities between PCA and phenobarbital induction, an attempt was made to further characterize the PCA inducible form using similar kinetic analysis. As with phenobarbital, PCA had no effect on the high-affinity component of aniline hydroxylase (Table 15). PCA did however appear to increase the activity of the low-affinity component slightly as well as decrease the apparent $\mathrm{K}_{\mathrm{m}}$. Based on the earlier suggestion that the low-affinity component in phenobarbital induced microsomes probably represents more than one form of P450, it is tempting to speculate that the difference in apparent $\mathrm{K}_{\mathrm{m}}$ 's reflects the induction of only one of these forms by PCA. The proposal by Hultmark et al. (1979) of at least three different forms of cytochrome $\mathrm{P} 450$ active in the demethylation of dichloro-p-nitroanisole in rat 1 iver microsomes prompted an investigation to determine if PCA demethylation could also be resolved into kinetic components. Thus, while the Lineweaver-Burke plots of PCADM (Figure 2) appeared linear, two factors should be considered. First, the substrate concentration range used for these experiments varied by only twenty-fold. Secondly, in these early experiments, acetone was incorporated as a vehicle for PCA. Although the transition to Tween 80 alone, as substrate carrier followed shortly thereafter, it was later learned that acetone produced inhibitory effects similar to ethanol in uninduced microsomes (Hultmark et al., 1979). By widening the substrate concentration range and avoiding organic solvent 
vehicles, PCA demethylase activity did in fact display a biphasic nature (Figure 13). The summary of the kinetic data for the two forms of PCA demethylase as a function of age and treatment (Table 16) provided some interesting correlations with a number of results throughout the entire study.

The close similarity in the apparent $K_{m}$ values for the highaffinity component in uninduced and induced pigs would suggest that the same form of cytochrome $P 450$ exists in both sources. Unlike the high-affinity form of aniline hydroxylase, however, this component is induced by phenobarbital. The small contribution of the high-affinity component to the total phenobarbital induced activity would further indicate that this form is a minor inducible form. Collectively, these assumptions compare favorably with the report by Thomas and coworkers (1980) of an identical form of cytochrome P450 (P450a) present in uninduced, phenobarbital and 3-methylcholanthrene induced rat liver microsomes. In all cases, this form accounted for a small fraction $(3-7 \%)$ of the total cytochrome $\mathrm{P} 450$ concentration.

In contrast to the high-affinity component, the marked differences in the apparent $K_{m}$ values of the low-affinity component would indicate that the induced and uninduced forms of cytochrome $P 450$ are different. Hence, the predominance of the low-affinity component in the total phenobarbital induced PCADM activity would suggest that this form may be the major phenobarbital inducible form described by Tsuji et al. (1980).

The low-affinity component in uninduced microsomes represents, most likely, the P450-control form in pigs (Tsuji et al., 1980). 
Whether this form is similar to the "ethanol sensitive" constitutive form in rats (Hultmark et al., 1979) remains to be determined. It may be worth noting, however, that the kinetic parameters in uninduced adult pigs from earlier experiments (Figure 2) are remarkably similar to those for uninduced adult pigs' high-affinity component (Table 16). Thus, the presence of acetone in the early PCA demethylase assay may have inhibited the expression of the low-affinity constitutive form.

In agreement with the age-dependent changes in the degree of phenobarbital's effect on aniline hydroxylase activity, a similar phenomenon was observed for PCA demethylase. The magnitude of phenobarbital's effect on the low affinity component of PCADM remains relatively constant with age. However, since the constitutive and phenobarbital inducible forms of $P 450$ responsible for the low-affinity activity are probably different, these results may be misleading. Although uninduced microsomes may contain a small amount of the phenobarbital inducible form of P450 (Thomas et al., 1980; Tsuji et al., 1980), kinetic analysis was not able to separate out the contribution of the component in uninduced pigs. Therefore, the magnitude of phenobarbital's effect is most likely underestimated. For the same reasons above, age-dependent changes in the inducibility of this particular form would not be detectable.

In contrast, the high-affinity component does undergo age related changes in the degree of induction. The increase in activity over basal level in eight week old pigs is approximately $50 \%$ of the effect observed in one week old animals. This effect is consistent with that 
seen in aniline hydroxylase activity where a similar $50 \%$ decrease in the inducibility of the low-affinity component was observed between one and eight weeks of age.

In summary, based on the biphasic kinetic characteristics of two substrates, as a function of age and treatment, it would appear that at least four forms of cytochrome $\mathrm{P} 450$ exist in hepatic microsomes of miniature pig. They are: (1) the high-affinity component of aniline hydroxylase, present in uninduced and induced microsomes, but not altered by phenobarbital or PCA induction, (2) the low-affinity components of aniline hydroxylase and PCA demethylase in uninduced microsomes, (3) the high-affinity component of PCA demethylase, which displays age dependency in phenobarbital induction and most likely contributes to the phenobarbital induced, low-affinity activity of aniline hydroxylase. Furthermore, this is probably the form induced by PCA, and (4) the low-affinity components of PCA demethylase and aniline hydroxylase in phenobarbital induced microsomes.

The mechanism(s) by which temporal alterations are manifested in the induction of specific cytochrome $P 450$ subpopulations are presently not known. However, in view of the intimate relationship between endogenous substances, particularly steroid hormones, and the mixedfunction monooxygenase system, it is quite possible that these agents may play a role in cellular regulation of $\mathrm{P} 450$ subtypes. 


\section{CONCLUSIONS}

(1) Pentachloroanisole is metabolized in vitro to pentachlorophenol by hepatic microsomes from miniature pigs. The requirement for NADPH, inhibition by carbon monoxide, and production of a substrate binding spectrum indicate that the compound is catalyzed via a cytochrome $\mathrm{P} 450-$ dependent demethylation reaction.

(2) The relatively large increase in the rate of PCA demethylation following phenobarbital induction strongly suggests that PCA is preferentially catalyzed by a phenobarbital inducible form(s) of cytochrome P450. The very low levels of activity, coupled with the inability to detect a substrate binding spectrum in uninduced microsomes suggests that the substrate-specific form of $\mathrm{P} 450$ is absent or present in very low concentration in uninduced microsomes.

(3) The postnatal developmental pattern of hepatic mixedfunction monooxygenase activity in miniature pigs is similar to that in other laboratory species. In most parameters measured, an increase between one and four weeks of age is followed by a plateau to eight weeks of age. The additional rise in activity for aniline hydroxylase and PCA demethylase between eight and sixteen weeks of age, observed in kinetic experiments, may be associated with the attainment of sexual maturity in miniature pigs. 
(4) Pentachloroanisole treatment produced increases in all MFO parameters measured in one week old minipigs. The qualitative nature of PCA's induction is similar to that of phenobarbital. The greatest effect, a three-fold increase in its own metabolism, suggests that the compound induces a specific form of cytochrome P450, similar to that induced by phenobarbital.

(5) Pentachlorophenol treatment produced increases in some, but not all MFO parameters in one week old piglets. The overall qualitative differences produced by PCA and PCP suggests that the two compounds induce different species of cytochrome $\mathrm{P} 450$ which exhibit overlapping substrate specificity in some cases.

(6) The proliferation of smooth endoplasmic reticulum observed following treatment with all three compounds indicates that the magnitude of the biochemical effects in MFO induction does not necessarily correlate with alterations in the cellular content of this organelle.

(7) The age related decrease in catalytic activities observed in phenobarbital and PCA treated pigs is suggestive of changes in the relative contribution of different subpopulations of cytochrome P450 to the observed overall specific activity. The almost identical decreases in PCA demethylase, aniline hydroxylase and nitroanisole demethylase catalytic activities between one and eight weeks of age suggests that the contribution of a particular form of $\mathrm{P} 450$, active to varying degrees on all three substrates, decreases with development. 
(8) The biphasic kinetic profiles observed for aniline hydroxylase and PCA demethylase activities indicates that multiple forms of cytochrome 9450 are active in the metabolism of both substrates. By integrating the effects of age and phenobarbital treatment on the various kinetic species, it is suggested that at least four forms of cytochrome 4450 exist in miniature pig microsomes. The inducibility of at least one form by phenobarbital appears to decrease with age and the magnitude of this change correlates well with the effects seen in catalytic activity profiles. 


\section{REFERENCES}

Agins, A.P., Peggins, J.O., Garthoff, L.H. and Khan, M.A.: Metabolism of pentachloroanisole by hepatic microsomal cytochrome 8450 in rats and miniature swine. Fed. Proc. 41: 1054, 1982.

Ahlborg, W.G., Larsson, K. and Thunberg, T.: Metabolism of pentachlorophenol in vivo and in vitro. Arch. Toxicol. 40: 45-53, 1978.

Ahlborg, W.G. and Thunberg, T.: Chlorinated phenols; occurrence, toxicity, metabolism and environmental impact. CRC Critical Reviews in Toxicology 7: 1-35, 1980.

Alvares, A.P., Bickers, D.R. and Kappas, A.: Polychlorinated biphenyls; a new type of inducer of cytochrome $P 448$ in the liver. Proc. Nat. Acad. Sci. 70: 1321-1325, 1973.

Alvares, A.P., Schilling, G., Levin, W. and Kuntzman, R.: Studies on the induction of $\mathrm{CO}$-binding pigments in liver microsomes by phenobarbital and 3-methylcholanthrene. Biochem. Biophys. Res. Comm. 29: $521-526,1967$.

Arrheniuus, E., Renberg, L., Johansson, L. and Zetterquist, M.: Disturbance of microsomal detoxification mechanisms in liver by chlorophenol pesticides. Chem.-Biol. Interact. 18: 35-46, 1977.

Atlas, S.A., Boobis, A.R., Feltob, J.S., Thorgeursson, S.S. and Nebert, D.W.: Ontogenetic expression of polycyclic aromatic compound inducible monooxygenase activities and forms of cytochrome $\mathrm{P}-450$ in rabbit. J. Biol. Chem. 252: 4712-4721, 1977.

Axelrod, J.: The enzymatic N-demethylation of narcotic drugs. J. Pharmacol. Exp. Ther. 117: 322-330, 1956.

Basu, T.K., Dickerson, J. and Parke, D.: Effect of development on the activity of microsomal drug metabolizing enzymes in rat liver. Biochem. J. 124: 19-24, 1971.

Bevenue, A. and Beckman, H.: Pentachlorophenol. A discussion of its properties and its occurrence as a residue in human and animal tissue. Residue Rev. 19: 83-134, 1967.

Boobis, A.R., Kahn, G.C., White, C., Brodie, M.J. and Davies, D.S.: Biphasic O-deethylation of phenacitin and 7-ethoxycoumarin by human and rat liver microsomal fractions. Biochem. Pharmacol. 30: 2451-2456, 1981 . 
Book, S.A. and Bustard, L.K.: The fetal and neonatal pig in biomedical research. J. Anim. Sci. 38: 997-1002, 1974.

Bornheim, L.M. and Franklin, M.R.: Metabolic-intermediate complex formation reveals major changes in rat hepatic cytochrome $\mathrm{P}-450$ subpopulations in addition to those forms previously purified after phenobarbital, B-Naphthoflavone and isosafrole induction. Mol. Pharmacol. 21: 527-532, 1982 .

Brodie, B.B., Axelrod, J., Cooper, J.R., Gaudette, L., LaDu, B.N., Mitoma, C. and Udenfriend, S.: Detoxification of drugs and other foreign compounds by liver microsomes. Science 121: 603-604, 1955.

Brodie, B.B., Gillette, J.R. and LaDu, B.N.: Enzymatic metabolism of drugs and other foreign compounds. Ann. Rev. Biochem. 27: 427-454, 1958.

Burke, M.D., Prough, R.A. and Mayer, R.T.: Characteristics of a microsomal P448-mediated reaction; ethoxyresorufin 0-deethylase. Drug Metab. Disp. 5: 1-8, 1977.

Carlson, G.P.: Effect of trichlorophenols on xenobiotic metabolism in the rat. Toxicology 11: 145-151, 1978.

Cinti, D.L.: Agents activating the liver microsomal mixed function oxidase system. Pharmacol. Ther. A. 2: 727-749, 1978.

Collman, J.P. and Sorrell, T.N.: A model for the carbonyl adduct of ferrous cytochrome P450. J. Amer. Chem. Soc. 97: 4133-4134, 1975.

Conney, A.H.: Pharmacological implication of microsomal enzyme induction. Pharmacol. Rev. 19: 317-366, 1967.

Conney, A.H., Davison, C., Gastel, R. and Burns, J.J.: Adaptive increases in drug metabolizing enzymes induced by phenobarbital and other drugs. J. Pharmacol. Exp. Ther. 130: 1-8, 1960.

Conney, A.H., Levin, W., Jacobson, M., Kuntzman, R., Cooper, D.Y. and Rosenthal, 0.: Specificity in the regulation of the 6-, 7- and 16-hydroxylation of testosterone by rat liver microsomes. Microsomes and Drug Oxidations, ed. J.R. Gillette, A.H. Conney, G.J. Cosmides, R.W. Estabrook, J.R. Fouts and G.J. Mannering, pp. 279-295, Academic Press, New York, 1969.

Conney, A.H., Miller, E.C. and Miller, J.A.: The metabolism of methylated aminoazo dyes; evidence for induction of enzyme synthesis in the rat by 3-methylcholanthrene. Cancer Res. 16: 450-459, 1956.

Coon, M.J.: Drug metabolism by cytochrome P450; progress and perspectives. Drug Metab. Disp. $\underline{9}: 1-4,1981$. 
Cooper, D.Y., Levin, S., Narashimhulu, S., Rosenthal, O. and Estabrook, R.W.: Photochemical action spectrum of the terminal oxidase of mixedfunction oxidase systems. Science 147: 400-402, 1965.

Cresteil, Th., Flinois, J.P., Pfister, A. and Letoux, J.P.: Effect of microsomal preparations and induction on cytochrome P-450-monooxygenases in fetal and neonatal rat liver. Biochem. Pharmacol. 28: $2057-2063,1979$.

Cresteil, Th., Mahu, J.L., Dansette, P.M. and Leroux, J.P.: In vivo administration of hydroxylated phenobarbital metabolites; effects on rat hepatic cytochromes P450, Epoxide Hydrolase and UDP-glucuronosyltransferase. Biochem. Pharmacol. 29: 1127-1133, 1980.

Czerjesi, A.J. and Johnson, E.L.: Methylation of pentachlorophenol by Trichoderma vergatum. Can. J. Microbiol. 18: 45-49, 1972.

Curtis, R.F., Dennis, C., Gee, J.M., Gee, M.G., Griffiths, N.M., Land, D.G., Peel, J.L. and Robinson, D.: Chloroanisoles as a cause of musty taint in chickens and their microbiological formation from chlorophenols in broiler house litters. J. Sci. Food Agric. 25; $811-815,1974$.

Curtis, R.F., Land, D.G., Griffith, N.M., Gee, M., Peel, J.L., Dennis, C. and Gee, J.M.: 2,3,4,6-Tetrachloroanisole association with musty taint in chicken and microbiological formation. Nature (London) 235: $223-224,1972$.

Danner, J. and Resnick, H.: Use of the fluorescent probe 1-anilino-8naphthalene sulfonate to monitor the interactions of chlorophenols with phospholipid membranes (1iposomes). Biochem. Pharmacol. 29: 2471-2475, 1980 .

Dolphin, D., James, B.R. and Welborn, H.C.: Proton activities for three states of cytochrome $\mathrm{P}^{450} \mathrm{Cam}$. Biochem. Biophys. Res. Comm. 88: $415-421,1979$.

Earl, F.L., Tegeris, A.S., Whitmore, G.E., Morisom, R. and Fitzhugh, O.G.: The use of swine in drug toxicity studies. Ann. N.Y. Acad. Sci. $111: 671-688,1964$.

Elshourbagy, N.A. and Guzelian, P.S.: Separation, purification and characterization of a novel form of hepatic cytochrome $\mathrm{P} 450$ from rats treated with pregnenolone-16a-carbonitrile. J. Biol. Chem. 255: $1279-1285,1980$.

England, D.C., Winter, L.M. and Carpenter, L.E.: The development of a breed of miniature swine: a preliminary report. Growth 18: 207-214, 1954. 
Enoch, H.G. and Strittmatter, P.: Cytochrome b reduction by NADPHcytochrome P450 reductase. J. Biol. Chem. 254: 8976-8981, 1979.

Estabrook, R.W. and Cohen, B.: Organization of the microsomal electron transport system. Microsomes and Drug Oxidations, ed. J.R. Gillette, A.H. Conney, G.J. Cosmides, R.W. Estabrook, J.R. Fouts and G.J. Mannering, Academic Press, New York, 1969.

Estabrook, R.W., Cooper, D.Y. and Rosentha1, O.: The light reversible carbon monoxide inhibition of the steroid C2l-hydroxylase system of the adrenal cortex. Biochem. Z. 338: 741-755, 1963.

Estabrook, R.W. and Werringloer, J.: The measurement of difference spectra; application to the cytochromes of microsomes. Methods in Enzymology, Vol. 52, ed. S. Fleisher and L. Packer, pp. 212-220, Academic Press, New York, 1978.

Firestone, D., Clower, M., Jr., Borsetti, A.A., Teske, R.H. and Long, P.E.: Polychloro-dibenzo-p-dioxin and pentachlorophenol residues in milk and blood of cows fed technical pentachlorophenol. J. Agr. Food Chem. 27: 1171-1177, 1979.

Fouts, J.R. and Adamson, R.H.: Drug metabolism in the newborn rabbit. Science 129: 897, 1959.

Fouts, J.R. and Rogers, L.A.: Morphological changes in the liver accompanying stimulation of microsomal drug metabolizing enzyme activity by phenobarbital, chlordane, benzpyrene or methylcholanthrene in rats. J. Pharmacol. Exp. Ther. 147: 112-119, 1965.

Freudenthal, R.I., Leber, P., Emmerling, D., Kerchner, G. and Campbell, D.: Characterization of the hepatic microsomal mixed-function oxidase enzyme system in miniature pigs. Drug Metab. Disp. 4: 25-27, 1976.

Garkinkel, D.: Studies on pig liver microsomes; enzymatic and pigment composition of different microsomal fractions. Arch. Biochem. Biophys. $77: 493-509,1958$.

Gelboin, H.V.: Studies on the mechanism of methylcholanthrene induction of enzyme activities; stimulation of microsomal and ribosomal amino acid incorporation: the effects of polyuridylic acid and actinomycin D. Biochem. Biophys. Acta 91: 130-144, 1964.

Gigon, P.L., Gram, T.E. and Gillette, J.R.: Studies on the rate of reduction of hepatic microsomal $P 450$ by reduced nicotinamide adenine dinucleotide phosphate. Mol. Pharmacol. 5: 109-122, 1969.

Glickman, A.H., Statham, C.N., Wu, A. and Lech, J.J.: Studies on the uptake, metabolism and distribution of pentachlorophenol and pentachloroanisole in rainbow trout. Toxicol. Appl. Pharmacol. 41: 649-658, 1977. 
Goldstein, J.A., Freisen, M., Linder, R.E., Hickman, P., Hass, J.R. and Bergman, H.: Effects of pentachlorophenol on hepatic drug metabolizing enzymes and porphyria related to contamination with chlorinated dibenzo-p-dioxins and dibenzufurans. Biochem. Pharmacol. 26: $1549-1557,1977$.

Gram, T.E. and Fouts, J.R.: Time course differences in the metabolism of drugs by hepatic microsomes from rats, rabbits, and mice. J. Pharmacol. Exp. Ther. 152: 363-371, 1966.

Grasdalen, H., Backstrom, D., Eriksson, L.E.G., Ehrenberg, A., Moldeus, P., Von Bahr, C. and Orrenius, S.: Heterogeneity of cytochrome $\mathrm{P} 450$ in rat liver microsomes; selective interaction of metyrapone and SKF 525A with different fractions of microsomal cytochrome P450. Febs. Letters 60: 294-299, 1975.

Greenlee, W.F. and Poland, A.: An improved assay of 7-ethoxycoumarin O-deethylase activity; induction of hepatic enzyme activity in C57BL/6J and DBA/2J mice by phenobarbital, 3-methylcholanthrene and 2,3,7,8-tetrachlorodibenzo-p-dioxin. J. Pharmacol. Exp. Ther. 205: $596-605,1978$.

Guenthner, T.M. and Mannering, G.J.: Induction of hepatic monooxygenase systems in fetal and neonatal rats with phenobarbital, polycyclic hydrocarbons and other xenobiotics. Biochem. Pharmacol. 26: 567-575, 1977.

Hayaishi, 0.: Oxygenases (0. Hayaishi, ed.), Academic Press, New York, 1962 .

Hernandez, P.H., Gillette, J.R. and Mazel, P.: Studies on the mechanism of action of mammalian hepatic azoreductase; Asoreductase activity of reduced nicotinamide adenine dinucleotide phosphate-cytochrome $c$ reductase. Biochem. Pharmacol. 16: 1859-1875, 1967.

Hodgson, E. and Dauterman, W.C.: Metabolism of Toxicants; phase I reaction. Introduction to Biochemical Toxicology, ed. E. Hodgson and F.R. Guthrie, Elsevier North Holland, Inc., New York, 1980.

Holloway, O.W. and Wakil, S.J.: Requirement for reduced diphosphopyridine nucleotide cytochrome $b_{5}$ reductase in stearyl coenzyme $A$ desaturation. J. Biol. Chem. 245: 1862-1865, 1970.

Horecker, B.L.: Triphosphopyridine nucleotide-cytochrome c reductase in liver. J. Biol. Chem. 183: 593-605, 1950.

Huang, M.T., West, S.B. and Lu, A.Y.H.: Separation, purification and properties of multiple forms of cytochrome $P 450$ from the liver of phenobarbital-treated mice. J. Biol. Chem. 251: 4659-4665, 1976. 
Hultmark, D., Sundh, K., Johnsson, L. and Arrhenius, E.: Dichloro-pnitroanisol 0-demethylase; evidence for separate ethanol inhibited and phenobartibal-inducible enzymes. Biochem. Pharmacol . 28: 1587$1590,1979$.

Imai, Y.: Reconstituted O-dealkylase systems containing various forms of liver microsomal cytochrome P-450. J. Biochem. 86: 1697-1707, 1979.

Imai, Y., Ito, A. and Sato, R.: Evidence for biochemically different types of vesicles in the hepatic microsomal fraction. J. Biochem. 60: 417-428, 1966.

Imai, Y. and Sato, R.: The roles of cytochrome $b_{5}$ in a reconstituted N-demethylase system containing cytochrome P-450. Biochem. Biophys. Res. Comm. 75: 420-426, 1977.

Jefcoate, C.R.: Measurement of substrate and inhibitor binding to microsomal cytochrome $\mathrm{P} 450$ by optical-difference spectroscopy. Methods in Enzymology, Vol. 52, ed. S. Fleisher and L. Packer, pp. 258-279, 1978.

Jondorf, W.R., Maickel, R.P. and Brodie, B.B.: Inability of newborn mice and guinea pigs to metabolize drugs. Biochem. Pharmacol. 1: 352-354, 1959.

Jonen, H.G., Huthwohl, B., Kahl, R. and Kahl, G.F.: Influence of pyridine and some pyridine derivatives on spectral properties of reduced microsomes and on microsomal drug metabolizing activity. Biochem. Pharmacol. 23: 1319-1329, 1974.

Kahl, G.F., Freiderici, D., Bigelow, S.W., Odey, A.B. and Nebert, D.W.: Ontogenetic expression of regulatory and structural gene products associated with the Ah locus; comparison of rat, mouse, rabbit and Sigmoden hispedis, Dev. Pharmacol. Ther. 1: 137-162, 1980.

Kato, R., Loeb, L. and Gelboin, H.V.: Microsome specific stimulation by phenobarbital of amino acid incorporation in vivo. Biochem. Pharmacol. 14: 1164-1166, 1965.

Kaufman, D.D.: Degradation of pentachlorophenol in soil and by soil microorganisms. in Pentachlorophenol, Environmental Science Research Series, Vol. 12, K.R. Rao, ed. Plenum Press, New York, pp. 27-39, 1978.

Kimbrough, R.D.: Toxicity of chlorinated hydrocarbons and related compounds. Arch. Envir. Hlth. 25; 125-131, 1972.

Kimbrough, R.D. and Lindner, R.E.: The effect of technical and $99 \%$ pure pentachlorophenol on the rat liver; Light microscopy and ultrastructure. Toxicol. App 1. Pharmacol. 33: 131-132, 1975. 
Klingenberg, M.: Pigments of rat liver microsomes. Arch. Biochem. Biophys. 75: 376-386, 1958 .

Klinger, W., Muller, D., Kleeberg, U. and Barth, A.: Peri- and postnatal development of phase I reaction. Developmental Toxicology, ed. C.A. Kimmell and J. Buelke-Sam, Raven Press, New York, 1981.

Knudsen, I., Verschuuren, H.G., Tonkelaar, E., Kroes, R. and Helleman, P.F.W.: Short term toxicity of pentachlorophenol in rats. Toxicology 2: $141-152,1974$.

Kotake, A.N.: Direct measurement of aminopyrine N-demethylase and antipyrene hydroxylase activities in a monolayer rat primary isolated hepatocyte system. Biochem. Pharmacol. 30: 2473-2479, 1981.

Kuehl, D.W., Veith, G. and Leonard, E.: Brominated compounds found in waste water treatment effluents and their capacity to bioaccumulate. In Water Chlorination, ed. Jolley, Gorchev and Hamilton, Ann Arbor Science, Ann Arbor, Michigan, 1978.

Kuenzig, W., Kamm, J.J., Boublik, M. and Burns, J.J.: The effects of phenobarbital on the microsomal mixed-function oxidase system and hepatic ultra-structure in the perinatal guinea pig. Basic and Therapeutic Aspects of Perinatal Pharmacology, ed. P.L. Morselli, S. Garattini and F. Sereni, Raven Press, New York, 1975.

Kuntzman, R., Levin, W., Schilling, G. and Alvares, A.: The effects of 3-methylcholanthrene and phenobarbital on liver microsomal hemoproteins and on the hydroxylation of benzypyrene. Microsomes and Drug Oxidations, ed. J.R. Gillette, A.H. Conney, G.J. Cosmides, R.W. Estabrook, J.R. Fouts, and G.J. Mannering, pp. 349-370, Academic Press, New York, 1969.

Kuriyama, Y., Omura, T., Siekevitz, P. and Palade, G.R.: Effect of phenobarbital on the synthesis and degradation of the protein components of rat liver microsomal membranes. J. Biol. Chem. 244: 20172026, 1969.

Lipscomb, J.D. and Gunsalus, I.C.: Structural aspects of the active site of cytochrome ${ }^{450}{ }_{\mathrm{cam}}$. Drug Metab. Disp. 1: 1-5, 1973.

Litterst, C.L., Gram, T.E., Leber, M.P., Emmerling, D. and Freudenthal, R.I.: A comprehensive study of in vitro drug metabolism in several laboratory species. Drug Metab. Disp. 4: 203-207, 1976.

Lowry, O.H., Rosebrough, N.H., Farr, A.L. and Randal1, R.J.: Protein measurement with the folin phenol reagent. J. Biol. Chem. 193: 265-272, 1951 . 
Lu, A.Y.H. and Coon, M.J.: Role of hemeprotein P450 in fatty acid whydroxylation in a soluble enzyme system from liver microsomes. J. Biol. Chem. 243: 1331-1332, 1968.

Lu, A.Y.H., Levin, W., Selander, H. and Jerina, D.M.: Liver microsomal electron transport systems; the involvement of cytochrome $b_{5}$ in the NADPH-supported cytochrome P-450-dependent hydroxylation of chlorobenzene. Biochem. Biophys. Res. Comm. 61: 1348-1355, 1974.

Lu, A.Y.H. and West, S.B.: Multiplicity of mammalian microsomal cytochromes P450. Pharmacol. Rev. 31: 277-295, 1980.

Lucier, G.W., Sonawane, B.R., McDaniel, O.S. and Hook, G.E.R.: Postnatal stimulation of hepatic microsomal enzymes following administration of TCDD to pregnant rats. Chem.-Biol. Interact. 11: 15-26, 1975.

Mailman, R.B., Kulkarni, A.P., Baker, R.C. and Hodgson, E.: Cytochrome P450 difference spectra; effect of chemical structure on type II spectra in mouse hepatic microsomes. Drug Metab. Disp. 2: 301-308, 1974.

Marshall, W.J. and McClean, A.E.M.: A requirement for dietary lipids for induction of cytochrome $\mathrm{P} 450$ by phenobarbitone in rat liver microsomal fraction. Biochem. J. 122: 569-573, 1971.

Mason, H.W.: Mechanisms of oxygen metabolism. Science 125: 1185-1188, 1957.

Mazel, P.: Experiments illustrating drug metabolism in vitro. Fundamentals of Drug Metabolism and Drug Disposition, ed. B.N. LaDu, H.G. Mandel, E.L. Way, pp. 546-582, Williams and Wilkins, Baltimore, 1969.

Mannering, G.J.: Significance of stimulation and inhibition of drug metabolism. Selected Pharmacological Testing Methods, ed. A. Burger, pp. 5l-119, Marcel Dekker, New York, 1968.

McCoy, G.D.: Differential effects of ethanol and other inducers of drug metabolism on the two forms of hamster liver microsomal aniline hydroxylase. Biochem. Pharmacol. 29: 285-288, 1980.

Miyazaki, T., Kaneko, S., Horii, S. and Yamagishi, T.: Identification of polyhalogenated anisoles and phenols in oysters collected from Tokyo Bay. Bull. Environm. Contam. Toxicol. 26: 577-584, 1981.

Mueller, G.C. and Miller, J.A.: The reductive cleavage of 4-dimethylaminoazobenzene by rat liver; the intracellular distribution of the enzyme system and its requirement for triphosphopyridine nucleotide. J. Biol. Chem. 180: 1125-1136, 1949. 
Nash, T.: The colorimetric estimation of formaldehyde by means of the Hantzsch reaction. Biochem. J. 55: 416-421, 1953.

Nebert, D.W., Eisen, H.J., Negishi, M., Lang, M.A., Hjelmeland, L.M. and Okey, A.B.: Genetic mechanisms controlling the induction of polysubstrate monooxygenase (P-450) activities. Ann. Rev. Pharmacol. Toxicol. 21: 431-462, 1981 .

Nebert, D.W. and Gelboin, H.V.: Drugs and microsomal enzyme formation in vivo and in mammalian cell culture. Microsomes and Drug Oxidations, ed. J.R. Gillette, A.H. Conney, G.J. Cosmides, R.W. Estabrook, J.R. Fouts and G.J. Mannering, Academic Press, New York, pp. 389-430, 1969.

Nebert, D.W., Negishi, M., Lang, M.A., Hjelmeland, L.M. and Eisen, H.J.: The Ah locus, a multigene family necessary for survival in a chemically adverse environment; comparison with the immune system. Adv. in Genetics 21: 1-52, 1982 .

Neims, A.H., Warner, M., Langhnan, P.M. and Aranda, J.V.: Developmental aspects of the hepatic cytochrome P-450 monooxygenase system. Ann. Rev. Pharmacol. 16: 427-445, 1976.

Netter, K.J. and Seidel, G.: An adaptively stimulated O-demethylating system in rat liver microsomes and its kinetic properties. J. Pharmacol. Exp. Ther. 146: 61-65, 1964.

Omura, T. and Sato, R.: The carbon monoxide-binding pigment of liver microsomes; Evidence for its hemoprotein nature. J. Biol. Chem. 239: $2370-2378,1964$.

Oprian, D.D., Vatsis, K.P. and Coon, M.J.: Kinetics of reduction of cytochrome $\mathrm{P}^{-450 \mathrm{LM}_{4}}$ in a reconstituted liver microsomal enzyme system. J. Biol. Chem. 254: 8895-8902, 1979.

Orrenius, S. and Ericcson, J.L.E.: Enzyme-membrane relationship in phenobarbital induction of synthesis of drug metabolizing enzyme system and proliferation of endoplasmic membranes. J. Cell Biol. 28: $181-198,1966$.

Pederson, T.C., Buege, J.A. and Aust, S.D.: The role of reduced nicotinamide dinucleotide phosphate-cytochrome-c-reductase in liver microsomal lipid peroxidation. J. Biol. Chem. 248: 7134-7141, 1973.

Phillips, A.H. and Langdon, R.G.: Hepatic triphosphopyridine nucleotide-cytochrome C reductase; isolation, characterization, and kinetic studies. J. Biol. Chem. 237: 2652-2660, 1962.

Poland, A. and Glover, E.: Comparison of 2,3,7,8-tetrachlorodibenzo-pdioxin, a potent inducer of aryl hydrocarbon hydroxylase with 3methylcholanthrene. Mol. Pharmacol. 10: 349-359, 1974. 
Poland, A. and Glover, E.: Stereospecific, high affinity binding of 2,3,7,8-tetrachlorobenzo-p-dioxin by hepatic cytosol. J. Biol. Chem. 251: 4936-4946, 1976.

Pond, W.G. and Houpt, K.A. (ed.): The Biology of the Pig, Cornell University Press, Ithica, 1978.

Posner, H.S., Mitoma, C., Rothberg, S. and Udenfriend, S.: Enzymatic hydroxylation of aromatic compounds; Studies on the mechanism of microsomal hydroxylation. Arch. Biochem. Biophys. 94: 280-290, 1961 .

Prasad, M.R. and Joshi, V.C.: Regulation of rat hepatic stearoyl coenzyme A desaturase. J. Biol. Chem. 254: 997-999, 1979.

Rein, H., Maricic, S., Janig, G., Vuk Pavlovid, S., Benko, B., Ristau, 0 . and Ruckpaul, K.: Haem accessibility in cytochrome P450 from rabbit liver. A proton magnetic relaxation study by stereochemical probes. Biochem. Biophys. Acta. 446: 325-330, 1976.

Remmer, H., Schenkman, J. and Estabrook, R.W.: Drug interaction with hepatic microsomal cytochrome. Mol. Pharmacol. 2: 187-190, 1966.

Ryan, D.E., Thomas, P.E., Korseniowski, D. and Levin, W.: Separation and characterization of highly purified forms of liver microsomal P450 from rats treated with polychlorinated biphenyls, phenobarbital, and 3-methylcholanthrene. J. Biol. Chem. 254: 1365-1374, 1979.

Ryan, D.E., Thomas, P.E. and Levin, W.: Properties of liver microsomal cytochrome $\mathrm{P} 450$ from rats treated with isosafrole. Microsomes, Drug Oxidations, and Chemical Carcinogenesis, Vol. 1, ed. M.J. Coon, A.H. Conney, R.W. Estabrook, H.V. Gelboin, J.R. Gillette and P.J. O'Brien, Academic Press, New York, 1980.

Schenkman, J., Remmer, H. and Estabrook, R.W.: Spectral studies of drug interaction with hepatic microsomal cytochrome. Mol. Pharmacol. 3: $113-123,1967$.

Schubert, I. and Netter, K.J.: Evidence for endogenous triggering of perinatal inducibility of hepatic monooxygenase. Biochem. Pharmacol. 30: 2901-2906, 1981 .

Schwetz, B.A., Quast, J.F., Keeler, P.A., Humiston, C.G. and Kociba, R.J.: Results of a two year toxicity and reproduction studies on pentachlorophenol in rats. In Phentachlorophenol, Environmental Science Research Series, Vol. 12, pp. 301-309, K.R. Rao, ed., Plenum Press, New York, 1978.

Segel, I.H.: Enzyme Kinetics: Behavior and Analysis of Rapid Equilibrium and Steady-State Enzyme Systems, John Wiley \& Sons, New York, 1975. 
Shiverick, K.T. and Neims, A.H.: Multiplicity of testosterone hydroxylases in a reconstituted hepatic cytochrome $P 450$ system from uninduced male rats. Drug Metab. Dispos. 7: 290-295, 1979.

Short, C.R. and Davis, L.E.: Perinatal development of drug-metabolizing enzyme activity in swine. J. Pharmacol. Exp. Ther. 174: 185-196, 1970.

Short, C.R., Kinden, D.A. and Stith, R.: Fetal and neonatal development of the microsomal monooxygenase system. Drug Metab. Rev. 5: $1-42,1976$.

Short, C.R. and Stith, R.D.: Perinatal development of hepatic microsomal mixed function oxidase activity in swine. Biochem. Pharmacol. 22: $1309-1319,1973$.

Sih, C.J.: Enzymatic mechanism of steroid hydroxylation. Science 163: 1297-1300, 1969.

Sladek, N.E. and Mannering, G.J.: Induction of drug metabolism qualitative differences in the microsomal N-demethylating systems stimulated by polycyclic hydrocarbons and by phenobarbital. Mol. Pharmacol. 5: $186-199,1969$.

Sligar, S.G., Cinni, D.L., Gibson, G.C. and Schenkman, J.B.: Spin state control of the hepatic cytochrome 4450 redox potential. Biochem. Biophys. Res. Comm. 90: 925-932, 1979.

Soyka, L.F. and Long, F.J.: In vitro inhibition of drug metabolism by metabolites of progesterone. J. Pharm. Exp. Ther. 182: 320-325, 1972.

Stonard, M.D. and Greig, J.B.: Different patterns of hepatic microsomal activity produced by administration of pure hexachlorobiphenyl isomers and hexachlorobenzene. Chem.-Biol. Interact. 15: 365-379, 1976.

Strittmatter, P. and Velick, S.F.: A microsomal cytochrome reductase specific for diphosphopyridine nucleotide. J. Biol. Chem. 221: 277$286,1956 \mathrm{~b}$.

Strittmatter, P. and Velick, S.F.: The isolation and properties of microsomal cytochrome. J. Biol. Chem. 221: 253-264, 1956a.

Strobel, H.W. and Digman, J.D.: Purification and properties of NADPHcytochrome $\mathrm{P} 450$ reductase. Methods in Enzymology, Vol. 52, ed. S. Fleischer and L. Packer, pp. 89-96, 1978.

Sugiyama, T., Miki, N. and Yamano, T.: The obligatory requirement of cytochrome $b_{5}$ in the p-nitroanisol 0-demethylation reaction catalyzed by cytochrome $P 450$ with a high affinity for cytochrome $b_{5}$. Biochem. Biophys. Res. Comm. 90: 715-720, 1979. 
Testa, B. and Jenner, P.: Inhibitors of cytochrome P450s and their mechanism of action. Drug Metab. Rev. 12: 1-117, 1981.

Thomas, P.E., Ryan, D.E. and Levin, W.: Immunochemical quantitation of three forms of hepatic cytochrome $\mathrm{P} 450$ in rats; effects of age and induction. Microsomes, Drug Oxidations, and Chemical Carcinogenesis, Vol. 1, ed. M.J. Coon, A.H. Conney, R.W. Estabrook, H.V. Gelboin, J.R. Gillette and P.J. O'Brien, Academic Press, New York, 1980.

Tsuji, H., Muta, E. and Ullrich, V.: Separation and purification of liver microsomal monooxygenases from induced and untreated pigs. Hoppe-Seyler's S. Physiol. Chem. 361: 681-696, 1980.

Vermilion, J.L. and Coon, M.J.: Identification of the high and low potential flavins of liver microsomal NADPH-cytochrome P450 reductase. J. Biol. Chem. 253: 8812-8819, 1978.

Vodicnik, M.J., Glickman, A.H., Rickert, D.E. and Lech, J.J.: Studies on the disposition and metabolism of pentachloroanisole in female mice. Toxicol. Appl. Pharmacol. 56: 311-316, 1980.

Weinbach, E.C.: The effect of pentachlorophenol on oxidative phosphorylation. J. Biol. Chem. 210: 545-550, 1954.

White, R.E. and Coon, M.J.: Oxygen activation by cytochrome P450. Ann. Rev. Biochem. 49; 315-356, 1980.

Williams, C.H. and Kamin, H.: Microsomal triphosphopyridine nucleotidecytochrome c reductase of liver. J. Biol. Chem. 237: 587-596, 1962.

Wilson, J.T.: Identification of somatotropin as the hormone in a mixture of somatotropin, adrenocorticotropic hormone and prolactin which decreased liver drug metabolism in the rat. Biochem. Pharmacol. 18: 2029-2031, 1969 .

Yasukochi, Y. and Masters, B.S.S.: Some properties of a detergent solubilized NADPH-cytochrome c (cytochrome P450) reductase purified by biospecific affinity chromatography. J. Biol. Chem. 251: 5337-5344, 1976. 


\section{APPENDIX A}

Analysis of Pentachlorophenol and Pentachloroanisole for Non-Phenolic Contaminants.

\begin{tabular}{|c|c|c|c|}
\hline Source & $\begin{array}{c}\text { PCP }^{2} \\
(\text { Aldrich } 99 \%)\end{array}$ & PCP & PCA \\
\hline \multicolumn{4}{|c|}{ Dibenzo-p-dioxins } \\
\hline Hexachloro- & $<0.01 \mathrm{ppm}$ & $<0.01$ & $<0.01 \mathrm{ppm}$ \\
\hline Heptachloro- & $<0.01$ & $<0.01$ & $<0.01$ \\
\hline Octachloro- & $\leq 150.0$ & $\leq 1.50$ & $<0.01$ \\
\hline \multicolumn{4}{|l|}{ Dibenzofurans } \\
\hline Hexachloro- & $<0.01$ & $<0.01$ & $<0.01$ \\
\hline Heptachloro- & $<0.01$ & $<0.01$ & $<0.01$ \\
\hline Octachloro- & $<0.01$ & $<0.01$ & $<0.01$ \\
\hline
\end{tabular}

${ }^{1}$ Samples were analyzed by Gas Chromatography by the Analytical Chemistry section, Office of Pesticides, U.S. EPA, Beltsville, MD. Sensitivity of methods was between $1-10 \mathrm{ppb}$.

${ }^{2}$ Aldrich $99 \%$ PCP was utilized as source for further purification of PCP and synthesis of PCA for the study. 


\section{APPENDIX B \\ Electron Microscopy Procedures ${ }^{1}$}

At the time of piglet sacrifice, liver sections were blotted an placed immediately into Karnovsky's fixative containing sucrose. Tissues were refrigerated for one week and then transferred to Dr. Seibel.

Tissues were removed, cut into smaller slices and returned to fresh fixative for 10 days. At that time, slices were washed with cacodylate buffer ( $\mathrm{pH}$ 7.4) with $7 \%$ sucrose, and allowed to stand overnight in clean buffer. Tissue was next post fixed for 2 hours in $\mathrm{OsO}_{4}$ and then subjected to graded alcohol dehydration $(30 \%-100 \%)$, followed by 2 changes of propylene oxide and a propylene oxide:Epon mixture $(1: 1)$. Tissues were next placed in $100 \%$ Epon mixture at room temperature overnight and then embedded for 4 days in Epon mixture at $60^{\circ}$.

Blocks of tissue were thin sectioned with a Porter-Blum MT2 ultramicrotome and double stained with lead citrate and alcoholic uranyl acetate. An AEI-6B Transmission Electron Microscope was used for this study.

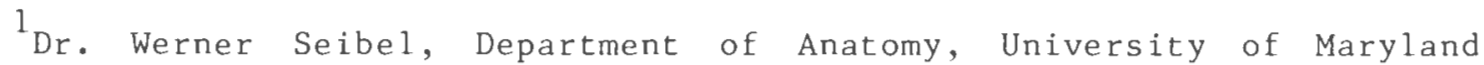
School of Dentistry, Baltimore, MD (personal communication).

2Karnovsky, M.J.: A formaldehyde-glutaraldehyde fixative of high oxmolality for use in electron microscopy. J. Cell Biol. 27: 137A, 1965.

3 Reynolds, E.S.: The use of lead citrate at high pH as an electron opaque stain in electron microscopy. J. Cell Biol. 17: 208-2l2, 1963. 